JACOB FEREZINI JUNIOR

\title{
ESTUDO DO COMPORTAMENTO VEICULAR EM MANOBRAS DE SAÍDAS DE ACLIVES ATRAVÉS DE UM PROGRAMA COMPUTACIONAL EM MATLAB- SIMULINK
}

\author{
Dissertação apresentada ao Departamento de \\ Engenharia Mecânica da Universidade de São \\ Paulo, para a obtenção do Título de Mestre em \\ Engenharia Mecânica. \\ Área de Concentração: Dinâmica das Máquinas e \\ Sistemas. \\ Orientador: Prof. Dr. Antonio Carlos Canale
}


AUTORIZO A REPRODUÇÃO E DIVULGAÇÃO TOTAL OU PARCIAL DESTE TRABALHO, POR QUALQUER MEIO CONVENCIONAL OU ELETRÖNICO, PARA FINS DE ESTUDO E PESQUISA, DESDE QUE CITADA A FONTE.

Ficha catalográfica preparada pela Seção de Tratamento da Informação do Serviço de Biblioteca - EESC/USP

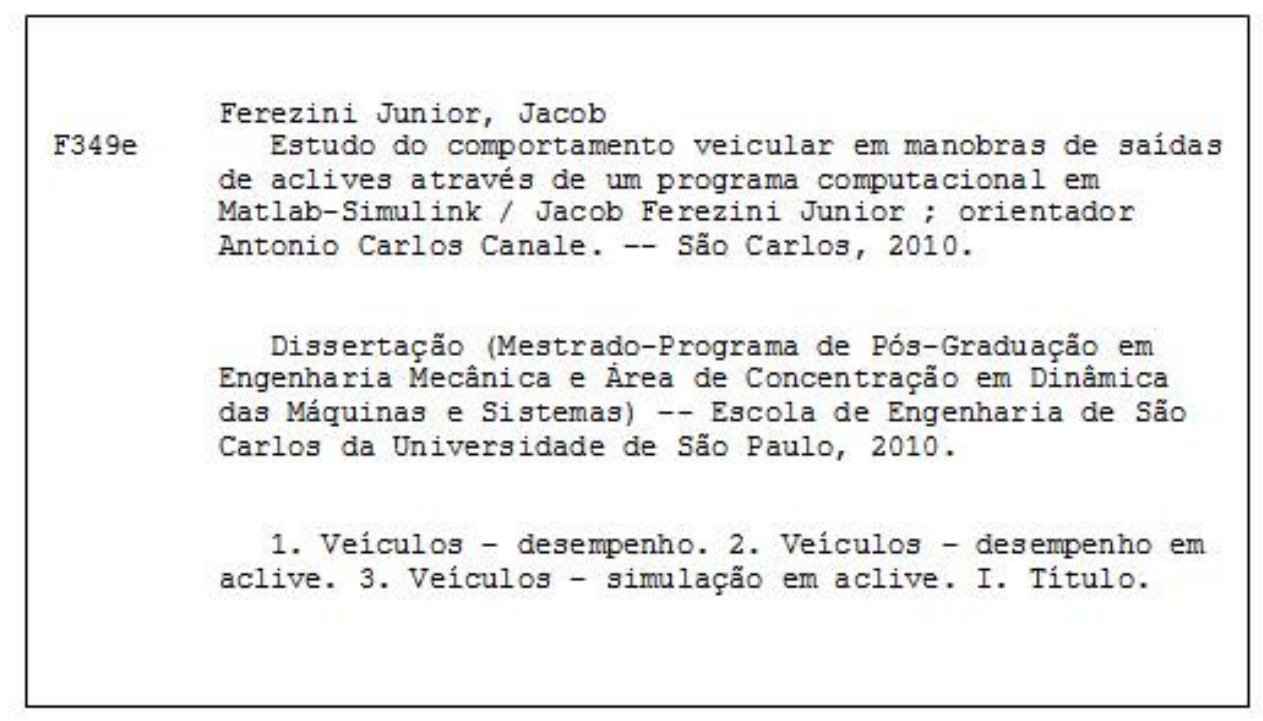


Candidato: Engenheiro Mecânico JACOB FEREZINI JÚNIOR.

Dissertação defendida e julgada em 17/12/2010 perante a Comissão Julgadora:

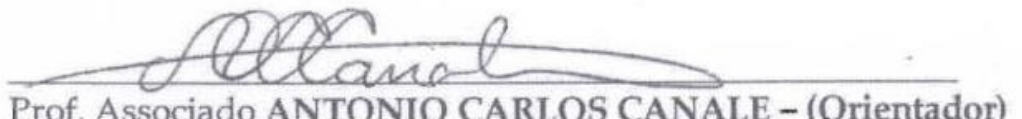

APNO $Y A D O$

Prof. Associado ANTONIO CARLOS CANALE - (Orientador)

(Escola de Engenharia de São Carlos/USP)

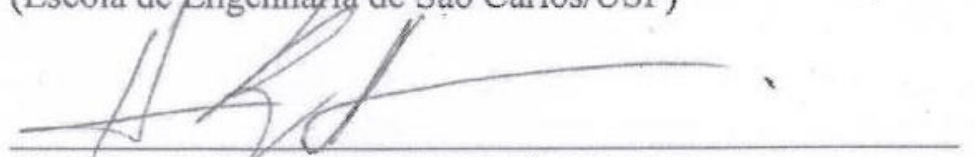

aprovado

Prof. Dr. HELKO APARECIDO NAVARRO

(Escola de Engenharia de São Carlos/USP)

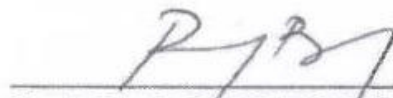

APROVADO

Prof. Dr. ROBERTO BORTOLUSSI

(Faculdade de Engeriharia Industrial/FEI)

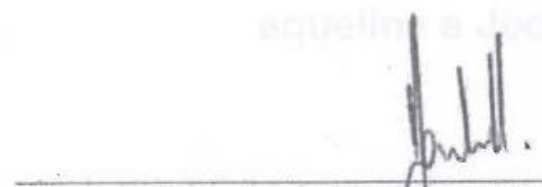

Prof. Associado JONAS DE CARVALHO Coordenador do Programa de Pós-Graduação em

Engenharia Mecânica

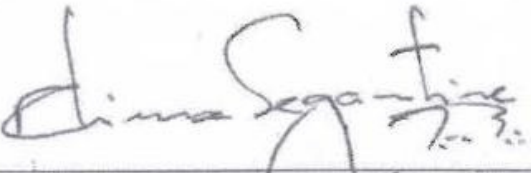

Prof. Associado PAULO CÉSAR LIMA SEGANTINE Presidente da Comissão de Pós-Graduação da EESC 
Aos meus pais, Elza Maria Calderan Ferezini (em memória) e Jacob Ferezini

E minhas irmãs:

Jaqueline e Joceline. 


\section{AGRADECIMENTOS}

Agradeço a Deus por me dar saúde, força de vontade e confiança para realizar este trabalho.

Agradeço aos meus pais Elza Maria Calderan Ferezini (em memória) e Jacob Ferezini que sempre me incentivaram a buscar os meus objetivos.

Ao Prof. Dr. Antonio Carlos Canale, pela confiança, apoio e dedicação para a conclusão deste trabalho, período que muito me ensinou e motivou frente às dificuldades.

À Escola de Engenharia de São Carlos "EESC-USP" pela oportunidade de realização do curso de mestrado.

À Faculdade de Engenharia Industrial "FEl" a qual me proporcionou a os conceitos de Engenharia Automobilística e ao Prof. Dr. Roberto Bortolussi, pelos seus ensinamentos acadêmicos, também por sua amizade todos estes anos.

À Ford Motor Company do Brasil pelo apoio na realização do curso de mestrado e contribuição no desenvolvimento do experimento em seu Campo de Provas de Tatuí.

Aos amigos da BLUE HOUSE, pela motivação, apoio e amizade.

À Aline Rocha, pelo amor, apoio e paciência em todos os momentos.

A todos aqueles que, direta ou indiretamente, colaboraram para a concretização deste trabalho. 


\section{SUMÁRIO:}

Lista de Figuras:

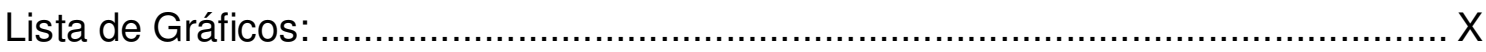

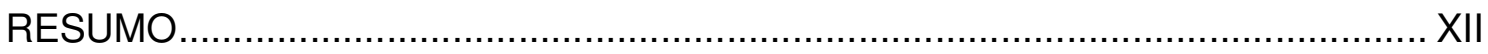

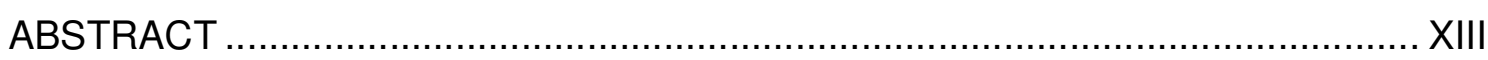

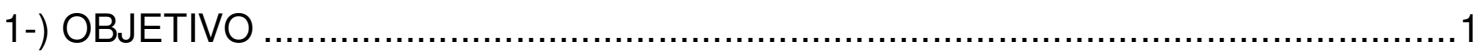

2-) INTRODUÇÃO

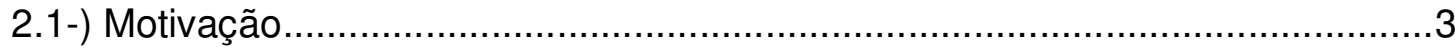

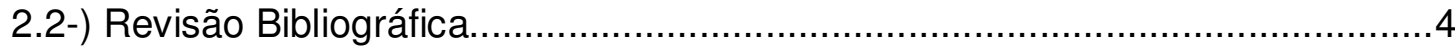

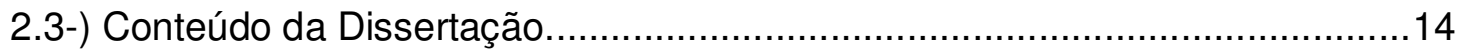

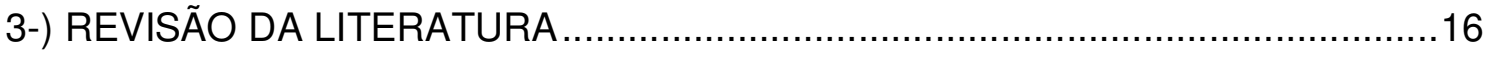

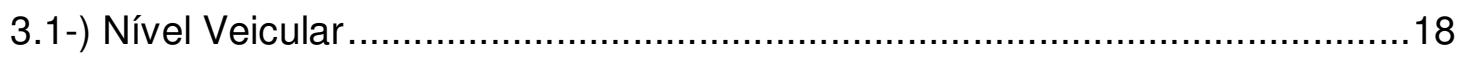

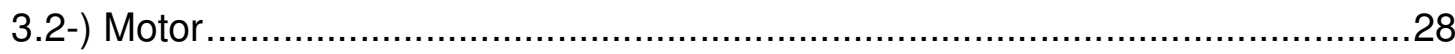

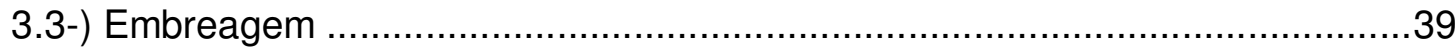

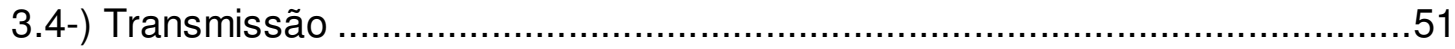

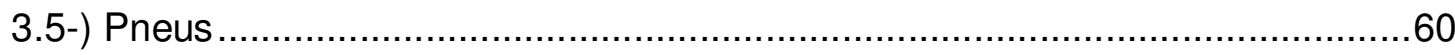

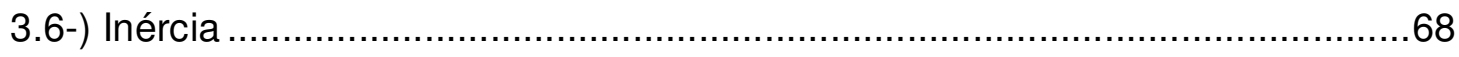

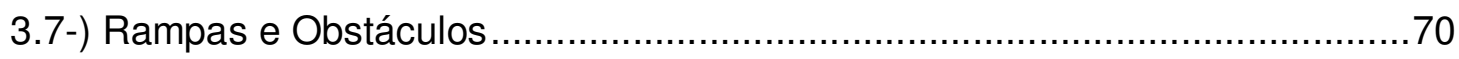

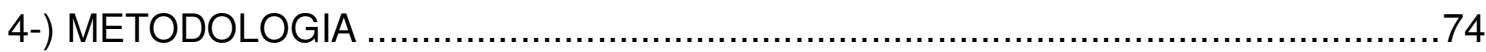

4.1-) Modelo Físico e Matemático Proposto .......................................................76

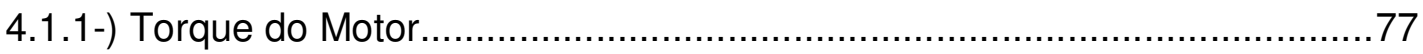

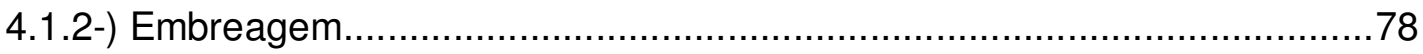

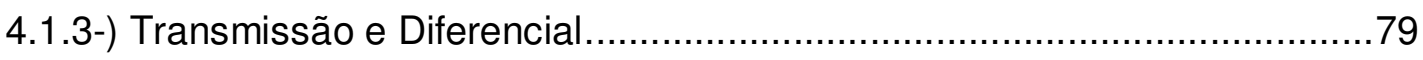

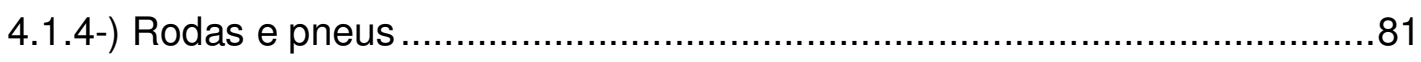

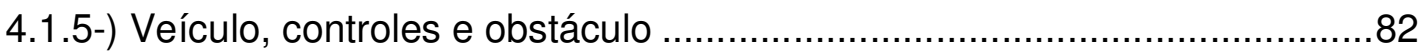

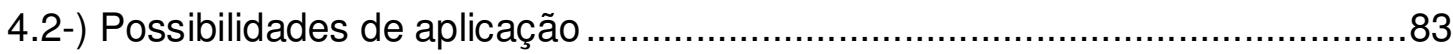

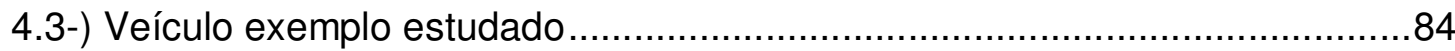

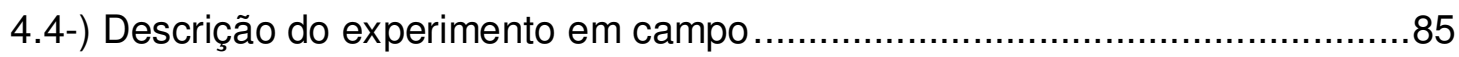

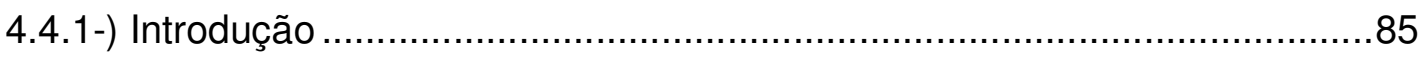

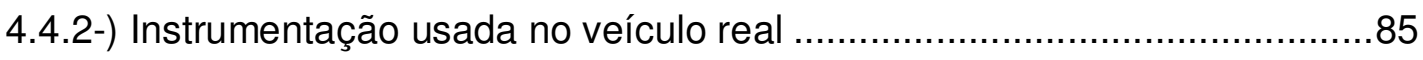

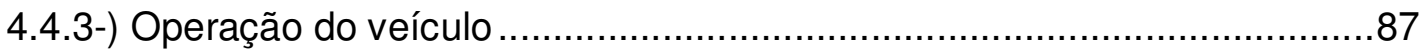

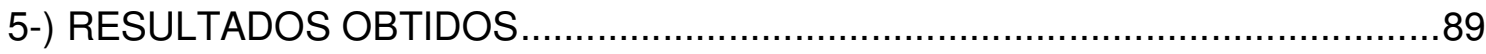

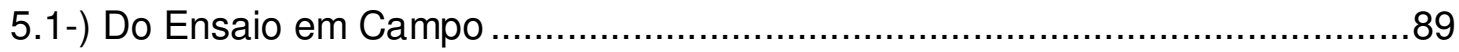

5.2-) Resultados do Modelo Teórico e programa de simulação ...............................93

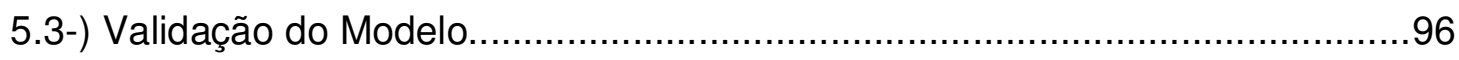

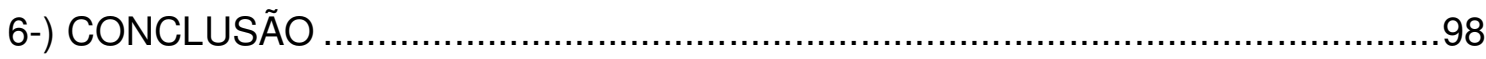

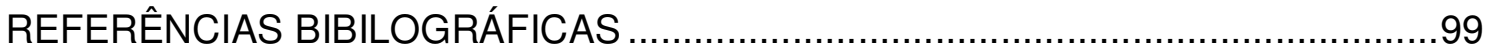




\section{Lista de Figuras:}

Figura 1: Componentes que influenciam o desempenho veicular. 4

Figura 2: Esquema da configuração de teste em bancada - Sistema de Controle de Pressão da Embreagem (Quan e Krishnaswamy, 2000)....

Figura 3: Dinamômetro "Scroll" e veículo para validação de "software" de desempenho veicular (Rafael, Leandro C., et al., 2007). 12

Figura 4: O projeto do Cugnot Steam Trolley (1769) - (Eckermann) ........................16

Figura 5: História Automotiva - Eras (Eckermann) ...............................................16

Figura 6: Distância entre Eixos e Bitola (Wikipedia - The Free Encyclopedia, 2010) 18 Figura 7: Tração no Eixo Dianteiro (Wikipedia The Free Encyclopedia, 2010) .........20 Figura 8: Tração Traseira / Motor Dianteiro (Wikipedia The Free Encyclopedia, 2010)

Figura 9: Tração Traseira / Motor Traseiro (Wikipedia The Free Encyclopedia, 2010)

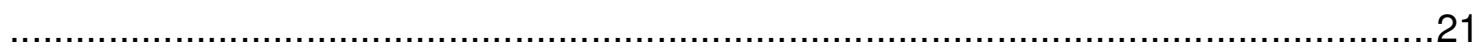

Figura 10: Tração Integral (Wikipedia The Free Encyclopedia, 2010)......................22

Figura 11: Centro de Gravidade Longitudinal (Gillespie, 1992) .............................23

Figura 12: Posicionamento do C.G. na Direção Longitudinal....................................23

Figura 13: Veículo com um dos Eixos Elevado ..................................................25

Figura 14: Construção de Maquete (design) - (Automotive Design, 2010).................26

Figura 15: Forças Aerodinâmicas (Ball e Stone, 2004) ………............................27

Figura 16: Principais Elementos de um Motor de Combustão Interna Alternativo.....29

Figura 17: Geometria Básica dos Motores de Combustão Interna (Heywood, 1988)30

Figura 18: Ciclo de Operação do motor dois tempos (Garcia e Brunetti, 1992) ........32

Figura 19: Ciclo de Operação do Motor quatro Tempos (Heywood, 1988) ...............32

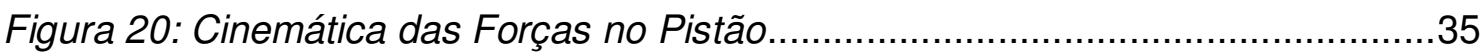

Figura 21: Esquema para determinação de Potência de atrito $\left(N_{a}\right)$..........................36

Figura 22: Embreagem tipo cônico (Sweber.de, 2008) ...........................................39

Figura 23: Embreagem de expansão da sapata ou tambor (Shaver, 1997) ...............40

Figura 24: Embreagem multi-disco Hele-Shaw (Shaver, 1997)..............................40

Figura 25: Embreagem de disco único (ZF Sachs, 2010) .....................................41

Figura 26: Componentes de Embreagem com mola membrana (ZF Sachs, 2010) ..42 Figura 27: Atuação da Mola Membrana no acoplamento/desacoplamento (ZF Sachs,

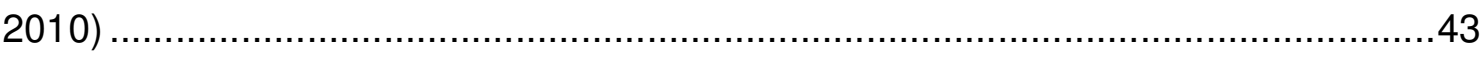

Figura 28: Componentes do Disco de Embreagem (ZF Sachs, 2010) ....................44 
Figura 29: Dimensionamento do Disco de Embreagem (Argachoy, 2004)...............44

Figura 30: Representação do comportamento da mola de absorção ("Cushion").....45

Figura 31: Comportamento da mola "Cushion" durante acoplamento da embreagem

Figura 32: Posicionamento dos Pedais (Embreagem, Freios e Acelerador) .............48

Figura 33: Descrição do curso de Pedal de Embreagem (Shaver, 1997) .................49

Figura 34: Engrenagens de dentes retos (Ball e Stone, 2004) ...............................51

Figura 35: Engrenagem helicoidal (Ball e Stone, 2004) ........................................52

Figura 36: Engrenagem Pinhão-coroa de dentes retos (Ball e Stone, 2004) ...........52

Figura 37: Engrenagem Pinhão-Coroa Espiral (Ball e Stone, 2004) ........................52

Figura 38: Esquema da transmissão de movimento e diagrama de forças na engrenagem. (Ball e Stone, 2004) .......................................................... 53

Figura 39: Principais componentes de uma caixa de transmissão manual

(Clutches_N_More, 2010) .........................................................................54

Figura 40: Caixa de transmissão simplificada (How Stuff Works, 1998-2010) ..........55

Figura 41: Sistema de engate com sincronização (Costa, 2001-2002) ....................56

Figura 42: Fluxo de torque na transmissão (Costa, 2001-2002) .............................57

Figura 43: Veículo em Curva de Baixa Velocidade (Ball e Stone, 2004)...................58

Figura 44: Componentes do diferencial (Ball e Stone, 2004) ................................59

Figura 45: Dinâmica simplificada do diferencial (Wikipedia the Free Encyclopedia,

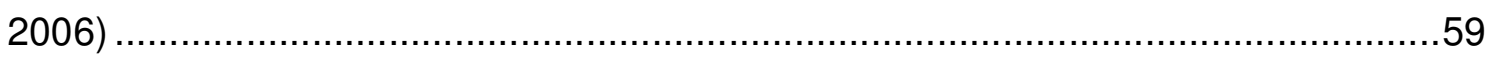

Figura 46: Tipos construtivos dos pneus: Diagonal e Radial (Gillespie, 1992).........61

Figura 47: Designação de um pneu (Exemplo) ...............................................61

Figura 48: Representação do raio dinâmico do pneu.........................................62

Figura 49: Distribuição de pressão no pneu (Gillespie, 1992) ...............................63

Figura 50: Mecanismos de atrito do pneu (Gillespie, 1992) .................................64

Figura 51: Distribuição de pressão na área de contato - aceleração ........................65

Figura 52: Representação da inclinação de rampa .............................................70

Figura 53: Rua Inclinada no centro de Porto Alegre (Silveira, 2007).......................71

Figura 54: Medição de aclive com transferidor .................................................72

Figura 55: Rua Artur Sampaio Moreira - Diadema-SP (32\%) (Pasianot, 2006)........72

Figura 56: Rua Monte Alegre - Perdizes-SP (31\%) (Pasianot, 2006) .....................73

Figura 57: Rua Amorin Castro - Butantã-SP (26\%) (Pasianot, 2006)......................73

Figura 58: Ilustração da Metodologia utilizada ................................................74 
Figura 59: Modelo Matemático - Desempenho em Rampa (Programa Matlab Simulink). .76

Figura 60: Determinação do torque instantâneo do motor (Programa Matlab

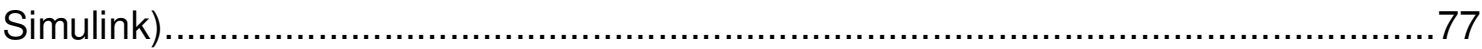

Figura 61: Representação do curso de pedal de embreagem e mola "cushion".......78

Figura 62: Representação do torque transmitido pela embreagem...........................79

Figura 63: Representação do torque transmitido pela transmissão e diferencial para as rodas (Programa Matlab Simulink) .80

Figura 64: Representação do diagrama de blocos forças atuantes nos pneus

(Programa Matlab Simulink) 81

Figura 65: Forças aplicadas ao veículo na manobra de arrancada. .82

Figura 66: Diagrama de blocos representando veículo e a rampa...........................83

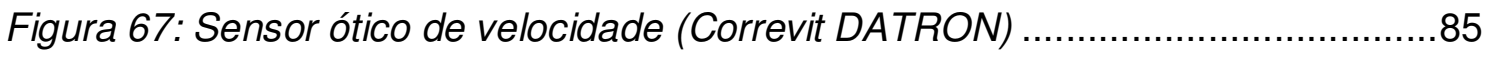

Figura 68: Monitoramento do curso de pedal de acelerador ...................................86

Figura 69: Monitoramento do curso do pedal de embreagem .................................87 


\section{Lista de Gráficos:}

Gráfico 1: Licenciamento de veículos novos nacionais - 1957/2007 (ANFAVEA, 2008).

Gráfico 2: Capacidade de rampa crítica em função da distribuição de Peso no Eixo Direcional (Rempei, Gyo-ichi, et al., 1977).

Gráfico 3: Característica dos motores com diferentes velocidades e potências para uma mesma aceleração (Gao, Maghbelli, et al., 2003)

Gráfico 4: Mapa da eficiência do motor (Exemplo) (Andrew, Sylvain, et al., 2007)...13

Gráfico 5: Diagrama $p-V$ didático para um motor quatro tempos .33

Gráfico 6: Diagrama $p-\theta$ para um motor quatro tempos 34

Gráfico 7: Trabalho indicado ou do ciclo de combustão (Heywood, 1988). .36

Gráfico 8: Curvas Características dos Motores. 38

Gráfico 9: Porcentagem de acoplamento VS Curso do pedal de embreagem 47

Gráfico 10: Força do pedal de embreagem VS Curso do pedal de embreagem .......50 Gráfico 11: Variação do raio dinâmico do pneu em função da velocidade do veículo (Vibrate Software, 2009).

Gráfico 12: Coeficiente de adesão VS (\%) de Escorregamento (Ball e Stone, 2004)66 Gráfico 13: Ilustração do porcentual de Inclinação (\%) e ângulo de inclinação (graus) (BW95, 2010) 71

Gráfico 14: Progressão da abertura da borboleta 89

Gráfico 15: Variação da Rotação do motor .90

Gráfico 16: Progressão do acoplamento da embreagem..... .90

Gráfico 17: Liberação do freio de estacionamento 91

Gráfico 18: Velocidade longitudinal desenvolvida pelo veículo 91 Gráfico 19: Espaço percorrido e aceleração longitudinal desenvolvida pelo veículo 92 Gráfico 20: Resultado do Modelo - velocidade do veículo e tangencial da roda ......93 Gráfico 21: Resultado do modelo: Espaço percorrido e Aceleração longitudinal ......94 Gráfico 22: Efeito das inércias no torque disponível pela embreagem...... .94

Gráfico 23: Força de tração das rodas dianteiras na manobra de arrancada..... .95

Gráfico 24: Forças Normais nos eixos dianteiro e traseiro. .95

Gráfico 25: Comparativo entre os resultados reais e resultados do modelo 96 
Lista de Tabelas:

Tabela 1: Coeficientes de adesão (Canale, 1989) ............................................66

Tabela 2: Dados técnicos do veículo exemplo estudado ........................................84 


\section{RESUMO}

\section{FEREZINI, J.J.. Estudo do comportamento veicular em manobras de saída de aclives através de um programa computacional em Matlab-Simulink}

Tese (Mestrado) - Escola de Engenharia de São Carlos, Universidade de São Carlos, São Carlos, 2010.

O desempenho de um veículo de passeio em manobras de arrancada em aclives elevados é um fator muito importante a ser considerado no desenvolvimento de um novo projeto ou modificação de um projeto já existente.

Este desempenho é influenciado por várias características do veículo, tais como: perfil e forma da curva de torque do motor, massa do veículo, relações de transmissão, tamanho do pneu entre outros.

Este trabalho propõe uma metodologia de simulação para prever o desempenho de um veículo com tração dianteira em aclives elevados, através da utilização de um modelo de simulação desenvolvido na plataforma Matlab Simulink.

Essa metodologia consiste na validação de um modelo de simulação capaz de representar todo o procedimento que envolve a saída de um veículo em um aclive elevado, levando em consideração a variação da rotação do motor, do pedal do acelerador, acoplamento da embreagem e o acionamento do freio de estacionamento. Uma medição real em veículo foi feita onde se registrou este comportamento e estes dados foram utilizados como valores de entrada no modelo de simulação.

Para a correlação do modelo de simulação, foram utilizados os gráficos que representam a variação do espaço percorrido, velocidade e aceleração longitudinal, onde os resultados práticos e teóricos mostraram-se próximos mostrando que o modelo de simulação desenvolvido em MatLab / Simulink é uma opção a ser utilizada, principalmente nas fases inicias de projeto e para otimização de projetos já existentes.

Palavras chave: Veículos - desempenho, Veículos - desempenho em aclive, Veículos - simulação em aclive. 


\section{ABSTRACT \\ FEREZINI, J.J. Behavior study of vehicle startability on grade maneuver through a computer program in Matlab-Simulink \\ (Master's Degree) - Escola de Engenharia de São Carlos, Universidade de São Carlos, São Carlos, 2010.}

The performance of a passenger vehicle maneuvering uphill sprint high is a very important factor to be considered in developing a new project or modifying an existing project.

This performance is influenced by various characteristics of the vehicle, such as profile and shape of engine torque curve, vehicle weight, gear ratios, tire size and others.

This paper proposes an analysis methodology to simulate the performance of a vehicle with front wheel drive in high slopes, through the use of a simulation model developed on the Matlab Simulink.

This methodology consists in validating a simulation model capable of representing the entire procedure involving the removal of a vehicle in a high slope, taking into account the variation of engine speed, accelerator pedal, the clutch engaging and brake actuation parking. An actual measurement of vehicle was registered where this behavior and these data were used as input values in the simulation model.

For the simulation model correlation, It was used the graphs represent the change in the space covered, vehicle speed and vehicle longitudinal acceleration, where the practical and theoretical results proved to be the next showing that the simulation model developed in Matlab / Simulink is an option be used, especially in the early stages of design and optimization of existing designs.

Keywords: Vehicle Performance; Vehicle uphill performance, Vehicle startability on grade. 


\section{1-) OBJETIVO}

O objetivo deste trabalho é a elaboração de uma metodologia e a validação de um modelo matemático capaz de representar o evento de arrancada a partir da imobilidade em aclives elevados para veículos de tração nas rodas dianteiras.

O conhecimento do comportamento do veículo em manobras de arrancada em aclives acentuados ("Startability on Grade") é um importante métrico para dimensionar as características dos componentes do trem de força, tais como: curva de torque do motor, embreagens, relações de transmissão e diferencial, raio dinâmico dos pneus entre outros.

Este comportamento será obtido através de uma análise teórica, utilizando-se de um aplicativo do programa computacional MatLab-Simulink ${ }^{\circledR}$ e de resultados práticos obtidos a partir de teste real feito em veículo.

A partir de um teste de saída de aclive em veículo real, são registrados os parâmetros que serão variáveis de entrada do modelo, que são: perfil de utilização do pedal de acelerador, pedal de embreagem, freio de estacionamento e gradiente de inclinação do aclive. São registrados também no decorrer da manobra, a variação do espaço percorrido, velocidade e aceleração longitudinal, onde estes são os parâmetros de correlação do modelo (práticos).

Com os parâmetros de entrada registrados, variáveis de entrada do modelo, é simulada através do modelo a mesma manobra de arrancada, onde são gerados os parâmetros de correlação analíticos (teóricos). Os resultados obtidos nas simulações serão comparados com os dados obtidos no teste real a fim de se obter uma correlação entre os dados e teóricos e práticos, o modelo tornará uma ferramenta útil para validar projetos futuros para este atributo de nível veicular.

Uma vez validado o modelo de simulação, este tem vital importância para as fases iniciais de novos projetos, contribuindo para a redução de custos de engenharia, construção de protótipos e testes físicos, além de proporcionar otimização de tempo de desenvolvimento. 


\section{2-) INTRODUÇÃO}

O crescente aumento da produção de veículos no Brasil e no Mundo pelas indústrias automobilísticas nos últimos anos e a constante disputa por maximização do lucro e participação no volume de vendas no mercado, são fatores que promovem a melhoria continuada da qualidade do produto final, como mostra Gráfico 1:

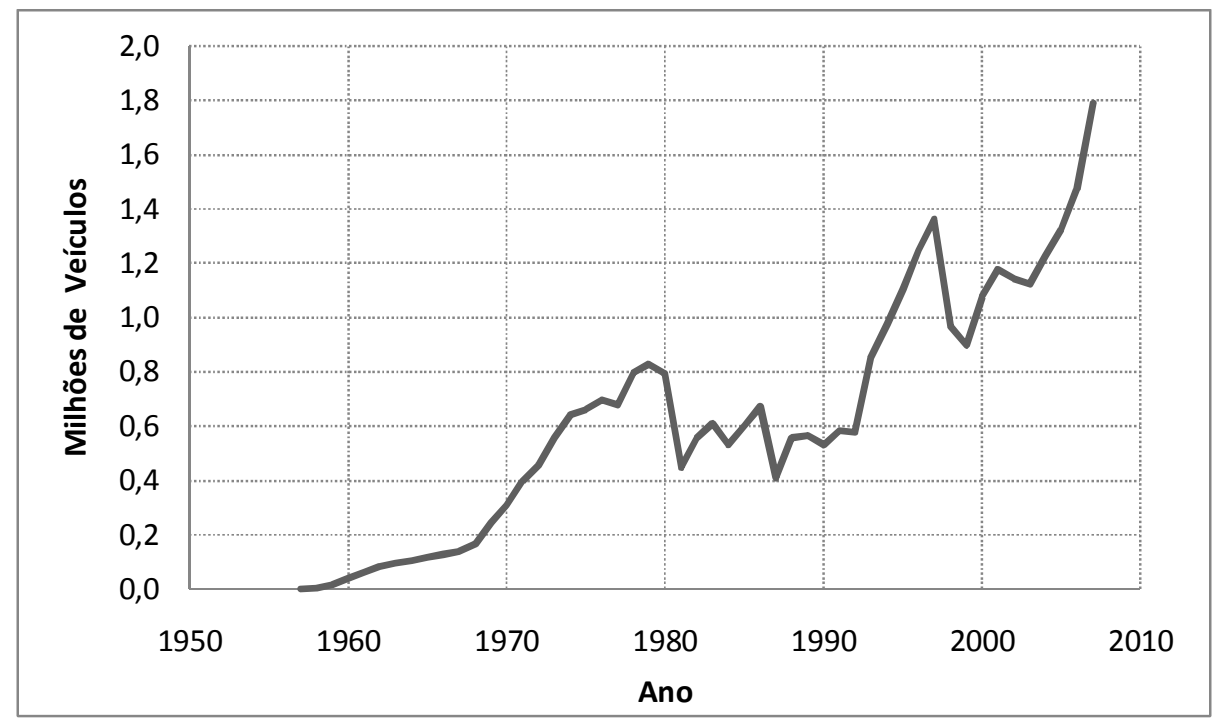

Gráfico 1: Licenciamento de veículos novos nacionais - 1957/2007 (ANFAVEA, 2008).

$\mathrm{Na}$ fase de desenvolvimento de um veículo novo ou melhoria de um produto já existente, diversos atributos são considerados para a boa execução do projeto, entre eles pode-se destacar: a forma da carroceria (design), itens de segurança, desempenho do motor e da transmissão, tecnologias elétricas embarcadas, nível de aceitável de ruído e emissões de gases, economia de combustível, custos com manutenção entre outros. Todos estes atributos vão de encontro à estratégia da empresa para enquadrar o seu produto no mercado para o seu público alvo com preço de venda competitivo.

O uso de ferramentas computacionais nas fases de desenvolvimento do produto, em muito contribuem para a melhoria dos atributos e na rapidez de tomada de decisões para melhor atender às expectativas dos consumidores alvo. 


\section{1-) Motivação}

Um dos itens mais importantes de um veículo de passeio para o consumidor é o seu desempenho em acelerações. Para manter bons níveis de satisfação dos consumidores com o desempenho do veículo em diversas condições de aceleração, torna-se uma obrigação para todos os fabricantes de veículos do Brasil atender às principais necessidades de seus clientes nos mercados os quais se deseja comercializar os veículos.

A sensação de desempenho é influenciada por várias características do veículo e é dificilmente mensurada por "avaliações objetivas" (1). A sensação de desempenho é muitas vezes caracterizada por "avaliações subjetivas" (2), que é obtida através da avaliação do motorista quando este submete o veículo a acelerações longitudinais.

O desempenho em acelerações é a definição tradicional de "Performance" de um veículo e esta é uma forma de diferenciar o quão rápido o veículo acelera de uma velocidade a outra. Ela está diretamente relacionada com o conjunto trem de força do veículo, o que basicamente é composto por motor, transmissão, diferencial e pneus. A sensação de desempenho por parte dos consumidores é proveniente de diversos efeitos, os quais incluem a aceleração do veículo, a resposta nas trocas de marchas, a qualidade sonora da aceleração e o controle das características do pedal do acelerador e da embreagem.

Uma das avaliações subjetivas muito utilizadas por consumidores de veículos com transmissões manuais e automáticas é a saída do veículo a partir da imobilidade em aclives. Um dos principais componentes solicitado nesta manobra é a embreagem, pois é este o componente que faz a conexão do motor com a transmissão do veículo, fazendo parte de todo o conjunto do trem de força.

$O$ bom dimensionamento e a validação do componente embreagem se fazem necessários para que o veículo possa atender à satisfação dos consumidores e, entre os meios de validação, está à construção de protótipos para testes de durabilidade em bancadas e em campo de provas. A motivação do presente estudo é justamente contribuir com uma metodologia e um modelo matemático que possa reproduzir esta manobra para um veículo real e servir como ferramenta para desenvolvimento de novos produtos.

(1) Avaliações Objetivas: Refere-se a avaliações que podem ser mensuradas (ex: tempo que o veículo leva para ir de 0 a 100 $\mathrm{km} / \mathrm{h}$ )

(2) Avaliações Subjetivas: Refere-se a avaliações não mensuráveis. Avaliação feita por comentários (ex: "O veículo tem um bom desempenho em retomadas de velocidade"). 


\section{2-) Revisão Bibliográfica}

Quando se fala sobre sensação de "Performance", a aceleração do veículo é a primeira característica que o consumidor percebe. A Figura 1 mostra os principais itens que influenciam no desempenho veicular:

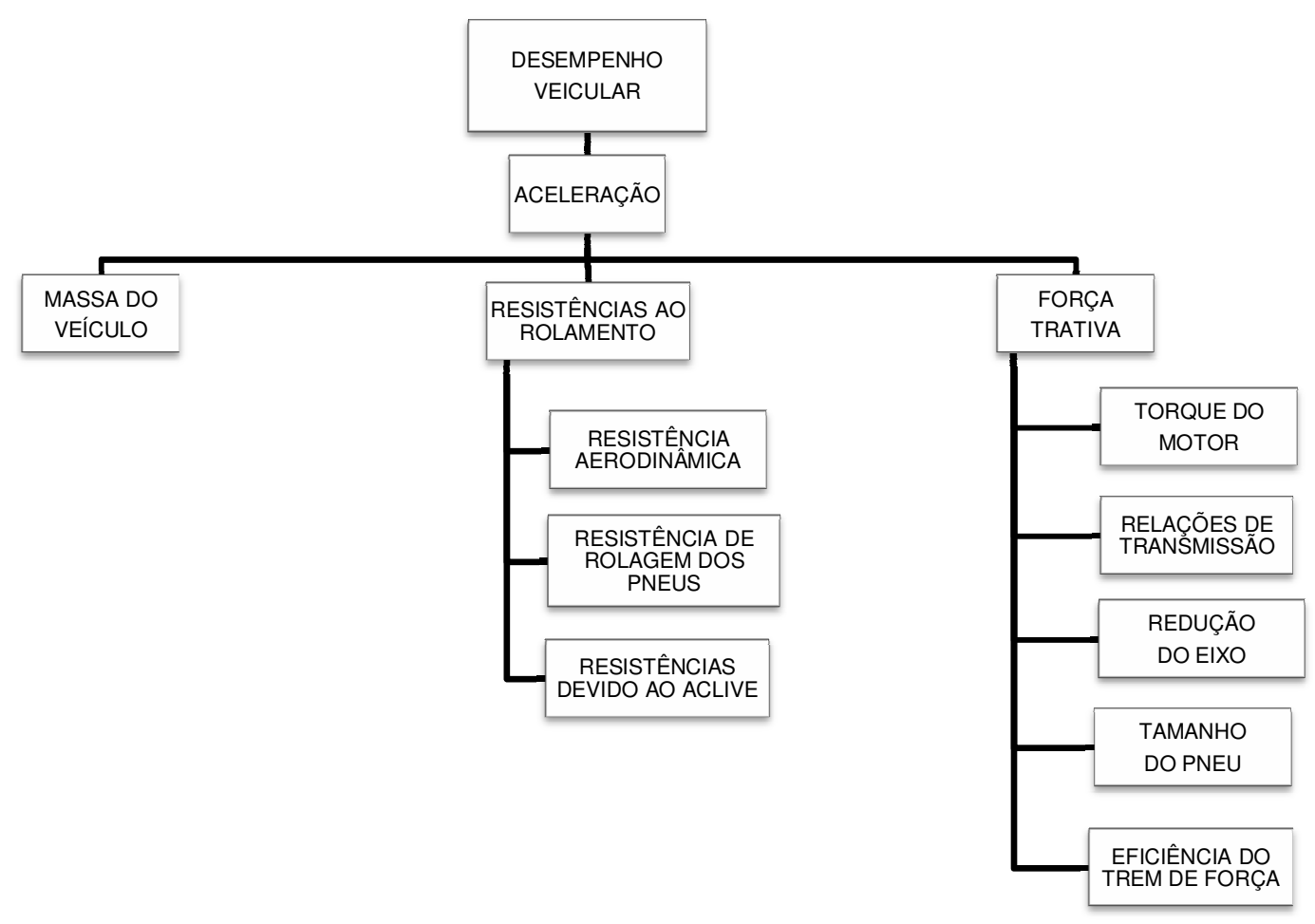

Figura 1: Componentes que influenciam o desempenho veicular

Em se tratando de desempenho veicular, a indústria automobilística em geral vem buscando uma relação completa entre várias características veiculares para satisfazer ao máximo os seus clientes. Entre elas, pode-se destacar:

- Aceleração do veículo: as duas principais características que influenciam a aceleração veicular são: "WOT (Wide Open Throttle)" que é a máxima aceleração que o veículo pode atingir com o acelerador totalmente aberto (pressionado) e o "part-throttle" que se refere às cargas parciais do acelerador (acionamentos parciais);

- Características do acelerador: se referem às três influências primárias do acelerador que são: a progressão, o esforço e a ergonomia;

- Características do manípulo de troca de marcha: se referem às duas influências primárias do manípulo de troca de marchas: tempo e 
sensação subjetiva das trocas de marcha, levando em consideração precisão e esforço dos engates;

- Característica Sonora: que se refere o nível e a qualidade sonora provida pelo conjunto trem de força do veículo;

- Aparência do Veículo: que se refere ao estilo do veículo a proporcionar ao consumidor a impressão de entrega de desempenho.

De acordo com o estudo de (Rempei, Gyo-ichi, et al., 1977), uma das principais vantagens de veículos com motor e tração dianteira, é promover um trem de força mais compacto, eliminando assim as vibrações e ruídos do eixo árvore motriz o que normalmente estão presentes nos veículos com tração traseira, além de promover uma melhoria na estabilidade direcional em curvas. Utilizando-se de um veículo de tração dianteira, (Rempei, Gyo-ichi, et al., 1977) estudaram o comportamento desta aplicação de trem de força para o mercado japonês, sob condições de estradas severas, rampas em montanhas e inverno rigoroso.

Uma das considerações importantes para manobras de arrancada em rampa é a diminuição considerável na força normal ao pavimento no eixo dianteiro. Este fator foi estudado por (Rempei, Gyo-ichi, et al., 1977) para prover uma distribuição aceitável de massa entre os eixos do veículo afim de evitar o deslizamento das rodas de um veículo de tração dianteira. No desenvolvimento de veículos de tração dianteira foram feitos cálculos e testes experimentais de subidas de rampas em diversas condições de terreno e condições climáticas presentes no Japão. Os resultados foram comparados para os dois veículos com tração dianteira e com tração traseira.

O Gráfico 2, obtido por (Rempei, Gyo-ichi, et al., 1977), mostra as mais váriadas condições de aclives em conjunto com várias distribuições de peso no eixo direcional, junto ainda com o tipo de pneu e a característica do coeficiente de adesão de cada tipo de pavimento examinado, onde:

$\mu$ = Coeficiênte de adesão (Pavimento / Pneu);

$\mu_{r}=$ Coeficiênte de Resistência ao Rolamento. 


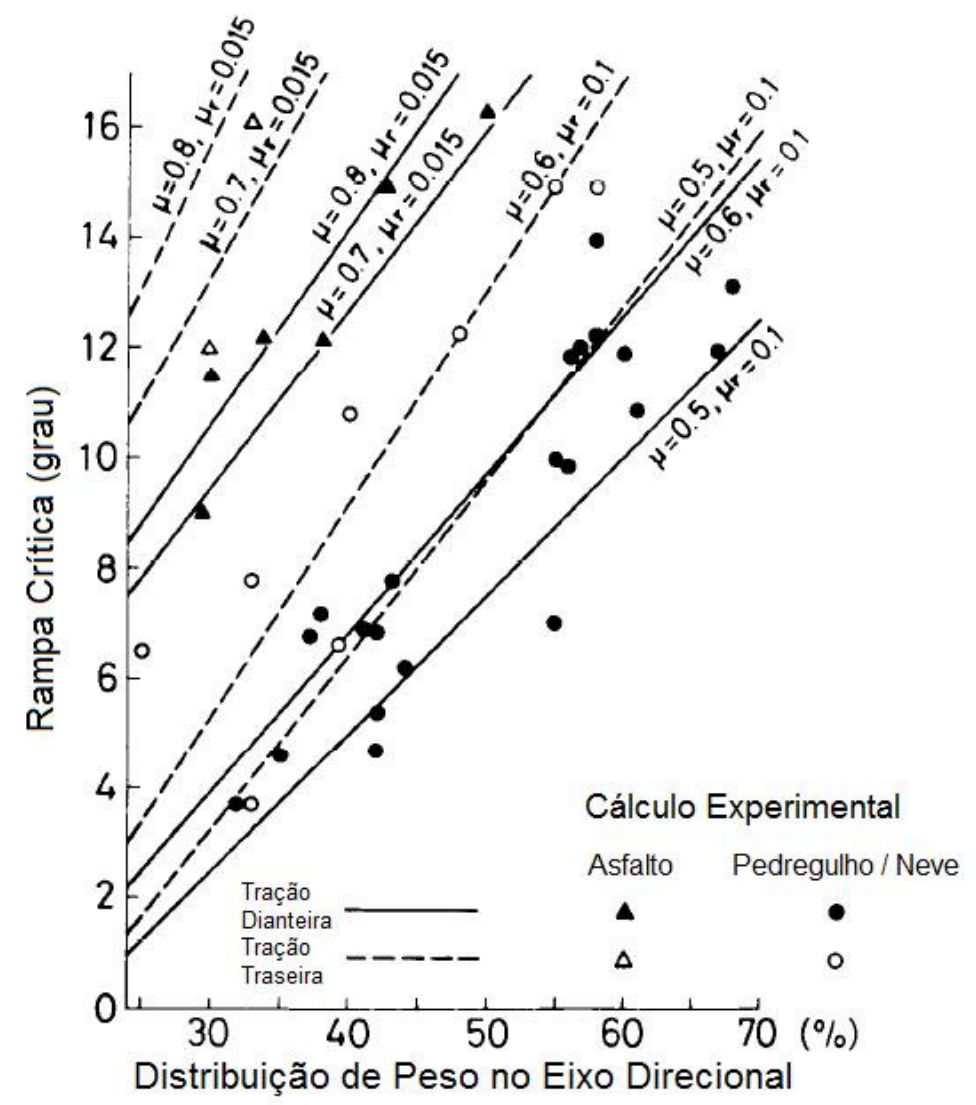

Gráfico 2: Capacidade de rampa crítica em função da distribuição de Peso no Eixo Direcional (Rempei, Gyo-ichi, et al., 1977).

Neste estudo de investigação, (Rempei, Gyo-ichi, et al., 1977) concluíram que acima de $61 \%$ de distribuição de peso estático no eixo direcional foram suficientes para atender à capacidade de rampa de forma satisfatória para o mercado do Japão.

Simulações de máximo desempenho veicular para 100\% de acelerador ("WOT - Wide Open Throttle") não são estudos recentes. As primeiras análises foram apresentadas por (Setz, 1961). Depois, (Hwang) e (Waters, 1972) combinaram a simulação do desempenho em WOT com a previsão do consumo de combustível para ciclos arbitrários de trajeto. No estudo elaborado por (Mencik, Tobler e Blumberg, 1978) foram feitas análises de uma simulação detalhada de um modelo simples de veículo e correlações com resultados de testes físicos em pista. O estudo foi feito com veículos de transmissões automáticas e manuais e foram abordados os "métricos" (3) de desempenho como: tempos de variação de velocidade 0-60 MPH ${ }^{(4)}$, retomadas de velocidade e tempos de aceleração (25 - $60 \mathrm{MPH}$ e $50-80 \mathrm{MPH}$ ), entre outros, sendo que os modelos de simulação descrevem o desempenho do

(3) Métricos: Termo que se refere a uma avaliação que pode ser mensurada e que podem ser passíveis de comparações. (4) 0-60 MPH: Refere-se uma avaliação objetiva que determina o tempo que o veículo necessita para alterar a sua velocidade de 0 a $60 \mathrm{MPH}$, onde $\mathrm{MPH}=$ milhas por hora $(1 \mathrm{MPH}=1,609 \mathrm{~km} / \mathrm{h})$. 
motor, conversor de torque e embreagem, da transmissão, das resistências ao rolamento do veículo ("Vehicle Road Load"), das perdas do trem de força e da interação entre pneu-solo. Para (Mencik, Tobler e Blumberg, 1978), apesar de muitos dados de engenharia veicular serem desconhecidos e as simplificações feitas nos modelos, principalmente nas regiões de transiente, os resultados obtidos na simulação comparados com os testes práticos, foram considerados aceitáveis.

Um estudo similar foi desenvolvido por (Starkey, Gray e Watts, 1988) para prever o comportamento da aceleração de um veículo de transmissão manual com 100\% de acelerador ("WOT"). Em seu estudo, foi abordada a influência do escorregamento do pneu ("tire slip" ou "slip ratio") e das trocas de marchas nas acelerações para a otimização da utilização de três tipos de caixa de transmissão diferentes (3, 4 e 5 marchas). Neste estudo, os autores indicaram que a distância do centro de massa ao eixo de tração e a rotação máxima do motor são fatores críticos para o desempenho do veículo, e também foram apresentados formas de otimização das relações de transmissão.

Ferramentas padrões para o desenvolvimento de simuladores estão disponíveis em diversos "softwares", e utilizando-se destas ferramentas, (Datta e Sinan, 1994) elaboraram um programa de simulação automotivo, desenvolvido na plataforma Systembuild and Xmath, capaz de modelar e executar simulações para os mais variados tipos de trem de força.

Neste trabalho, os autores abordaram os princípios que estão por trás do controle de velocidade automotivo ("Automotive Speed Control") na versão demonstrativa do "software", utilizando-se de uma explicação detalhada dos princípios físicos, demonstração da metodologia utilizada e a apresentação das possíveis aplicações dessas técnicas para a solução dos problemas de "design" automotivo.

Como resultado deste trabalho, os autores concluíram que o desenvolvimento de uma plataforma de simulação eficiente pode reduzir consideravelmente o tempo de "design" e testes para os novos projetos do trem de força de um novo veículo. 
No estudo de (Michael e John, 1996) uma simulação dinâmica de veículo foi desenvolvida para prever o comportamento veicular em acelerações com alto nível de escorregamento de pneu. Foi incorporado ao modelo de simulação uma curva empírica não linear que prevê a adesão do pneu em função do seu respectivo escorregamento.

O foco principal de seu estudo foi no comportamento do máximo desempenho em aceleração (100\% de acelerador) para um veículo de tração traseira, onde o modelo de simulação foi utilizado para prever o comportamento do pneu, do trem de força e do veículo neste tipo de manobra, além de ser uma útil ferramenta de desenvolvimento de novos produtos.

Os principais sistemas do veículo foram minuciosamente estudados, incluindo peso do veículo, a localização do centro de gravidade, o coeficiente aerodinâmico, as relações de transmissão, as inércias dos componentes do trem de força e suas eficiências. Um veículo foi testado a fim de comparar e correlacionar com os dados obtidos do modelo. Os autores (Michael e John, 1996) indicaram que os parâmetros que apresentam maior influência na manobra de aceleração 0 a $60 \mathrm{MPH}$ foram: o escorregamento do pneu, a transferência de peso nos eixos, a inércia do motor e a massa total do veículo.

O estudo proposto por (Mohamed e Dong, 1998), visou o desenvolvimento de um procedimento para otimizar a interação entre trem de força e chassis (parâmetros veiculares), dos quais se destacam: a massa do veículo, as relações de transmissão, a relação do diferencial, raio dinâmico do pneu, distância entre eixos e centro de gravidade.

O estudo envolve um modelo matemático e um desenvolvimento de um software em (FORTRAN77 e DOC/DOT), para otimizar o modelo de acelerações longitudinais (métrico 0-60 MPH), incluindo escorregamento de pneu e tempo de trocas de marcha e economia de combustível em regime permanente. No desenvolvimento deste procedimento, (Mohamed e Dong, 1998) concluíram que as relações de transmissão, diferencial, posição do centro de gravidade e massa do veículo, são parâmetros críticos para aceleração do veículo e economia de combustível.

No Universo das simulações e modelos veiculares, (Shih, 2000) contribui no processo de usar simulação e modelos para guiar a concepção do "design" de desempenho veicular. Em seu estudo, direcionado para veículos com transmissão 
automática, foram discutidos quatro modelos de aplicação que são: o desempenho do conversor de torque, as cinemáticas da caixa de transmissão, a aceleração com acelerador totalmente aberto e a economia de combustível do veículo. Esses modelos foram comparados nos seguintes parâmetros: tempo de aceleração com acelerador totalmente aberto, economia de combustível e emissões de gases, velocidade máxima do veículo e desempenho em rampas ("gradeability”), onde, com o modelo fiel, mudanças nas características dos componentes, podem ser observadas de imediato no desempenho do veículo.

Estudos em bancadas também são uma forma de validar componentes, é o que mostra o estudo de (Quan e Krishnaswamy, 2000), que descreve a modelagem em MatLab / Simulink, do desenvolvimento de um controlador e a implementação de um controle de pressão do sistema de embreagem de uma transmissão. Em seu estudo, se concentrou em identificar situações críticas que ocorrem no sistema de controle de pressão na embreagem através de um modelo analítico e com validação experimental. A Figura 2 mostra o esquema da configuração do teste em bancada proposto pelos autores:

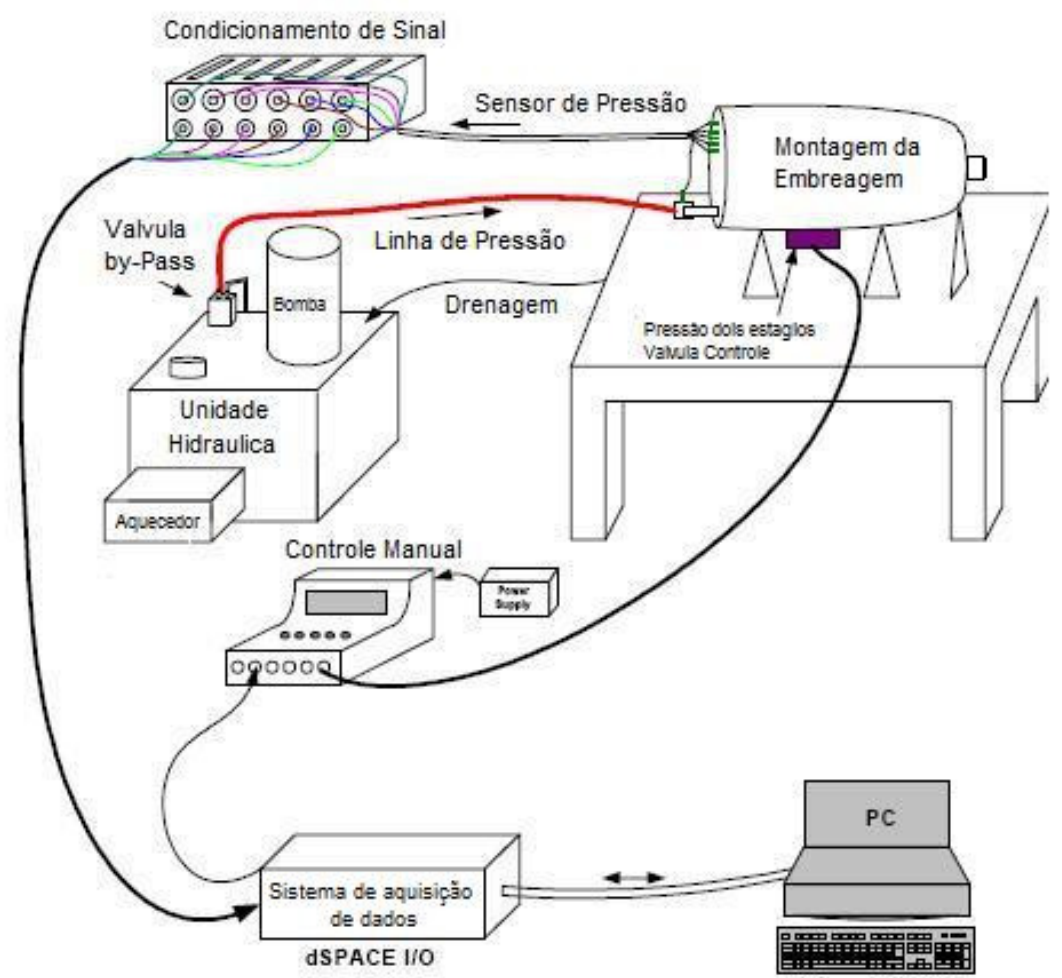

Figura 2: Esquema da configuração de teste em bancada - Sistema de Controle de Pressão da Embreagem (Quan e Krishnaswamy, 2000). 
O modelo de simulação não-linear foi apresentado e verificado pelo experimento e os resultados da simulação correlacionaram bem com dados experimentais.

No estudo de (Gao, Maghbelli, et al., 2003) foram investigados o impacto do tipo de tração no desempenho do veículo, a estrutura trem de força simplificada, o armazenamento de energia e a confiabilidade do sistema para várias unidades motoras, tais como: motor de indução e, utilização de imã permanente para aplicações em veículos militares. A capacidade de subir rampa com altos aclives é crucial para veículos militares, que depende de alto valor de torque nas rodas de tração em velocidades baixas. As forças aerodinâmicas são desprezíveis neste caso. Os autores (Gao, Maghbelli, et al., 2003) apresentaram o conceito de (força trativa / Peso do veículo) e o Gráfico 3 proposto por eles mostra que para altas velocidades tem se a perda de desempenho em acelerações, mas um ganho em força trativa e por conseqüência uma melhora na capacidade de rampa ("gradeability"), onde:

$X=$ Relação de transmissão;

$\mathrm{P}_{\mathrm{m}}=$ Potência requerida pelo motor;

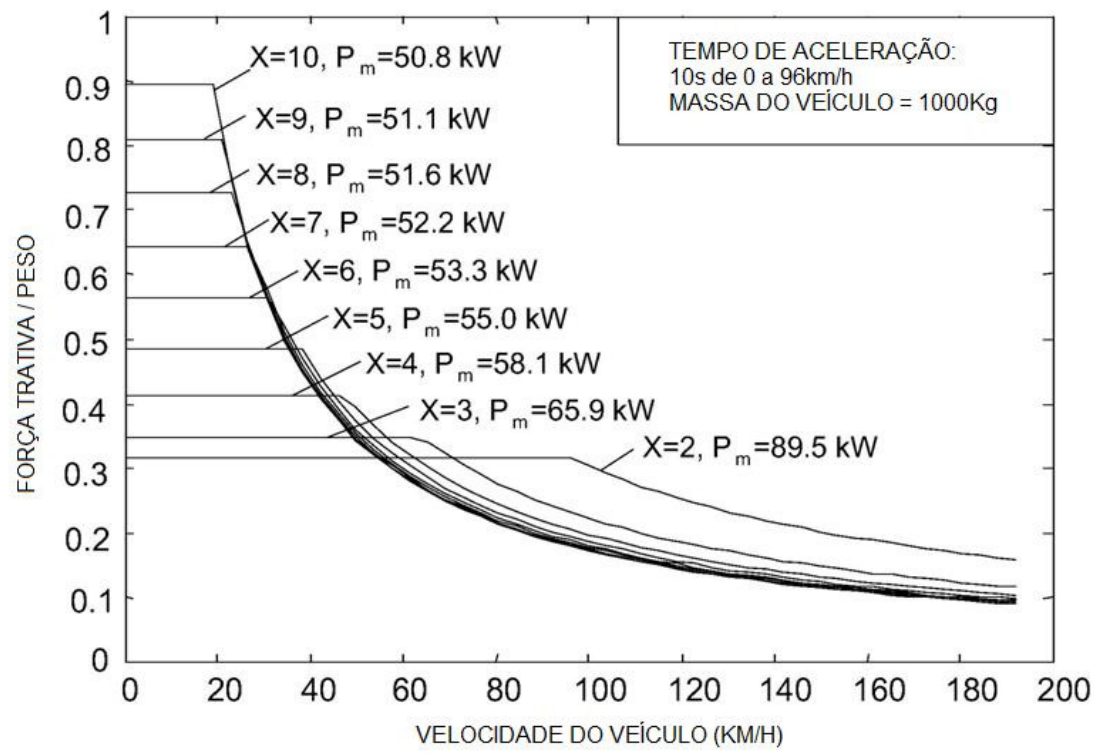

Gráfico 3: Característica dos motores com diferentes velocidades e potências para uma mesma aceleração (Gao, Maghbelli, et al., 2003)

Os autores (Gao, Maghbelli, et al., 2003) concluíram que uma grande faixa constante de potência simplifica o sistema de transmissão, utilizando uma simples 
relação de transmissão ao invés de várias relações, tornando a caixa de transmissão mais simples, compacta e confiável.

$\mathrm{Na}$ análise proposta por (Xi e Giorgio, 2004), economia de combustível, desempenho e dirigibilidade são três formas para se avaliar o comportamento de um veículo na tração. Simulações e medições reais em veículos são formas de se quantificar e qualificar estas métricas. De acordo com os autores, o desempenho do veículo na tração é medido nas suas acelerações, na capacidade de vencer aclives "gradeability" e capacidade de carregar "trailer" (veículo com carreta).

Neste trabalho, os autores definem Capacidade de Rampa (“Gradeability") como sendo a máxima rampa em que o veículo pode se mover a frente. $A$ capacidade de rampa definida por (Xi e Giorgio, 2004) é expressa em porcentagem e depende da força trativa do veículo, massa total do veículo, resistência ao rolamento do pneu e o coeficiente de atrito do pavimento.

No estudo feito por (Manoz, Mohan, et al., 2005) foi proposto um procedimento de concepção estatístico para a otimização das relações de transmissão (4 marchas sincronizadas) para aplicação em um caminhão leve. No estudo foi utilizado um software comercial (AVL CRUISE) e o veículo referência foi simulado e medido fisicamente para validação do modelo e possibilitando adaptações para novas configurações de veículos. Neste estudo, os autores não alteraram a relação de transmissão de primeira marcha, afim de não mudar a capacidade de rampa para esta marcha. Através de análises estatísticas utilizando o software MINITAB, um programa de computador voltado para fins estatísticos, (Manoz, Mohan, et al., 2005) fizeram avaliações com as relações de $2^{\circ}, 3^{\circ}$ e $4^{\circ}$ marchas, variando-as para obter otimização nos valores de consumo de combustível, desempenho e nível de emissões. A variação estatística das respostas das simulações dentro do limite dos parâmetros veiculares, permitiram relações de transmissões otimizadas e robustas para a aplicação.

A elaboração de um software computacional para a determinação de torque, potência e rotações do motor e da transmissão foi o objetivo do trabalho feito por (Rafael, Leandro C., et al., 2007). O Software elaborado na base Excel Windows utiliza como dados de entrada as seguintes características veiculares: curva de torque do motor, relações de transmissão da caixa de transmissão e diferencial, coeficiente de resistência a rolagem, massa do veículo, componente de inclinação de rampa, coeficiente aerodinâmico, área frontal, eficiência da transmissão e 
diâmetro do pneu. Os resultados provenientes do software foram validados através de medições reais em veículos no dinamômetro, como mostra a Figura 3:
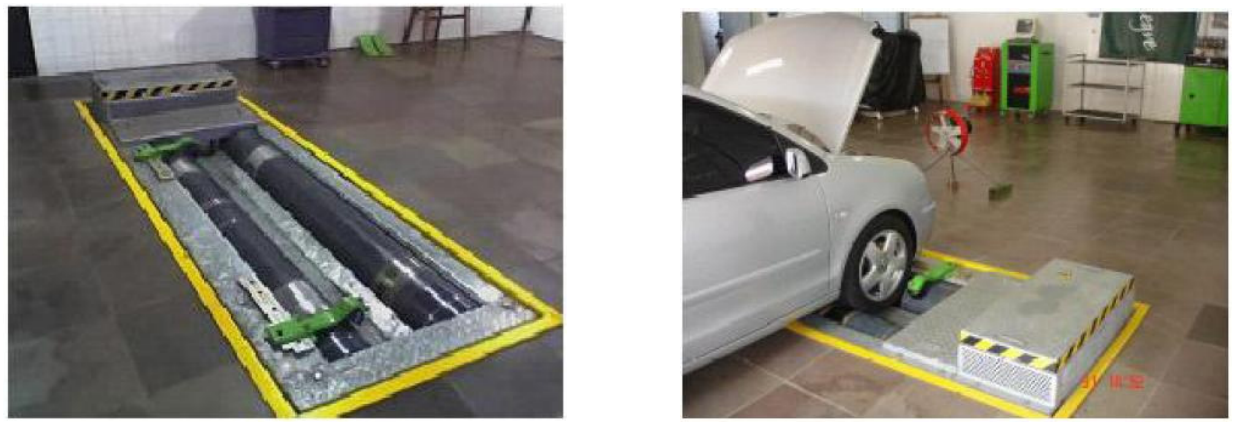

Figura 3: Dinamômetro "Scroll" e veículo para validação de "software" de desempenho veicular (Rafael, Leandro C., et al., 2007).

No desenvolvimento do "software", (Rafael, Leandro C., et al., 2007) geraram gráficos importantes para o desempenho veícular, dos quais pode-se destacar: potência na roda por marcha, força resistiva por marcha em relação à velocidade do veículo, força trativa total por marcha em função da velocidade do veículo e as forças resistivas totais ao rolamento também em função da velocidade do veículo.

Os resultados obtidos através do "software" foram comparados com as medições levantadas no dinamômetro e com as informações fornecidas pelo fabricante do veículo. De acordo com os autores, os resultados desta comparação se mostraram aceitáveis para determinação da curva de torque e potência de um motor, pois os valores encontrados nas análises correlacionaram com os dados fornecidos pelo fabricante, possibilitando assim a validação do "software" e o modelo matemático.

No estudo proposto por (Andrew, Sylvain, et al., 2007), o principal objetivo é promover a idéia de um veículo digital através do desenvolvimento de uma capacidade de simulação robusta e fiel afim de permitir o melhor entendimento do controle da "performance" de veículos fora de estrada "off-road"; concentrando-se em dois principais aspectos:

1-) Desenvolvendo uma familia de pneus e modelos de contato para simulações que promovam alta representatividade em terrenos fora e dentro de estrada em condições ambientais extremas;

2-) Promover uma investigação completa nas técnicas de co-simulação adequadas numericamente para modelos compostos por diversos fatores que 
contribuem para a "performance" do veículo, tais como: pneus, terrenos, trem de força, subsitemas e controle.

O modelo de simulação do trem de força utilizado por (Andrew, Sylvain, et al., 2007) se deu pela interação de blocos de componentes veículares, entre eles podese destacar: o mapa de torque do motor, posição do acelerador, embreagem, transmissão, freios. O Gráfico 4 mostra um exemplo do mapa da eficiência do motor que foi utilizado na plataforma do MATLAB Simulink:

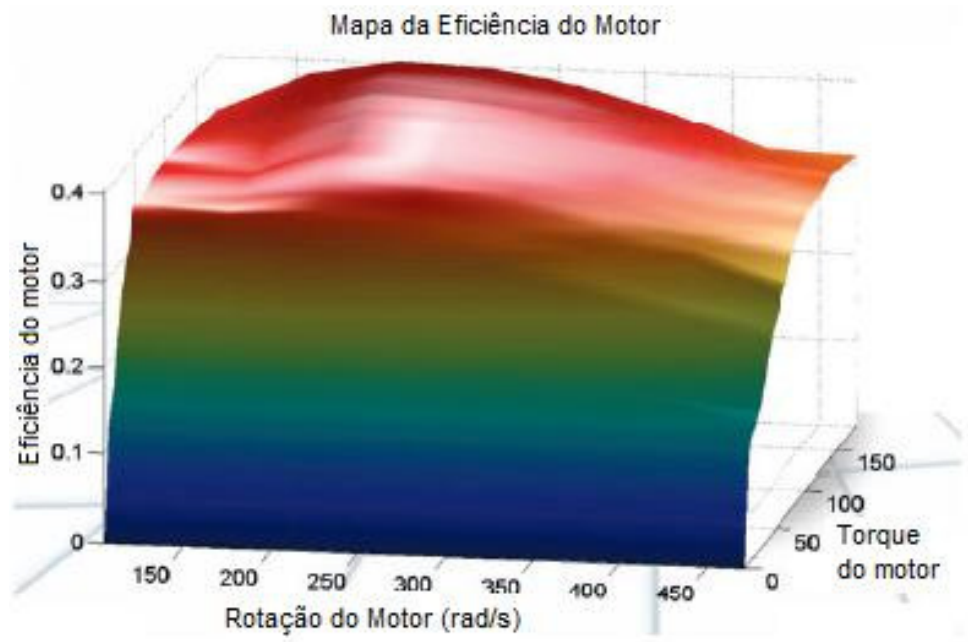

Gráfico 4: Mapa da eficiência do motor (Exemplo) (Andrew, Sylvain, et al., 2007).

O ambiente de simulação desenvolvido em plataformas diferentes (modelo veicular => especificado em ADAMS, modelo do trem de força => especificado em PSAT e os modelos de pneus => especificados em ADAMS (FTire ou FEAP)), permitiu para (Andrew, Sylvain, et al., 2007) um melhor entendimento do que é necessário para se executar as simulações em plataformas diferentes, das interfaces dos códigos de comunicação, do nível de fidelidade que se pode esperar da análise bem como do poder de calibração do modelo que se pode fazer. Concluiu-se, com este ambiente de simulação, que se trata de uma eficiente ferramenta para o desenvolvimento de novos veículos para diversos ambientes e características. 


\section{3-) Conteúdo da Dissertação}

Para proporcionar uma melhor compreensão do conteúdo desta dissertação, destaca-se a seguir os capítulos que a compõe:

- Capítulo 3: Revisão da Literatura:

Nesta sessão é abordado em detalhes todos os componentes que exercem influência direta no desempenho veicular em manobras de arrancada, os quais se destacam:

- Sessão 3.1: Nível Veicular;

- Sessão 3.2: Motor;

- Sessão 3.3: Embreagem;

- Sessão 3.4: Transmissão;

- Sessão 3.5: Pneus;

- Sessão 3.6: Inércias;

- Sessão 3.7: Rampas e obstáculos.

- Capítulo 4: Metodologia:

Nesta sessão é abordada toda a metodologia utilizada na simulação desenvolvida na plataforma MATLAB/SIMULINK para a modelagem da manobra de arrancada em altos aclives. São apresentados os cálculos e ferramentas utilizadas. O capítulo esta dividido da seguinte forma:

- Sessão 4.1: Modelo físico e matemático proposto;

- Sessão 4.2: Possibilidades de aplicação;

- Sessão 4.3: Veículo estudado;

- Sessão 4.4: Descrição do experimento. 
- Capítulo 5: Resultados obtidos:

Nesta sessão são apresentados e comparados todos os resultados obtidos através da modelagem veicular no software de simulação bem como as medições obtidas em veículo real. O capítulo esta dividido da seguinte forma:

- Sessão 5.1: Do ensaio em campo;

- Sessão 5.2: Do modelo teórico;

- Sessão 5.3: Validação do modelo.

- Capítulo 6: Conclusão:

Para finalizar a dissertação, nesta sessão é abordada a conclusão final deste trabalho levando em consideração tudo o que foi assumido na construção do modelo matemático e na metodologia utilizada, em conjunto com as referências bibliográficas consideradas e principalmente como forma de se tornar o modelo de simulação uma ferramenta para utilização no desenvolvimento de novos projetos. 


\section{3-) REVISÃO DA LITERATURA}

Quando se fala de automóvel, uma ferramenta tão importante nos dias de hoje para todos que se utilizam dos seus benefícios, se torna crucial saber como que todo o desenvolvimento desta poderosa máquina teve o seu início. De acordo com (Eckermann) a história do automóvel começa em meados de 1769, com a criação dos automóveis movidos a vapor com capacidade de transportar os seres humanos.
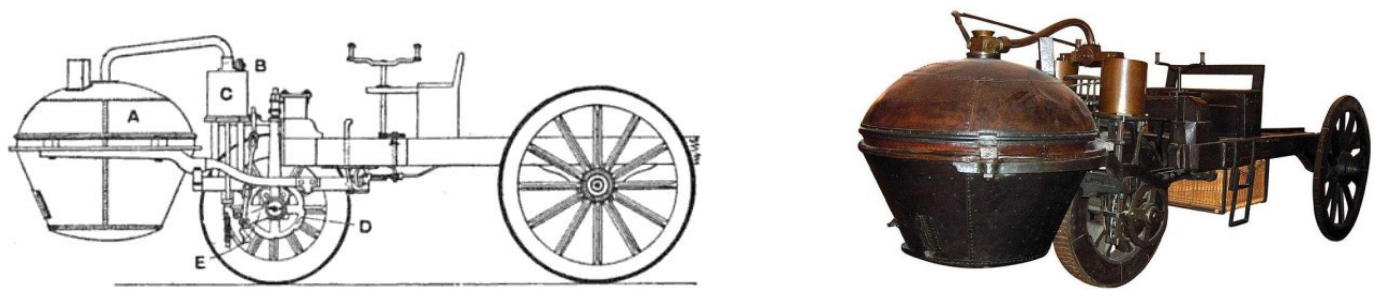

Figura 4: O projeto do Cugnot Steam Trolley (1769) - (Eckermann)

Em 1806, apareceram os primeiros carros movidos por motores de combustão interna utilizando o gás como combustível de propulsão, sendo este que levou à introdução em 1885 do onipresente motor de combustão interna a gasolina.

O início da história do automóvel pode ser dividido em uma série de eras com base no método predominante de propulsão automotiva durante esse tempo. Mais tarde, os períodos foram definidos por tendências de estilo exterior, tamanho e preferências de utilização, como mostra a Figura 5:

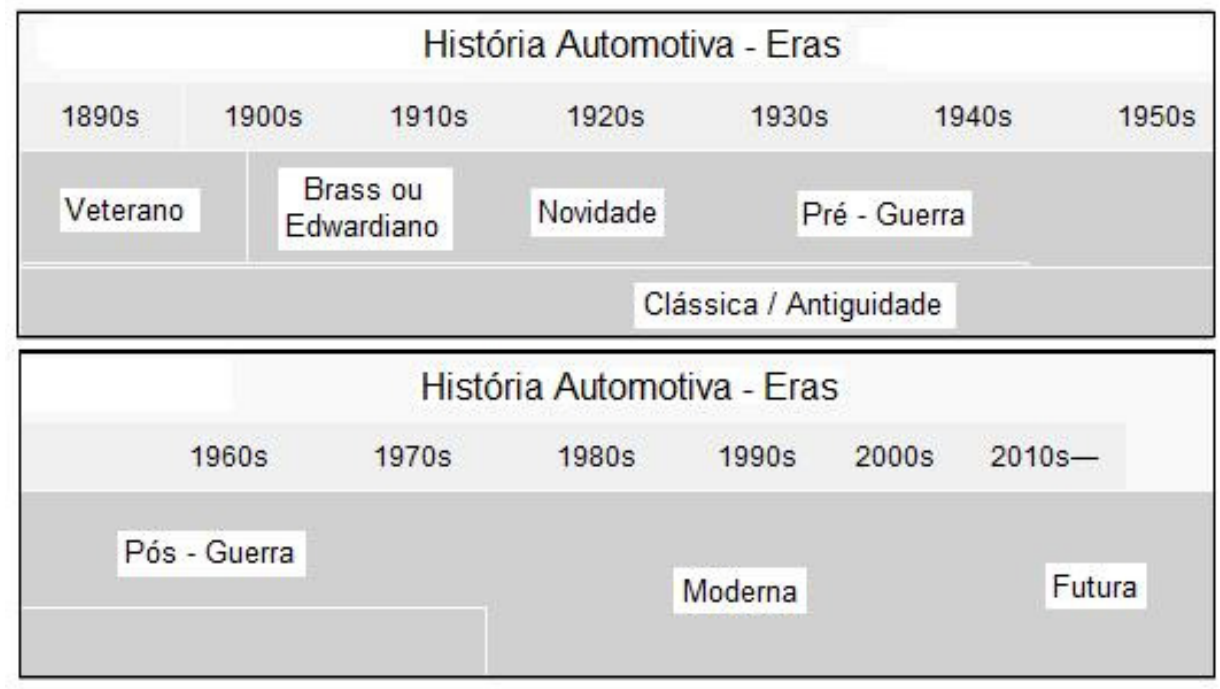

Figura 5: História Automotiva - Eras (Eckermann) 
A história do automóvel mostrou que houve uma considerável evolução a partir da década de 1980 e que, sem dúvida alguma, o sucesso do desenvolvimento de novos projetos veiculares foi função da engenharia automotiva moderna. O seu papel foi incorporar o que há de mais atual em termos de componentes mecânicos, elétrica embarcada, "design" voltado à segurança e a evolução dos seus respectivos subsistemas de engenharia, aplicados na produção dos mais variados produtos automotores, tais como: motocicletas, automóveis, ônibus e caminhões.

Inserido na engenharia automotiva, está 0 trabalho do engenheiro de desenvolvimento, o qual tem a responsabilidade de coordenar a entrega dos atributos de um veículo completo, ditado pelo fabricante, regulamentações / exigências governamentais, competição tecnológica e satisfação do consumidor.

A engenharia de desenvolvimento preocupa-se com as interações de todos os sistemas do veículo e é desejado que todos os vários componentes e sistemas de um automóvel funcionem como projetados, e adicionalmente, conforme afirma (Ball e Stone, 2004), o automóvel moderno é muito mais do que a soma de suas partes, cada componente deve trabalhar em harmonia com os outros, sob pena de não ter um produto desejado para o consumidor alvo. Somente como exemplo, de acordo com (ZF Sachs, 2010) uma das funções do sistema de embreagem é transmitir o torque do motor para a transmissão, junto com isso, o sistema deve prover um nível aceitável de: esforço e curso de pedal de embreagem, ruído e durabilidade.

Outro aspecto importante a ser considerado pela engenharia de desenvolvimento é a ponderação ("trade-off"), onde se é obrigado a entregar todos os atributos do veículo em um nível aceitável. Um exemplo disto é a ponderação entre o desempenho do motor / veículo e a economia de combustível. O veículo deve fornecer um nível aceitável de consumo de combustível, para seu consumidor, e também deve atender ao máximo desempenho possível, com todas as características presentes no veículo, como: massa total, relações de transmissão, inércias, forças aerodinâmicas, dispositivos de controle de emissões, pneus, etc.

O desempenho do veículo em aclives elevados também é um fator muito importante a ser considerado no desenvolvimento de novos projetos e é muitas vezes um requisito crucial para a aceitação ou não do produto no mercado. 


\section{1-) Nível Veicular}

O competitivo mercado de veículos automotores presente nos dias de hoje, forçam as empresas, que atuam nesta atividade, a otimizar ao máximo as suas plataformas de veículos. De acordo com (Michael, 1999), uma plataforma de automóvel é um conjunto compartilhado de "design" comum, aperfeiçoamento da engenharia e esforços de produção, bem como os principais componentes dos modelos distintos de um mesmo veículo, ou a partir outros veículos, desde que se mantenha uma relação entre eles.

Do ponto de vista técnico, (Muffatto, 1999) define uma plataforma de automóveis com as seguintes características:

- Assoalho: conjunto de peças de chapa que servem como base principal da carroceria monobloco, onde se concentram a maioria dos componentes mecânicos e estruturais;

- Distância entre eixos: o qual se designa a distância horizontal entre o centro do eixo dianteiro e o centro do eixo traseiro, como mostra a Figura 6:

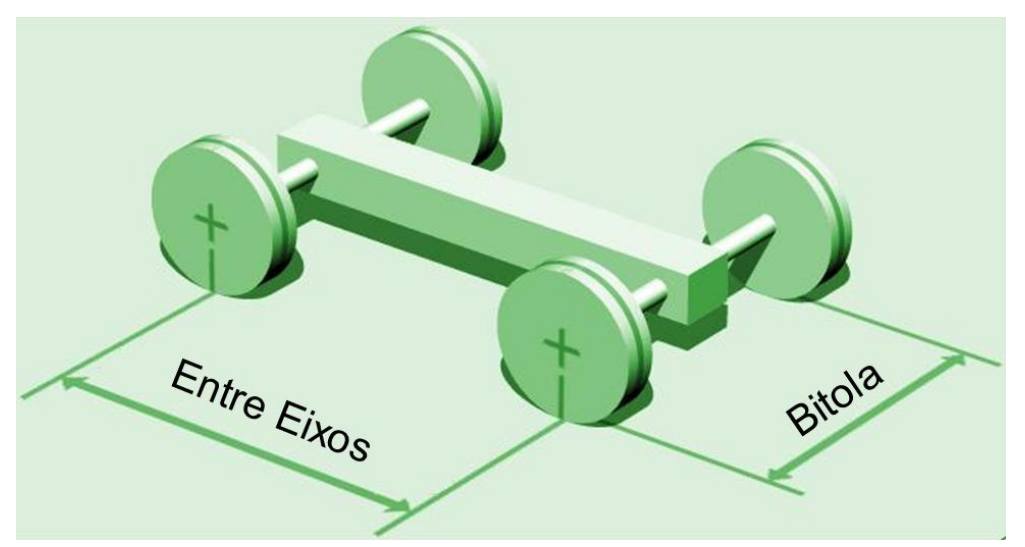

Figura 6: Distância entre Eixos e Bitola (Wikipedia - The Free Encyclopedia, 2010)

- Sistema de Direção: onde o regime de governo mais convencional é a de acionar as rodas dianteiras através de um comando manual que está posicionado à frente do condutor, o qual the permita desviar de obstáculos a partir de uma linha reta. O sistema de direção pode ser assistido através do fornecimento de uma porção de energia do motor, a 
través de componentes hidráulicos ou elétricos, onde este último demanda energia proveniente do alternador.

- Suspensões: conjuntos especificados na dianteira e traseira de um veículo, conectados através das molas, amortecedores e componentes de ligação do veículo com as rodas.

- Posicionamento e escolha de motores e componentes do trem de força. Este tópico será abordado com mais detalhes adiante.

A utilização de uma mesma plataforma segundo (Schlie e Yip, 2000), acompanhada com a tecnologia avançada e flexível, permite às montadoras reduzir drasticamente o tempo de desenvolvimento de produtos e os tempos de transições, enquanto o "design" modular e montagem permitem a construção de uma maior variedade de veículos através de um conjunto básico de componentes de engenharia. De acordo com (Muffatto, 1999), a utilização de uma estratégia de plataforma pode prover uma série de benefícios, os quais de destacam:

- Maior flexibilidade entre as plantas produtoras - Padronização;

- A redução de custos obtidos através da utilização de recursos em escala global;

- O uso crescente de plantas (maior produtividade devido à redução no número de diferenças);

- Redução do número de plataformas, como resultado de sua localização em uma base mundial.

Uma vez definida a estratégia de plataforma que será utilizada por um fabricante de automóvel, todos os esforços de engenharia são colocados no desenvolvimento deste novo produto. Conforme já mencionado anteriormente, o posicionamento e a escolha dos motores e trem de força fazem parte crucial do "layout" do novo veículo.

Muitas combinações diferentes de localização do motor e rodas motrizes são encontradas na prática, bem como a localização de cada uma é dependente da aplicação que o veículo vai ser utilizado. Fatores que influenciam a escolha do "design" incluem o custo, a complexidade, a confiabilidade, tamanho do habitáculo, 
tipos de carroceria, distribuição de peso e características de dirigibilidade do veículo. Os "layouts" podem ser divididos nas categorias: tração nas rodas dianteiras ou traseiras e existem ainda veículos com capacidade de tração nas quatro rodas.

Os tópicos abaixo são apresentados de forma resumida dos principais "layouts" de propulsão veicular:

\section{- Tração no Eixo Dianteiro:}

"Layouts" com tração no eixo dianteiro são aqueles em que as rodas dianteiras do veículo são as responsáveis pela transmissão de força ao solo. O "layout" mais popular usado nos carros atuais é o motor dianteiro, tração dianteira, com o motor na frente do eixo dianteiro, dirigindo as rodas dianteiras. Esta configuração é normalmente escolhida para carrocerias compactas, uma vez que o motor e as rodas motrizes estão no mesmo lado do veículo. Com isto, não há necessidade de um túnel central através do compartimento dos passageiros para acomodar um eixo propulsor entre o motor e as rodas motrizes. A Figura 7 mostra este "layout":

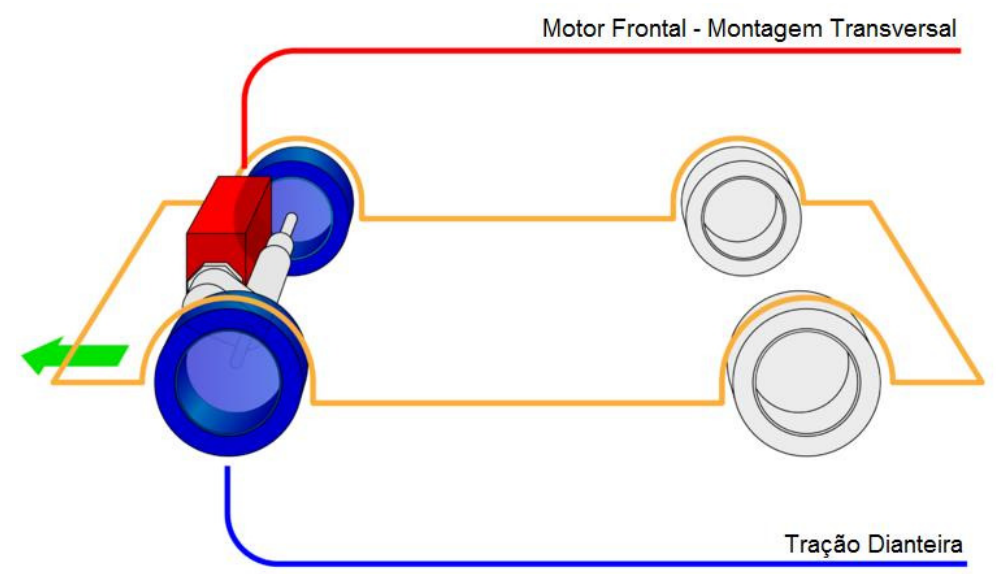

Figura 7: Tração no Eixo Dianteiro (Wikipedia The Free Encyclopedia, 2010)

De acordo com (Wikipedia The Free Encyclopedia, 2010) a conexão direta entre o motor e o semi-eixo reduz a massa e a inércia mecânica do sistema de transmissão em relação a um veículo de tração nas rodas traseiras com um similar motor e transmissão, o que permite maior economia de combustível. Outra característica afirmada por (William, 1995) é a massa do conjunto motor e transmissão nos veículos de tração dianteira mover o centro de gravidade mais para 
frente do veículo, melhorando assim a tração e a estabilidade direcional em pisos de baixa aderência.

\section{- Tração no Eixo Traseiro:}

Os veículos com tração traseira normalmente têm o posicionamento do motor localizado na parte dianteira do veículo, e as rodas motrizes estão localizadas na parte traseira. Motores posicionados na parte central e na traseira também são utilizados. De acordo com (Masatoshi, Hiroatsu, et al., 2006) este "layout" tradicional de automóvel foi utilizado para a maioria dos veículos no século 20. As Figura 8 e Figura 9 mostram estas configurações:

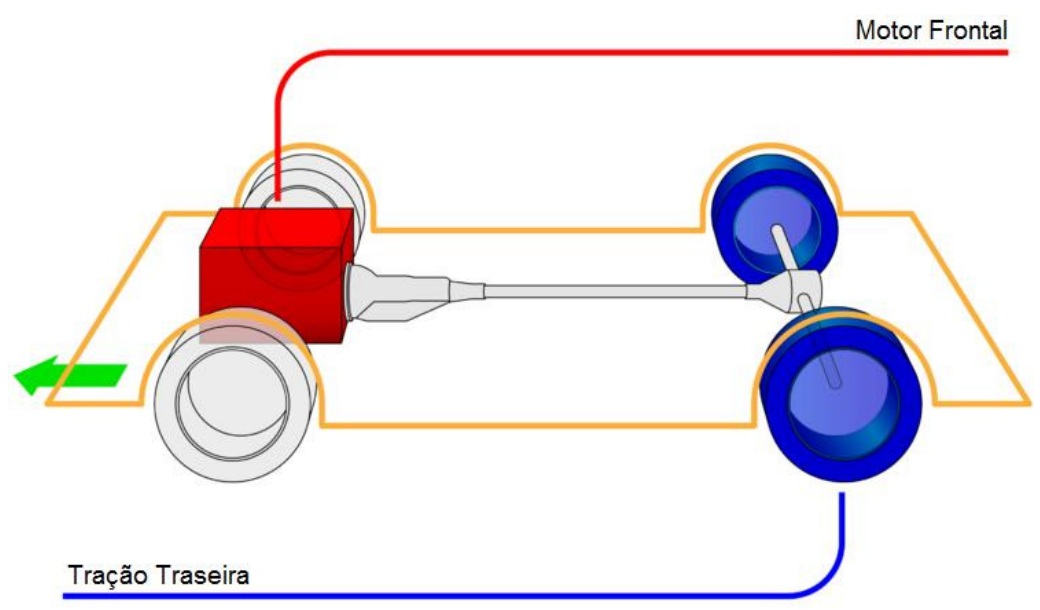

Figura 8: Tração Traseira / Motor Dianteiro (Wikipedia The Free Encyclopedia, 2010)

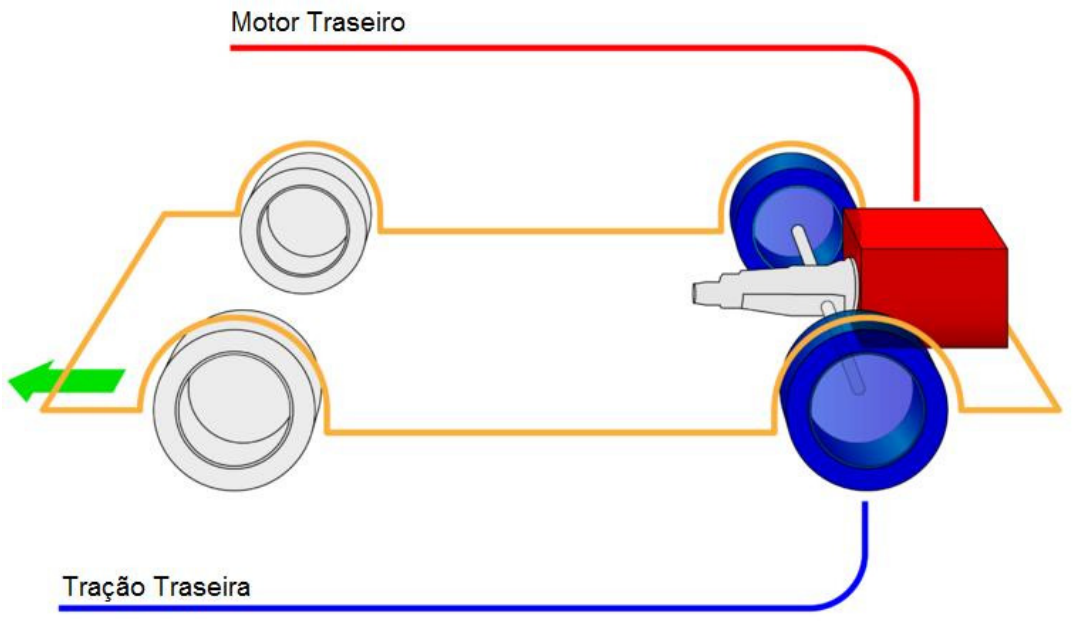

Figura 9: Tração Traseira / Motor Traseiro (Wikipedia The Free Encyclopedia, 2010) 
A grande maioria dos veículos de tração traseira usa motor montado longitudinalmente, na parte da frente do veículo, conectado às rodas traseiras através de um eixo cardam, que é ligado através de um diferencial aos semi-eixos das rodas traseiras.

Para veículos voltados para alto desempenho, a tração traseira é mais adequada, pois nas acelerações, ocorre a transferência de peso para as rodas de tração o que aumenta a força normal ao pavimento e conseqüente aumento de força de tração.

\section{- Tracão Integral (nas quatro rodas):}

O "layout" de tração integral nas quatro rodas, "4WD” ("Four Wheel Drive"), 4x4 (quatro por quatro), é um veículo de quatro rodas com sistema de transmissão que permite que todas as quatro rodas recebam torque do motor ao mesmo tempo. Sua utilização é mais comum em veículos fora de estrada e utilitários esportivos; no entanto esta configuração proporciona um melhor controle de estabilidade para veículos normais de rua em muitas superfícies com baixa aderência e também nas competições fora de estrada ("Rally"). A Figura 10 mostra este "layout":

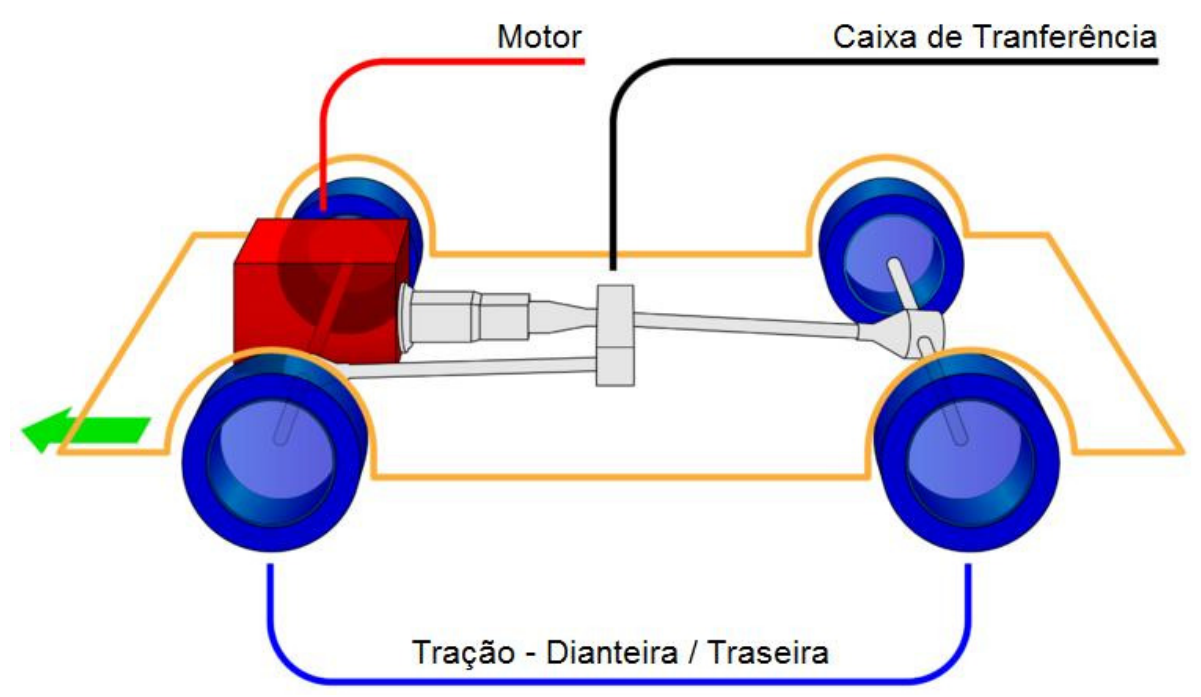

Figura 10: Tração Integral (Wikipedia The Free Encyclopedia, 2010)

O acionamento da tração nas quatro rodas, geralmente comum em veículos fora de estrada ("off-road"), pode ser efetuado manualmente pelo motorista ou 
automaticamente, sendo que o veículo identifica a demanda de torque necessária para cumprir o movimento em pisos de baixa aderência.

Diante do conhecimento das principais configurações de trem de força dos veículos, o posicionamento de um sistema de referência neles se torna necessário para prescrever o desempenho nas manobras de aceleração. O sistema de referência da Figura 11 é o mais utilizado:

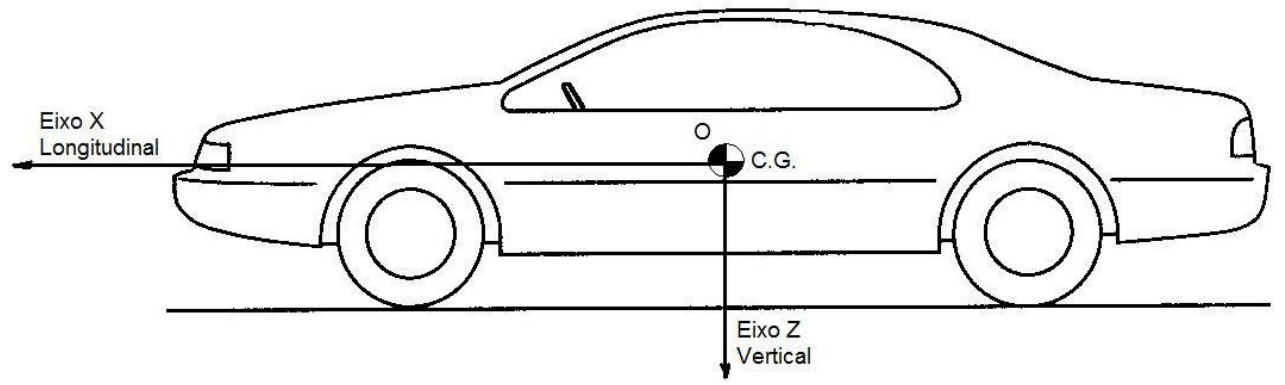

Figura 11: Centro de Gravidade Longitudinal (Gillespie, 1992)

O centro de gravidade (C.G) pode ser descrito por uma região no espaço onde se concentra toda a massa de um veículo. De acordo com (Canale, 1989), a determinação do C.G. nos veículos é de grande importância na obtenção das suas características de desempenho e estabilidade. A seguir são apresentados os métodos de medição do C.G:

- Posicionamento do C.G. na direção longitudinal: pode ser obtido pesando-se o veículo conforme mostra a Figura 12:

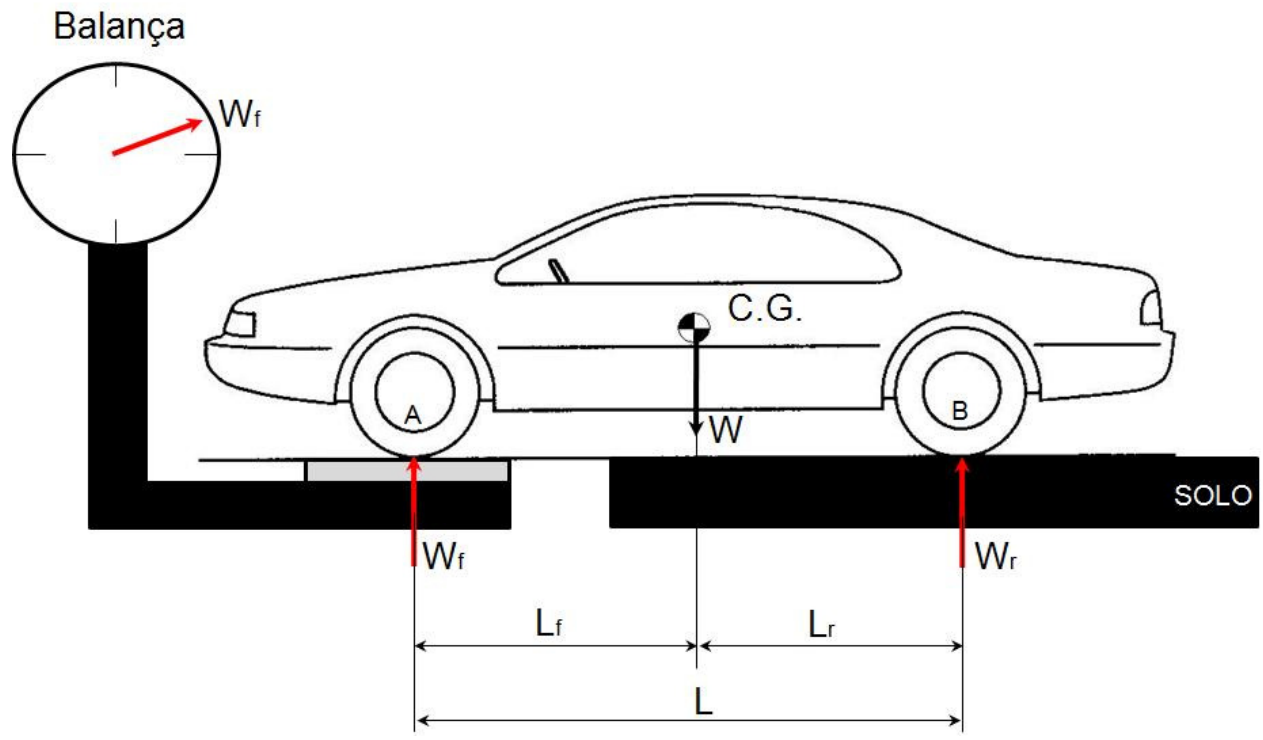

Figura 12: Posicionamento do C.G. na Direção Longitudinal 
Onde:

$\mathrm{W}=$ Força Peso do veículo representado na referência C.G (N);

$\mathrm{W}_{\mathrm{f}}=$ Força Normal no Eixo Dianteiro $(\mathrm{N})$;

$\mathrm{W}_{\mathrm{r}}=$ Força Normal no Eixo Traseiro (N);

$\mathrm{L}=$ Distância Entre Eixos $(\mathrm{mm})$;

$\mathrm{L}_{f}=$ Distância do C.G. ao Eixo Dianteiro $(\mathrm{mm})$;

$L_{r}=$ Distância do C.G. ao Eixo Traseiro (mm).

São conhecidos $W$ e $L$, é medido $W_{f}$ ou $W_{r}$ ou ambos e é calculado $L_{f}, L_{r}$. Segue abaixo as equações:

$W_{r}=W-W_{f}$

Somatória dos momentos em torno de "A".

$L_{f}=\frac{W_{r} \cdot L}{W}$

Somatória dos momentos em torno de "B".

$L_{r}=\frac{W_{f} \cdot L}{W}$

- Posicionamento do C.G. na direção vertical: A obtenção desta posição é mais trabalhosa e devem ser seguidos alguns procedimentos conforme Figura 13:

- Requer a medida de $W_{f}^{\prime}$ com veículo inclinado de uma quantidade "n" qualquer conhecida;

- O ângulo de inclinação deve ser medido acuradamente, geralmente pela determinação de uma ou ambas as distâncias L' ou n;

- As molas da suspensão devem ser travadas e a localização do C.G. na direção de $x\left(L_{r}\right)$ conhecida. 


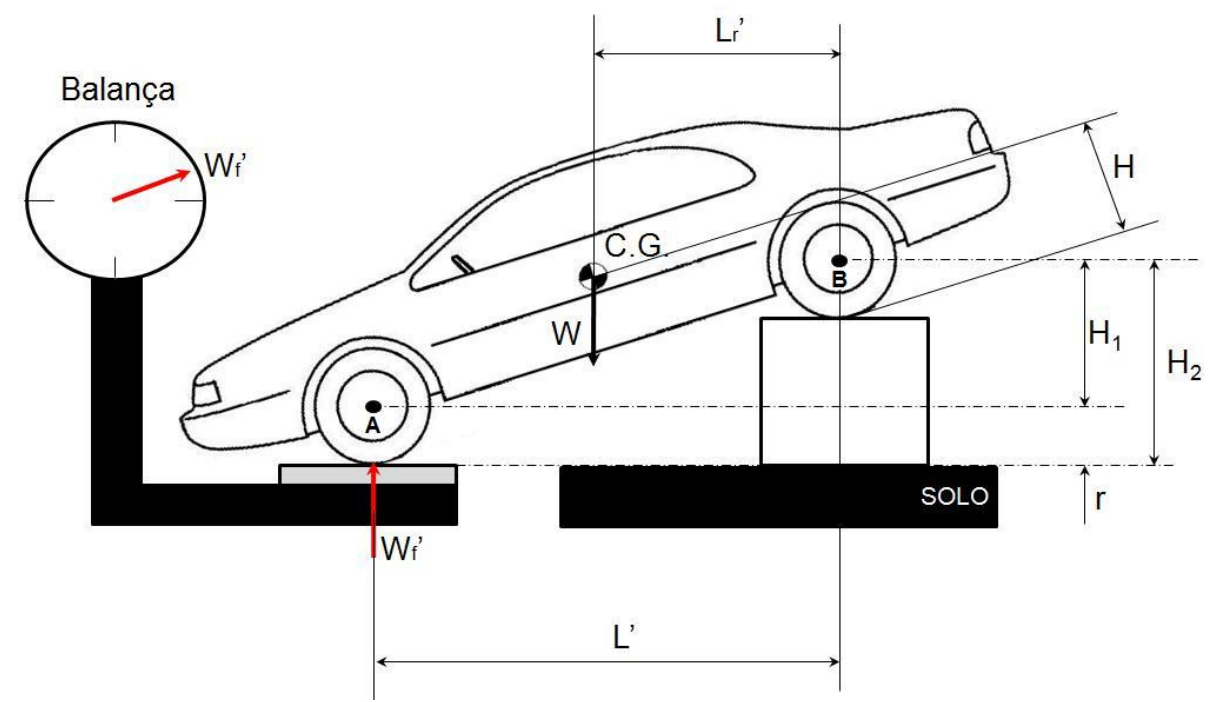

Figura 13: Veículo com um dos Eixos Elevado

Fazendo-se a somatória dos momentos em torno de "A", tem-se:

$L_{r}^{\prime}=\frac{W_{f}^{\prime} \cdot L^{\prime}}{W}$

Sendo $L^{\prime 2}=L^{2}-H_{1}{ }^{2}$ e substituindo em (4), temos:

$L_{r}^{\prime}=\frac{W_{f}^{\prime} \cdot \sqrt{L^{2}-H_{1}{ }^{2}}}{W}, \quad$ onde: $\quad H_{1}=H_{2}-r$

Desta forma, a altura do C.G. H é calculada por:

$H=\sqrt{L_{r}^{\prime 2}-L_{r}^{2}}+r$

Onde:

$\mathrm{H}_{1}=$ Altura de elevação do eixo menos o raio dinâmico do pneu (mm); $\mathrm{H}_{2}=$ Altura de elevação do eixo (mm);

$r=$ Raio dinâmico do pneu (mm);

$\mathrm{H}=$ Altura do C.G. em relação ao solo (mm). 
Outro aspecto muito importante no desenvolvimento de um novo veículo é o seu "design", onde os engenheiros desta área estão envolvidos na elaboração de uma aparência que agrade o consumidor alvo e, de certa forma, desenvolver plataformas que atendam às legislações de impacto e que possua a melhor ergonomia possível. O "design" automotivo está principalmente preocupado em atender as expectativas do consumidor alvo, através do desenvolvimento do aspecto visual e estético do veículo e também ser o responsável pela criação de novos conceitos e tendências para o produto.

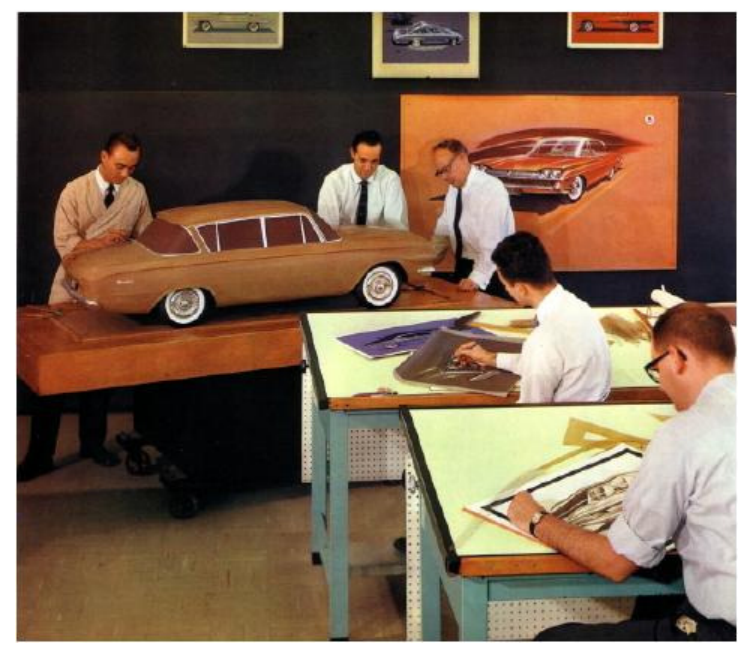

Figura 14: Construção de Maquete (design) - (Automotive Design, 2010)

Uma das principais preocupações no desenvolvimento de uma nova superfície de um veículo esta em diminuir o arraste aerodinâmico, onde este fator promove melhorias de ruído de vento, economia de combustível, estabilidade direcional e melhora no desempenho em velocidades mais elevadas. Para veículos de competição, o efeito aerodinâmico é utilizado para melhorar a tração das rodas e conseqüentemente as manobras.

Um automóvel aerodinâmico irá integrar todas as faces externas, tais como: arcos das rodas e linhas laterais a fim de propiciar a menor superfície possível. Para promover o melhor fluxo de ar, por exemplo, as palhetas do pára-brisa são posicionadas de forma a não se cruzarem na passagem do fluxo de vento e como conseqüência promover uma diminuição do arraste aerodinâmico.

O efeito das forças aerodinâmicas é claramente percebido em altas velocidades, pois considerando um veículo em movimento em linha reta no piso horizontal, segundo (Ball e Stone, 2004), o fluxo de ar depende da velocidade do 
veículo e do ar ambiente, como mostra a Figura 15. O vento tem um perfil de velocidade não-uniforme devido à topografia do local e da camada limite da terra, e, em geral, a velocidade vai variar tanto em magnitude e direção. As forças aerodinâmicas e momentos atuam no centro de pressão.

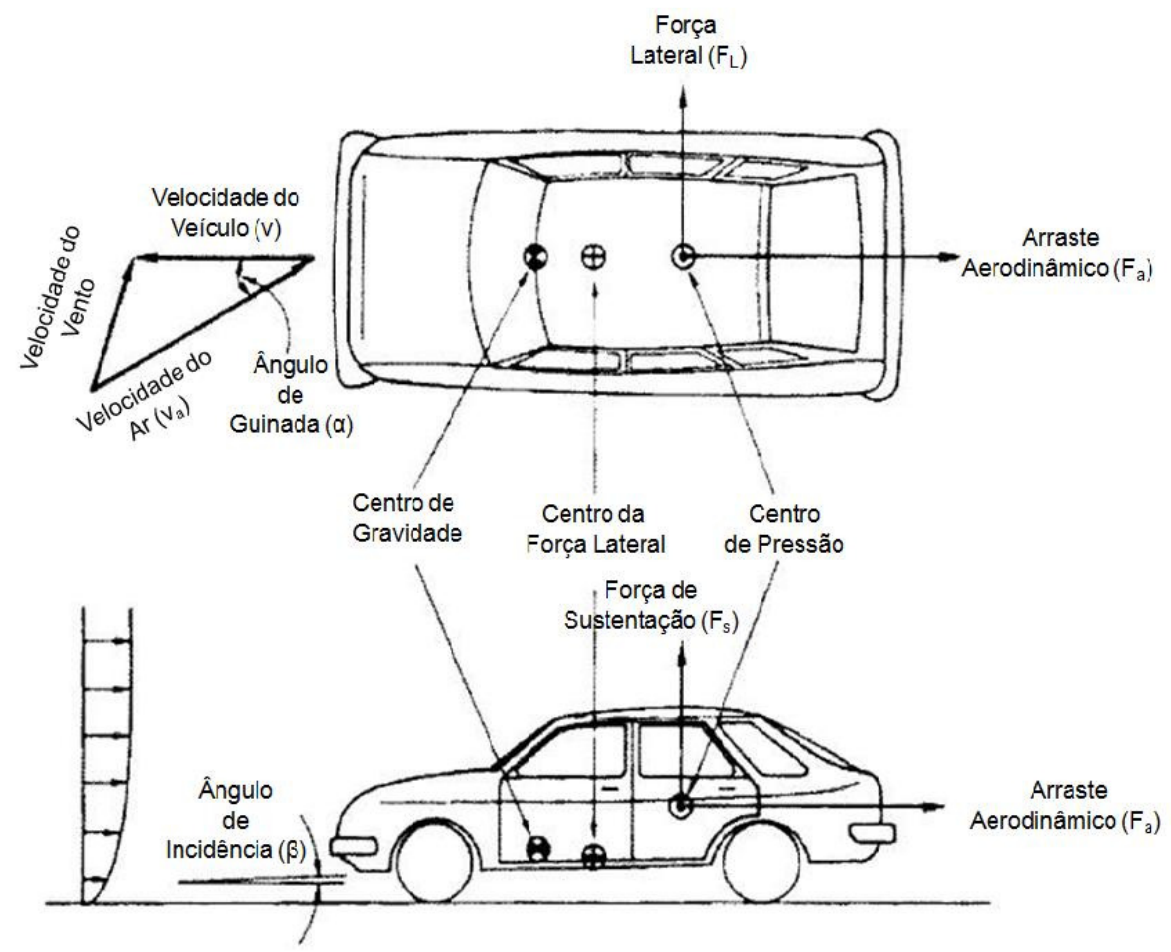

Figura 15: Forças Aerodinâmicas (Ball e Stone, 2004)

Conforme mostrado na Figura 15, a forças aerodinâmicas estão no sentido contrário ao movimento, e estas devem ser superadas pelas forças de tração do veículo. Segue a seguir a equação para o cálculo das forças de arrasto aerodinâmico:

$$
F_{a}=\frac{1}{2} \cdot \rho \cdot C_{d} \cdot A_{f} \cdot v^{2}
$$

Onde:

$\mathrm{F}_{\mathrm{a}}=$ Força de arraste aerodinâmico $(\mathrm{N})$;

$\rho=$ Densidade do $\operatorname{ar}\left(\mathrm{kg} / \mathrm{m}^{3}\right)$;

$\mathrm{C}_{\mathrm{d}}=$ Coeficiente aerodinâmico (-);

$A_{f}=$ Área frontal do veículo $\left(\mathrm{m}^{2}\right)$;

$\mathrm{v}=$ Velocidade relativa do veículo $(\mathrm{m} / \mathrm{s})$. 


\section{2-) Motor}

Nesta sessão serão abordadas de forma superficial as principais características dos motores de combustão interna presente nos veículos. De acordo com (Heywood, 1988), os motores de combustão interna tiveram início em 1876 quando Otto desenvolveu o motor de ignição por centelha e, em 1892, quando Diesel inventou os motores de ignição por compressão. Desde a sua invenção, os motores passaram por diversas transformações, entre elas pode-se destacar o contínuo aperfeiçoamento de seus processos de fabricação, a disponibilidade de suas novas tecnologias, o aumento da demanda de novos tipos de motores e principalmente as restrições ambientais vigentes em muitos países sobre o uso do motor.

Os motores de combustão interna e as indústrias que os desenvolvem e os fabricam desempenham um papel fundamental nas áreas de eficiência energética, propulsão e emissões de poluentes. Diante disto, se faz necessário o conhecimento das principais características que contemplam os motores de combustão interna e como elas interferem diretamente no desempenho veicular. Uma breve introdução sobre os componentes dos motores e suas características será apresentada nesta sessão.

De acordo com (Garcia e Brunetti, 1992), as máquinas térmicas são dispositivos que permitem a transformação de energia térmica em trabalho, e esta pode ser obtida através de várias fontes como a combustão interna de um combustível. A obtenção de trabalho é ocasionada por uma seqüência de processos realizados por uma substância denominada "fluido ativo", o qual participa diretamente da combustão nos motores de combustão interna.

Quanto à forma de se obter trabalho mecânico, os motores de combustão interna podem ser classificados em:

1-) Motores alternativos: quando o trabalho é obtido pelo vai-vem (movimento alternativo) de um êmbolo ou pistão, transformado em rotação contínua, por um sistema biela/manivela.

2-) Motores rotativos: quando o trabalho é obtido diretamente por um movimento de rotação. Ex: Turbinas a gás, motor Wankel.

3-) Motores de impulso: quando o trabalho é obtido pela força de propulsão gerada pelos gases expelidos em alta velocidade. Ex: Motor a jato e foguetes. 
Os motores de combustão interna são mais comumente utilizados para a propulsão de veículos rodoviários e em máquinas móveis portáteis. Geralmente utilizam combustíveis fósseis (principalmente derivados do petróleo), e estes motores têm sido utilizados nos transportes de cargas e passageiros em quase todos os veículos (automóveis, caminhões, motocicletas, barcos e em uma grande variedade de aviões e locomotivas).

$\mathrm{Na}$ aplicação automotiva, os motores alternativos são os que apresentam a melhor relação custo-benefício até o momento. Os motores mais comuns na aplicação automotiva, são os motores 2 tempos (2T) e os motores 4 tempos (4T), sendo o último que detém a maior aplicação nos veículos convencionais. A Figura 16 mostra os principais elementos de que compõe este tipo de motor:

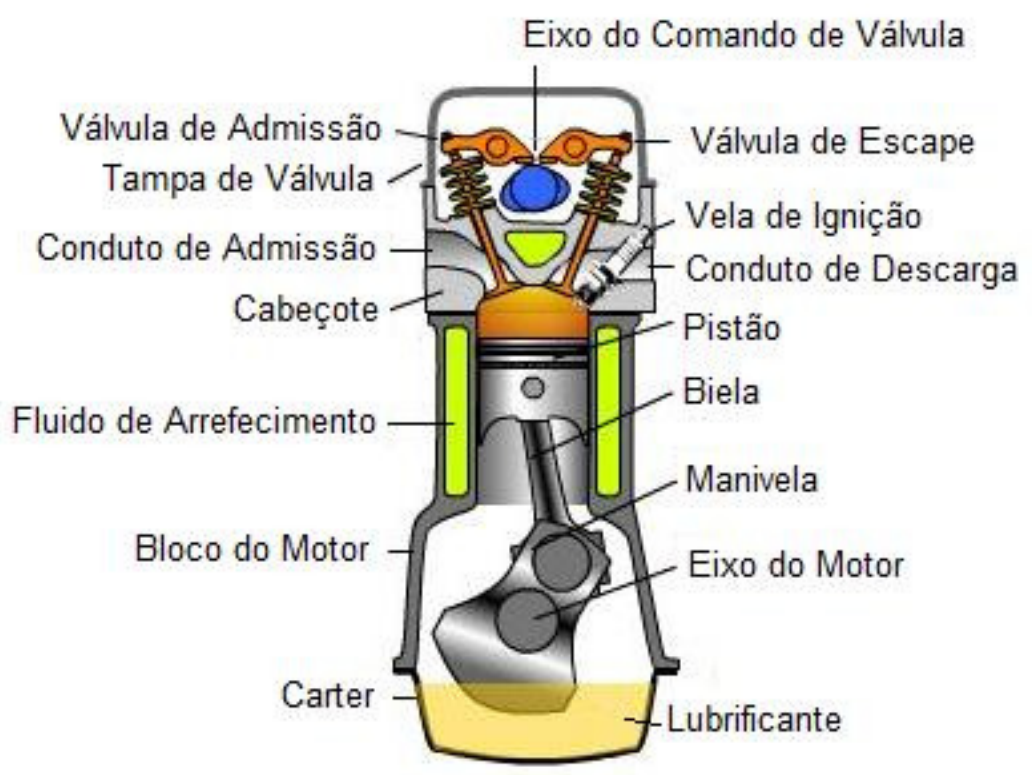

Figura 16: Principais Elementos de um Motor de Combustão Interna Alternativo (How Stuff Works, 1998-2010)

Neste tipo de motor, o pistão move-se para cima e para baixo dentro de um cilindro de alimentação e transmite o movimento através de uma biela e manivela conectada ao eixo de acionamento. O movimento do pistão varia do (PMS) - Ponto Morto Superior, posição onde a cabeça do pistão esta mais próxima da cabeça do cilindro e o (PMI) - Ponto Morto Inferior, posição onde a cabeça do cilindro esta mais afastada do cilindro. A distância entre o PMS e o PMI é o curso do pistão (s), o Volume Total (V1) é compreendido entre a cabeça do cilindro e a cabeça do pistão quando este se encontra no (PMI), o Volume Morto (V2) é o volume compreendido 
entre a cabeça do cilindro e a cabeça do Pistão quando este se encontra no PMS e o Volume deslocado ou Cilindrada unitária $\left(V_{d}=V_{1}-V 2\right)$ é o volume varrido, quando o pistão move-se do PMS ao PMI ou vice-versa. A Figura 17 mostra a geometria básica dos motores alternativos:

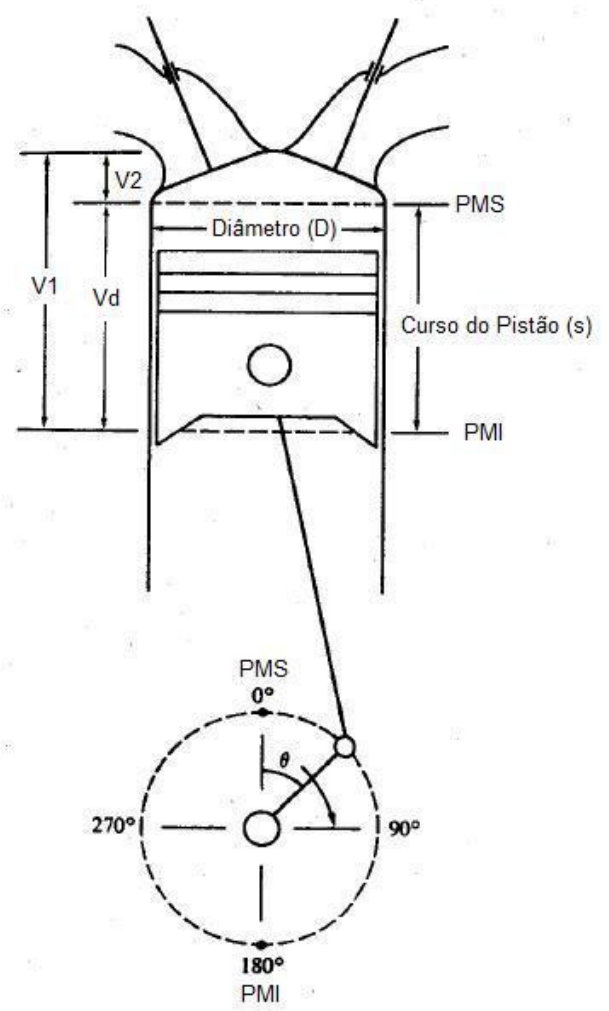

Figura 17: Geometria Básica dos Motores de Combustão Interna (Heywood, 1988)

De acordo com (Garcia e Brunetti, 1992), o Volume Deslocado ( $\left.\mathrm{V}_{\mathrm{d}}\right)$ e Volume Total $\left(\mathrm{V}_{\mathrm{t}}\right)$ são definidos como:

$$
\begin{aligned}
& V_{d}=\left(\frac{\pi \cdot D^{2}}{4}\right) \cdot s \\
& V_{t}=V_{d} \cdot z=\left(\frac{\pi \cdot D^{2}}{4}\right) \cdot z
\end{aligned}
$$

Onde:

$\mathrm{s}=$ Curso do pistão;

$\mathrm{D}$ = Diâmetro do pistão;

$z=$ Número de cilindros. 
E taxa ou relação de compressão $\left(r_{v}\right)$ é a relação entre o Volume Total $(V 1)$ e o Volume Morto (V2):

$$
r_{v}=\frac{V 1}{V 2}
$$

A taxa de compressão é um fator importante para prover mais eficiência e torque, pois quanto mais alta for a taxa de compressão, permitirá o motor extrair mais energia mecânica a partir de uma massa de mistura ar-combustível, devido a sua maior eficiência térmica. No entanto, altas taxa de compressão, afetam a sensibilidade do motor a detonação, principalmente quando o motor está sendo utilizado com combustível de baixa octanagem e isso pode danificar o motor se os sensores de detonação não estiverem presentes para retardar os tempos de injeção.

De acordo com (Garcia e Brunetti, 1992), a ignição representa o início da combustão que se inicia no fluido ativo, o qual é o responsável pelo funcionamento do motor. Nesta sessão será abordada apenas motores que de ignição por centelha ou ciclo Otto, nos quais a combustão no fluido ativo inicia-se graças à centelha que salta entre os eletrodos e a vela. Tal centelha atinge a mistura combustível-ar, previamente dosado pelo sistema eletrônico de injeção, através da entrada pela válvula de admissão. A combustão desta mistura provoca o aumento da pressão necessário para a movimentação do pistão.

O ciclo de operação, ou simplesmente ciclo, dos motores alternativos referemse ao conjunto de processos sofridos pelo fluido ativo que se repetem periodicamente. Os motores alternativos podem ser divididos em dois grupos: motores dois tempos (2T) e motores quatro tempos (4T), onde tempo (T) é o curso do pistão.

Os motores dois tempos (2T), inventado pelo Sr Dugal Clerk no final do século 19, são considerados como uma unidade de alimentação leve para os veículos rodoviários, dentro enquadram as seguintes aplicações: motocicleta, "scooters", motos de neve, karts de corrida, entre outros).

Quando se compara os motores 2T com o 4T, a diferença já começa pela sua nomenclatura. O motor de ciclo $2 \mathrm{~T}$ o ciclo realiza-se com dois cursos do pistão, correspondendo a uma única volta da manivela ou do eixo do motor. Muito menos 
trabalho é necessário para o bombeamento de gases para dentro e fora do cilindro. A Figura 18 mostra o ciclo de operação dos motores 2T:

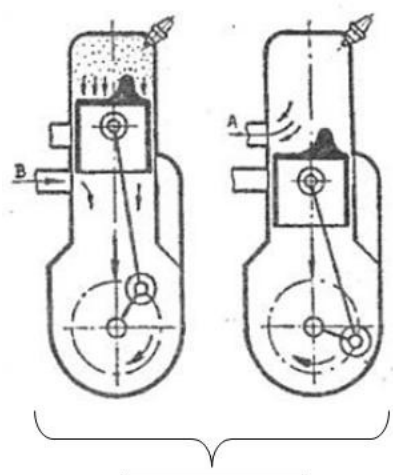

$1^{\circ}$ Tempo

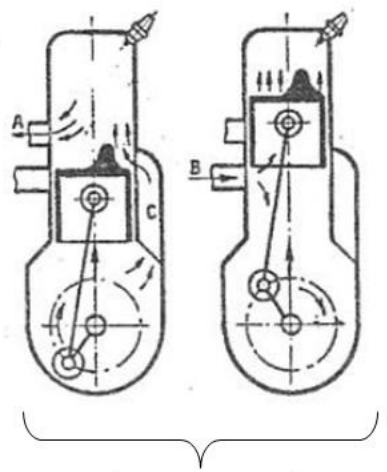

$2^{\circ}$ Tempo

Expansão/Escape Admissão/Compressão

Figura 18: Ciclo de Operação do motor dois tempos (Garcia e Brunetti, 1992)

Até o momento, nenhum outro projeto de motor produziu alta eficiência térmica, baixo consumo específico de combustível e alta potência específica em relação ao volume deslocado e sua massa. No entanto, a sua principal desvantagem em relação ao motor de 4T é o seu ruído excessivo e a emissão de poluentes, uma vez que este tipo de motor queima uma mistura de óleo e combustível.

Será abordado nesta sessão motores de quatro tempos, onde neste grupo o pistão percorre quatro vezes o curso, correspondendo a duas voltas da manivela e do eixo do motor. A Figura 19 mostra este ciclo de operação:

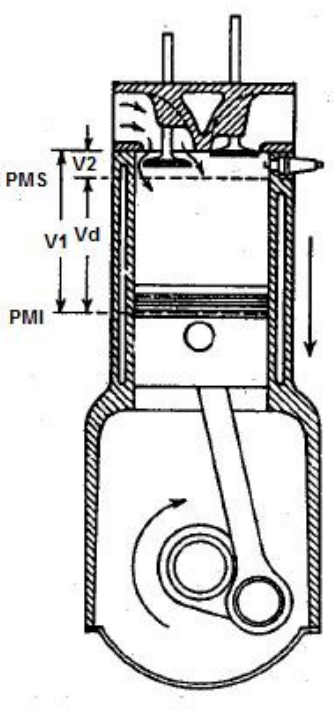

1 - Admissão

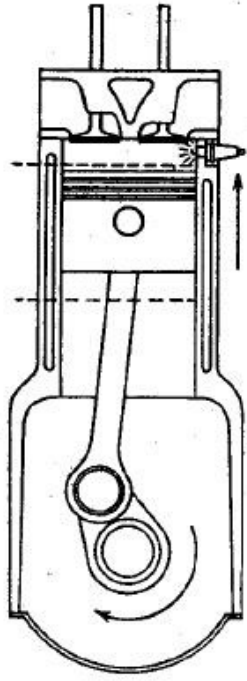

2 - Compressão

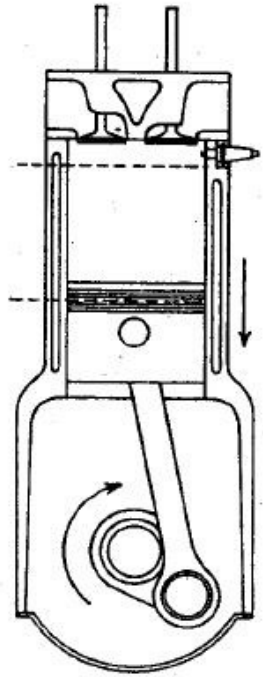

3 - Expansão

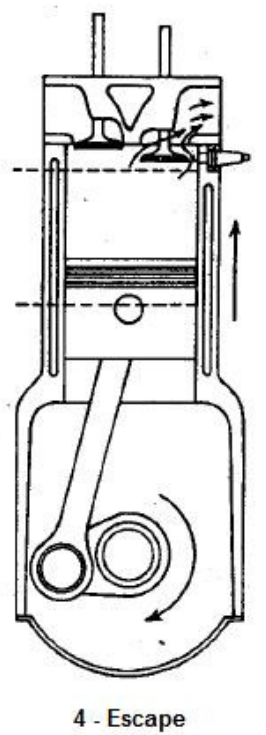

Figura 19: Ciclo de Operação do Motor quatro Tempos (Heywood, 1988) 
1- Tempo de Admissão: $O$ pistão desloca-se do PMS ao PMI. Neste movimento o pistão dá origem a uma sucção através da válvula de admissão (VA) que se encontra aberta. O cilindro é então preenchido com a mistura ar-combustível.

2- Tempo de Compressão: Fecha-se a VA e o pistão desloca-se do PMI ao PMS, comprimindo a mistura ar-combustível.

3- Tempo de Expansão: Pouco antes de se atingir o PMS salta a centelha que provoca a ignição da mistura. A combustão da mistura provoca um grande aumento de pressão, o que permite impelir o pistão para o PMI, de tal maneira que os gases produzidos na combustão sofrem uma expansão, sendo este o tempo no qual se obtém o trabalho útil do motor.

4- Tempo de Escape: Com a Válvula de Escape (VE) aberta, o pistão desloca-se do PMI ao PMS, empurrando os gases queimados para fora do cilindro, para poder assim reiniciar o ciclo pelo tempo de admissão.

Durante o funcionamento de um motor, afirma (Garcia e Brunetti, 1992), o fluido ativo é submetido a uma série de processos químicos e físicos que se repetem periodicamente dando origem ao chamado ciclo do motor. Este ciclo pode ser visualizado através de um diagrama p-V (Pressão x Volume), e aqui é apresentado, de forma simplificada, mas que possibilitam aplicações numéricas baseadas nas leis da Termodinâmica. O Gráfico 5 mostra o diagrama $\mathrm{p}-\mathrm{V}$ didático para um motor a quatro tempos de ignição por centelha:

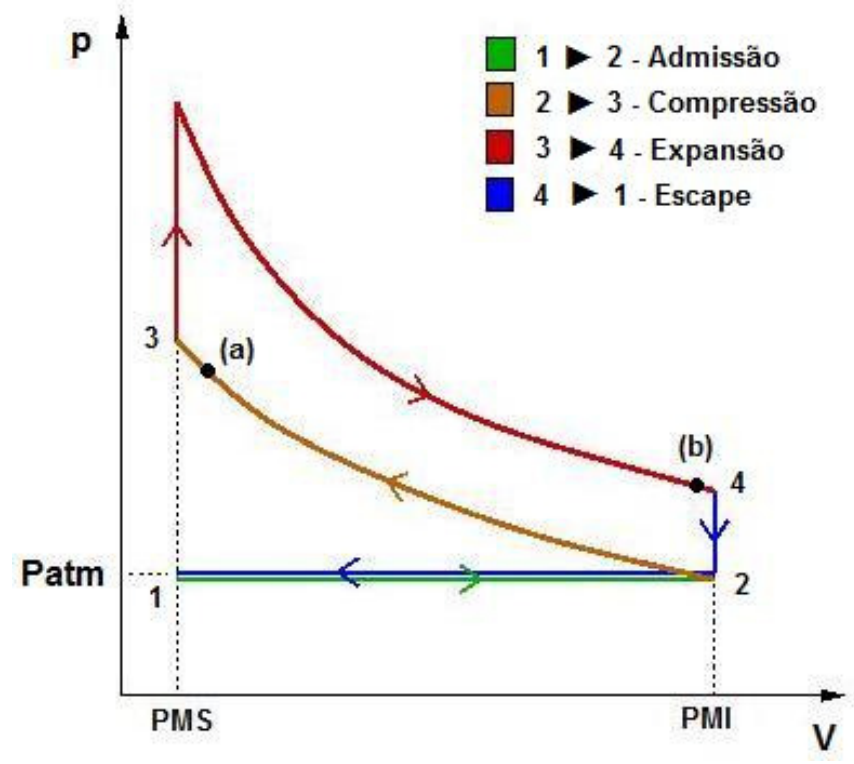

Gráfico 5: Diagrama p-V didático para um motor quatro tempos 
De acordo com (Garcia e Brunetti, 1992), o diagrama p-V acima permite uma análise completa do funcionamento do motor, uma vez que as áreas contidas abaixo do processo $\mathrm{p}-\mathrm{V}$ são proporcionais ao trabalho fornecido pelo motor, e adicionalmente, é possível estudar os instantes do salto de centelha e da abertura de válvulas, representadas por (a) e (b) respectivamente, para se obter melhorias do trabalho de expansão em função do mínimo trabalho de compressão do motor.

Um gráfico análogo que se pode obter através o gráfico $p-V$, é o $p-\theta$, conforme mostra o Gráfico 6, onde a pressão esta em função do ângulo $\theta$ correspondente a certo volume contido entre a cabeça do pistão e a cabeça do cilindro.

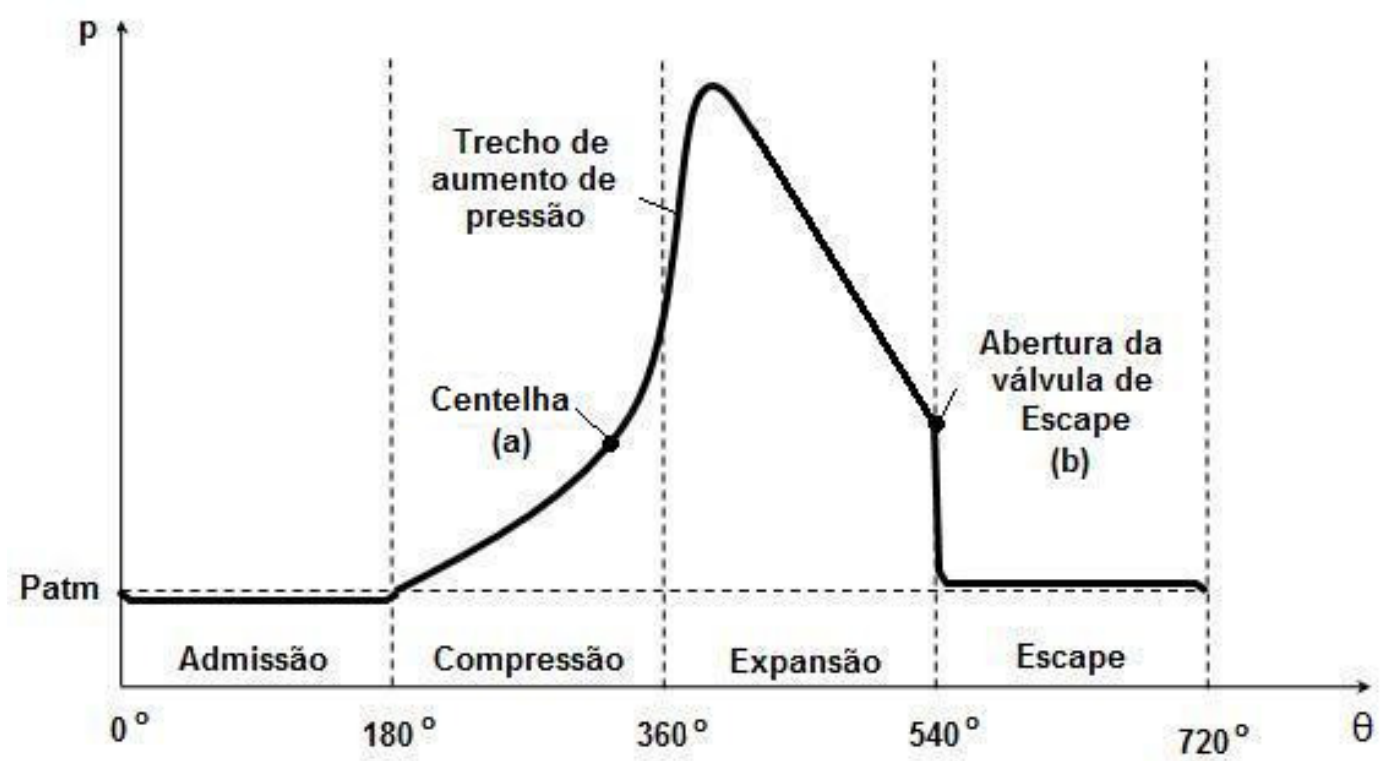

Gráfico 6: Diagrama p- $\theta$ para um motor quatro tempos

Segundo (Garcia e Brunetti, 1992), o Gráfico 6 é o mais adequado para o cálculo das forças aplicadas pela pressão nos diversos elementos do motor para cada posição da manivela, bem como para a análise da combustão.

Para determinar o desempenho de um motor, é essencial conhecer a cinemática das forças que ocorrem no motor quando este se encontra em funcionamento. A Figura 20 mostra o sistema pistão / biela / manivela formando o mecanismo responsável pelo aparecimento de um momento no eixo de um motor: 


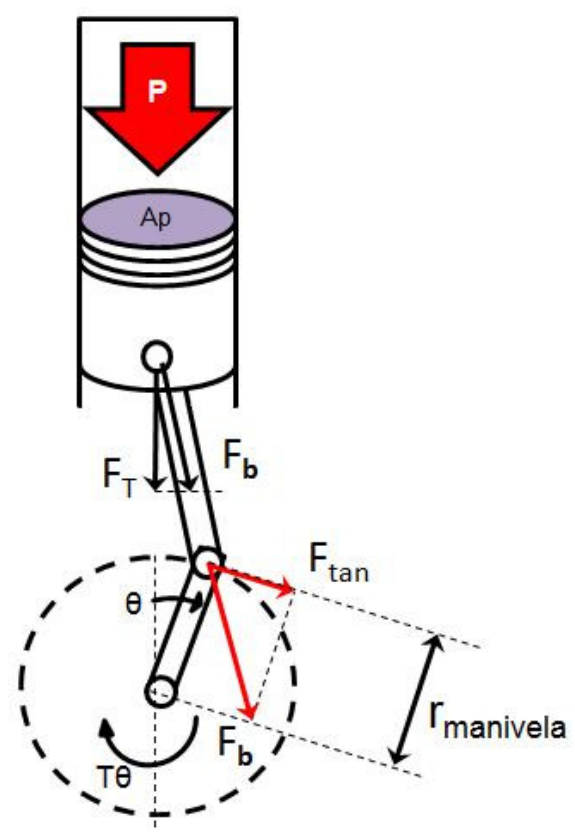

Figura 20: Cinemática das Forças no Pistão

Onde:

P: Pressão na câmara de combustão;

$A_{p}$ : Área do pistão;

$\mathrm{F}_{\mathrm{T}}$ : Força total no pistão;

$F_{b}$ : Força na biela;

$F_{\text {tan: }}$ Força tangencial na manivela;

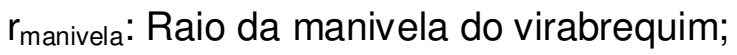

$T_{\theta}$ : Torque instantâneo no eixo do motor.

De acordo com (Garcia e Brunetti, 1992), a força total no pistão ( $F_{T}$ ) é obtida através da pressão $(P)$ proveniente da combustão, e esta força aplicada $\left(F_{T}\right)$ transmite-se à biela e posteriormente a manivela, dando origem a uma força tangencial $\left(F_{\text {tan }}\right)$ e conseqüentemente ao momento instantâneo no eixo do motor. $A$ pressão $(P)$ depende do ângulo $\theta$ percorrido pela manivela e, portanto, a $\left(F_{\text {tan }}\right)$ é variável.

Com o motor em funcionamento obtém - se um momento médio (torque) positivo e este é função da rotação do motor e da posição do acelerador (carga). Para uma dada posição do acelerador, o motor desenvolve certo torque e conforme afirma (Garcia e Brunetti, 1992) e (Heywood, 1988) o torque do motor é obtido 
através de um momento externo resistente, o qual é obtido por um freio dinamométrico, que podem ser eletromagnético, hidráulico ou por atrito mecânico.

Além do torque do motor, obtido através de um freio dinamométrico, existem outras propriedades que descrevem as qualidades do motor, seja quanto ao desempenho e quanto à eficiência:

- Potência efetiva $\left(\mathbf{N}_{\mathrm{e}}\right)$ : É a potência medida no eixo do motor:

$N_{e}=T . \omega=T .2 \pi \cdot n$

Onde:

$\mathrm{T}=$ Torque do motor;

$\omega=$ Velocidade angular do eixo do motor;

$\mathrm{n}=$ Rotação do motor.

- Potência de atrito $\left(\mathbf{N}_{\mathrm{a}}\right)$ : É a potência consumida internamente pelo motor. Ela pode ser obtida através do acionamento do motor de combustão desligado por meio de um dinamômetro elétrico que passa a funcionar como motor elétrico, conforme mostra a Figura 21:
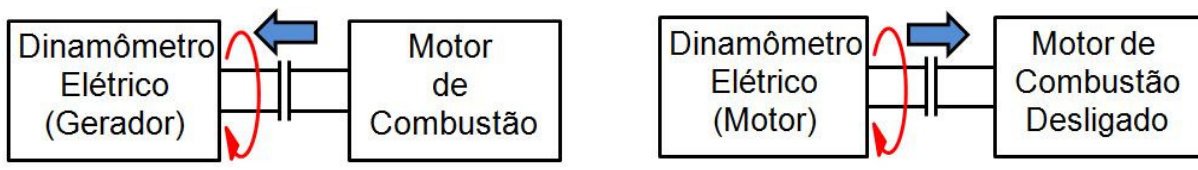

Figura 21: Esquema para determinação de Potência de atrito $\left(N_{a}\right)$

- Potência Indicada $\left(\mathbf{N}_{\mathrm{i}}\right)$ : É a potência desenvolvida na cabeça dos pistões, pelo ciclo termodinâmico do fluido ativo, onde da termodinâmica, as áreas no diagrama $\mathrm{p}-\mathrm{V}$ do $\begin{array}{lll}\text { Gráfico } & 7 \text { são }\end{array}$ proporcionais ao trabalho:

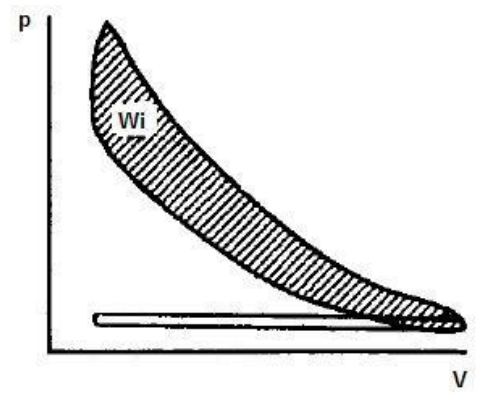

Gráfico 7: Trabalho indicado ou do ciclo de combustão (Heywood, 1988) 
Onde de acordo com (Heywood, 1988), o trabalho do ciclo (Wi) é dado por:

$W i=\oint p d V$

Como a potência é o trabalho por unidade de tempo, com o trabalho do ciclo a potência pode ser obtida multiplicando o mesmo pela freqüência com que é realizado, assim:

$N_{i}=W i \cdot\left(\frac{n}{x}\right)$

Onde:

$\mathrm{n}$ - Rotação do motor;

$\mathrm{x}=1$ - Para motores 2 tempos;

$\mathrm{x}=2$ - Para motores 4 tempos.

- Pressão Média Efetiva (PME): é a pressão aplicada constantemente na cabeça do pistão ao longo de um curso, o qual produziria o mesmo trabalho de um ciclo completo. De acordo com (Heywood, 1988) a PME pode ser expressa em função do torque do motor utilizando a seguinte equação:

$P M E=\frac{6,28 \cdot n_{R \cdot} T}{V_{d}}$

Onde:

PME: Expresso em kPa;

$\mathrm{T}$ : Expresso em Nm;

$\mathrm{V}_{\mathrm{d}}$ : Expresso em $\mathrm{dm}^{3}$.

$\mathrm{n}_{\mathrm{R}}$ : Número de Revoluções por Ciclo $\left(\mathrm{n}_{\mathrm{R}}=2\right.$ para motores 4 Tempos e $\mathrm{n}_{\mathrm{R}}=1$ para motores 2 Tempos).

Segundo (Heywood, 1988), a PME é essencialmente constante ao longo de uma vasta gama de tamanhos de motores, sendo possível assim comparar com esta norma a eficiência entre os motores de diferentes volumes deslocados, Além disso, 
para cálculos de desenvolvimentos de motores, é possível determinar o volume deslocado necessário para fornecer um dado torque ou potência, a uma velocidade específica, com base em valores apropriados de PME para uma aplicação em particular.

De acordo com (Garcia e Brunetti, 1992), as propriedades dos motores variam em função das condições de funcionamento e para a visualização desta variação, são construídas as curvas características dos motores a partir de ensaios realizados em laboratório, onde as mais usuais para fins comerciais são as curvas de plena carga de potência efetiva $\left(N_{e}\right)$, torque $(T)$ e consumo específico $\left(C_{e}\right)$, em função da rotação do motor, conforme mostra o Gráfico 8:

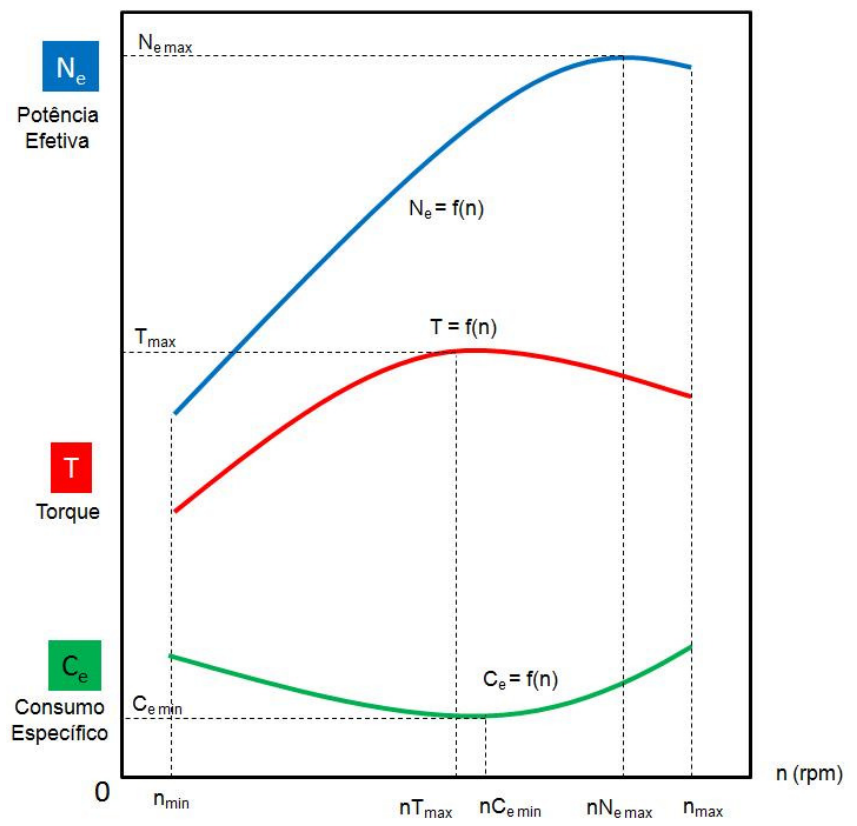

Gráfico 8: Curvas Características dos Motores

Um fator muito importante para a análise das curvas características é a correção da potência desenvolvida através das condições atmosféricas padrões. Segundo (Garcia e Brunetti, 1992), a potência desenvolvida pelo motor é função da pressão, da temperatura e da umidade do ambiente. O mesmo motor quando ensaiado em dias e locais diferentes, não irá produzir os mesmos resultados, dependendo das condições do ambiente naquele local e data. Torna-se necessário, para efeito de padronização e para eliminar o efeito do ambiente, corrigir a potência do motor observada para a que seria obtida num local padronizado. Uma das normas utilizadas para este efeito é a NBR5487/85, baseada na ISO 1585/82. 


\section{3-) Embreagem}

Um componente de fundamental importância no trem de força de um veículo de transmissão manual é a embreagem. Sem a presença deste componente não é possível o controle da transferência de torque do motor para a transmissão. De acordo com (Shaver, 1997), o registro do desenvolvimento de sistemas de embreagem iniciou-se em 1863, onde foram concebidos os múltiplos discos de embreagem de Weston. Muitos conceitos de embreagens foram desenvolvidos a partir deste, no entanto, os sistemas mais comum de embreagens foram os do tipo cônico, embreagem de expansão de sapata ou tambor e embreagens com dispositivos Multi-Disco, podendo trabalhar a seco ou banhado a óleo. Segue uma breve explicação feita por (Shaver, 1997) sobre os principais tipos de embreagens:

- Embreagem do tipo cônico: é composta de cone truncado confrontado com um cinto que faz às vezes do material de atrito e que é fixado a um cone de metal. A embreagem cônica foi a escolha dos engenheiros de "design" automotivo em 1920. Foi relativamente fácil de fabricar, bem confiável nas operações diárias, e de fácil manutenção. A Figura 22 mostra este tipo de embreagem:

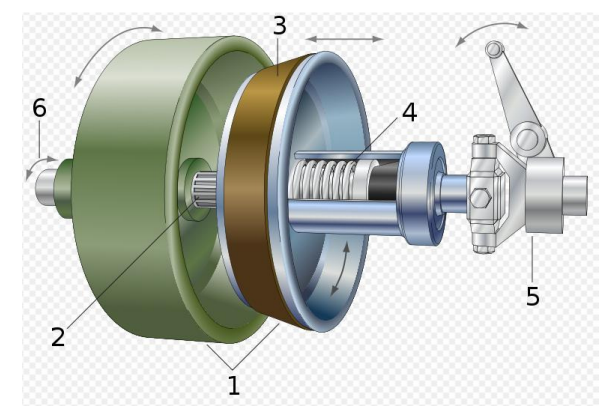

Figura 22: Embreagem tipo cônico (Sweber.de, 2008)

Onde:

1- Cone fêmea (verde), cone macho (azul);

2- Eixo,

3- Material de atrito;

4- Mola de retorno cone macho;

5- Controle da embreagem: separação dos cones por pressão;

6- Sentido de rotação: ambos são possíveis. 
- Embreagem de expansão da sapata ou tambor: esta proposta foi uma das primeiras alternativas onde era possível a construção da embreagem com superfícies de atrito interno ao tambor e melhorar assim as pressões centrífugas efetuadas pelas sapatas nesta superfície. Blocos de madeira e tiras de couro eram freqüentemente utilizadas como material de atrito nestes projetos. A Figura 23 mostra este tipo de embreagem.

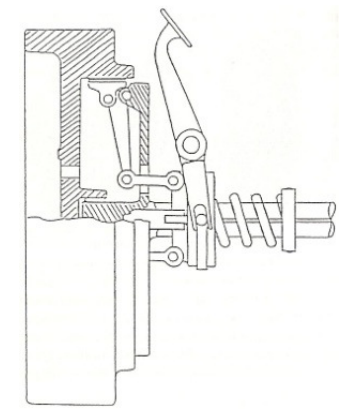

Figura 23: Embreagem de expansão da sapata ou tambor (Shaver, 1997)

- Embreagem multi-disco: a embreagem clássica de multi-disco leva o nome de seu inventor, o professor Hele-Shaw. A base de sua idéia é um mecanismo de discos múltiplos que exigiam uma considerável pressão para parar, considerando discos de metal banhados a óleo e também em pequeno diâmetro. Com isso, para se ter uma superfície de contato grande o suficiente que tenha vantagens em relação à embreagem tipo cônico, Hele-Shaw projetou discos com ondulações concêntricas, discos com perfurações e ranhuras para facilitar o escoamento do óleo, assegurando assim a suavidade e movimento gradual. A Figura 24 mostra este tipo embreagem.
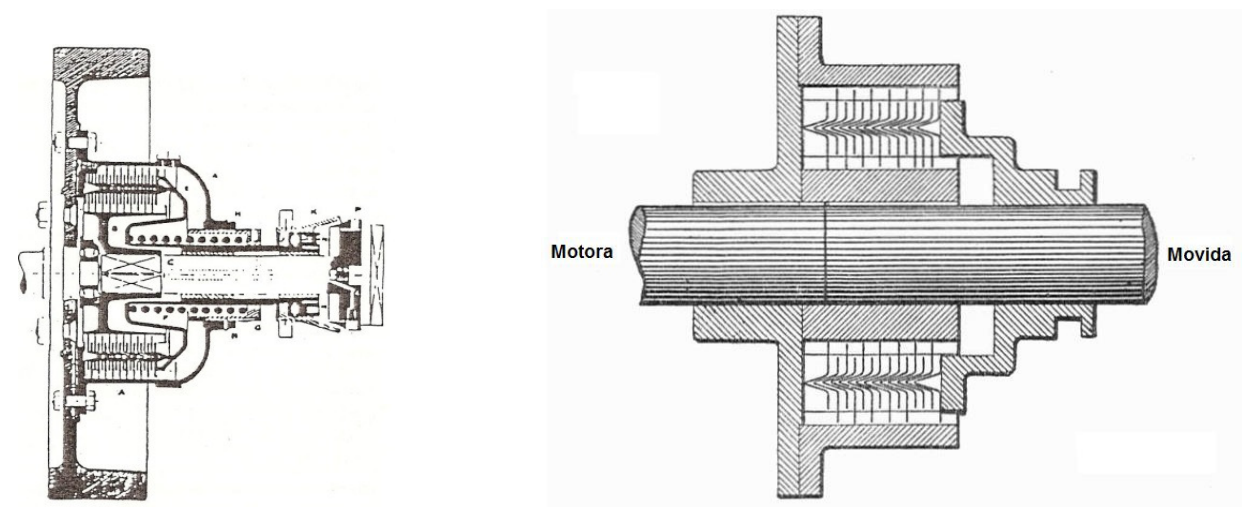

Figura 24: Embreagem multi-disco Hele-Shaw (Shaver, 1997) 
- Embreagem de disco único: de acordo com (Shaver, 1997), eficiência, desempenho e durabilidade são os principais objetivos deste tipo de embreagem. Devido ao fato de o disco de embreagem trabalhar a seco, este sistema oferece a vantagem de ser praticamente livre de manutenção e de não apresentar vazamentos (vedação da carcaça). Este tipo de embreagem foi o mais adequado para as aplicações automotivas que utilizam motores de combustão interna, pelo fato de ser compacta, fornecer uma boa dissipação de calor, baixa inércia de saída para a transmissão e baixo custo. A Figura 25 mostra este tipo de embreagem.

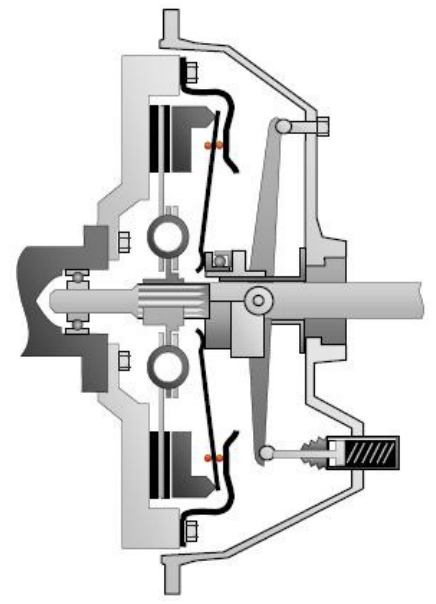

Figura 25: Embreagem de disco único (ZF Sachs, 2010)

Será abordado com um pouco mais de detalhes este tipo de embreagem, pois está presente na maioria das aplicações automotivas, inclusive no veículo de estudo desta dissertação.

De acordo com (ZF Sachs, 2010), as funções principais da embreagem são:

- Transmitir o torque do motor para a transmissão;

- Interromper a transmissão do torque do motor, para permitir a partida do veículo e a troca de marchas da transmissão;

- Amortecer as vibrações torcionais do motor;

- Prover modulação e conforto ao usuário. 
Adicionalmente, (Argachoy, 2004), afirma as qualidades de um sistema de embreagem:

- Progressividade;

- Transmissão sem escorregamento após o acoplamento;

- Equilíbrio - quando acoplado não oferece nenhum esforço axial.

O (Argachoy, 2004) subdivide as embreagens mecânicas:

- Ação por molas:

- Molas helicoidais;

- Mola membrana ou "Belleville"

- Ação pela força centrífuga

De acordo com (ZF Sachs, 2010), o projeto moderno de embreagem por ação de mola membrana apresenta os seguintes os componentes:

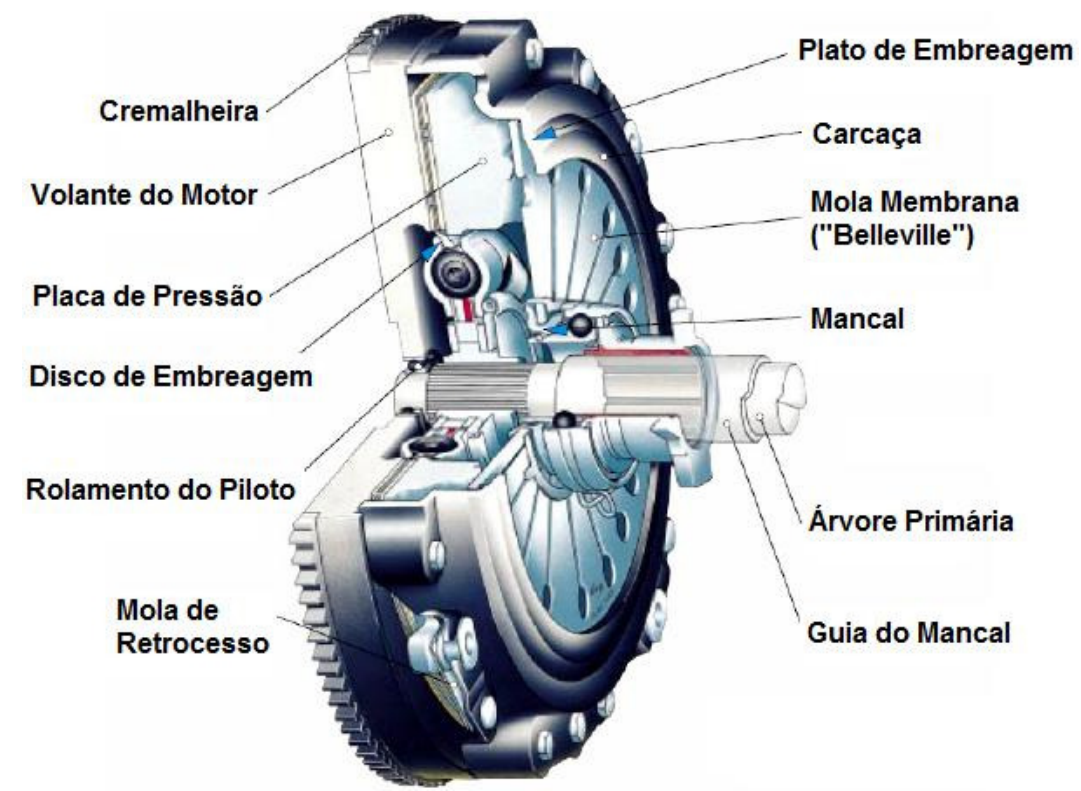

Figura 26: Componentes de Embreagem com mola membrana (ZF Sachs, 2010)

De acordo com (Shaver, 1997), a utilização da mola membrana "Belleville" traz como principal vantagem o fato de substituir o conjunto alavanca e mola por uma única peça, que faz a mesma função, além de promover novas vantagens como leveza no acionamento, melhor precisão na sua construção e simplicidade na instalação, além de ser mais facilmente refrigerada por trabalhar como efeito 
ventilador. A Figura 27 mostra o funcionamento da mola membrana, quando acoplada e desacoplada:

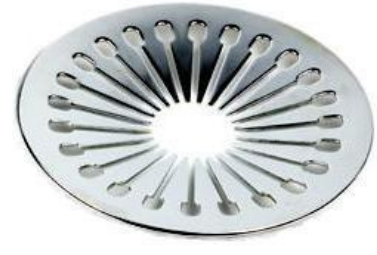

Mola Membrana

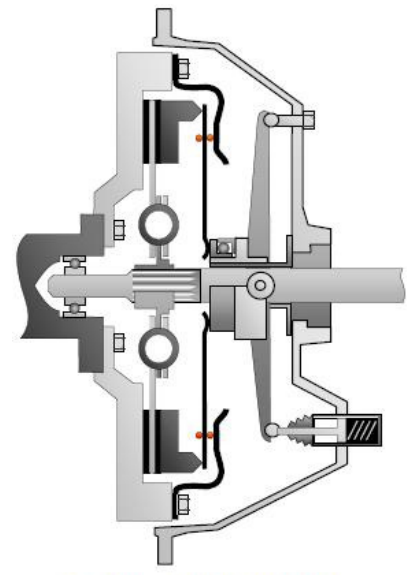

Embreagem Acoplada

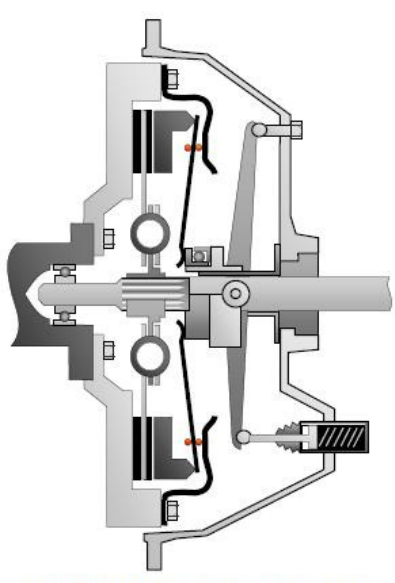

Embreagem Desaclopada

Figura 27: Atuação da Mola Membrana no acoplamento/desacoplamento (ZF Sachs, 2010)

O principal componente necessário para transmitir o torque do motor para o eixo de entrada da caixa de transmissão é o disco de embreagem. De acordo com (Ball e Stone, 2004) os discos de embreagem são compostos por um anel de atrito rebitado ou colado em ambos os lados da placa. Os discos de embreagem contêm molas de torção que visam proporcionar flexibilidade para a placa e com isso prolongar a vida do disco de embreagem e filtra as vibrações provenientes do volante do motor. A escolha do material de atrito é fundamental para o desempenho do disco de embreagem e de acordo com (Ball e Stone, 2004) ele deve fornecer as seguintes características:

- Coeficiente de atrito uniforme sobre toda a superfície;

- O atrito deve permanecer estável com as mudanças de temperatura;

- Deve prover boa condutividade térmica;

- Resistência ao desgaste;

- Resistência à fadiga térmica;

- Resistência a altas temperaturas.

Além das características acima, (Shaver, 1997) acrescenta ainda os seguintes objetivos primários para o material de atrito:

- Atender os critérios específicos de máximo desempenho;

- Minimizar os custos;

- Substituir asbestos. 
A Figura 28 representa o disco de embreagem com seus respectivos componentes:

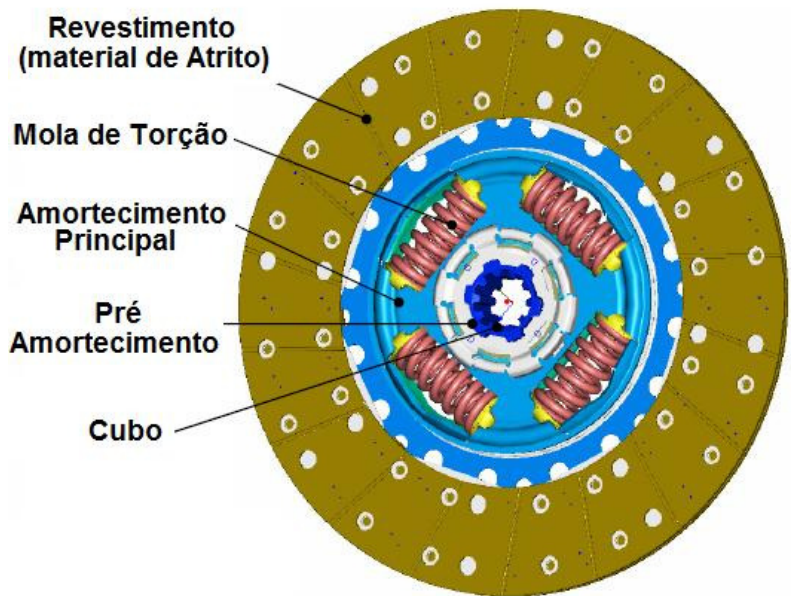

Figura 28: Componentes do Disco de Embreagem (ZF Sachs, 2010)

Para o dimensionamento do disco de embreagem, (Argachoy, 2004) e (Ball e Stone, 2004) apresentam uma metodologia onde o torque capaz ( $\left.T_{\text {cap }}\right)$ do disco é em função da carga normal $\left(\mathrm{P}_{\mathrm{L}}\right)$ aplicada pela placa de pressão, Área do disco de embreagem $\left(A_{\text {Disco }}\right)$, coeficiente de atrito estático da embreagem $\left(\mu_{\mathrm{s}}\right)$, número de superfícies em contato $(Z)$ e raio médio do disco $\left(R_{m}\right)$. São assumidas ainda as seguintes suposições básicas:

1-) Distribuição de carga $\left(P_{L}\right)$, uniforme ao longo do revestimento;

2-) Disco de embreagem novo ( $\mu_{\mathrm{s}}=$ constante);

3-) Pressão constante na superfície do disco.

A Figura 29 mostra os componentes deste dimensionamento:
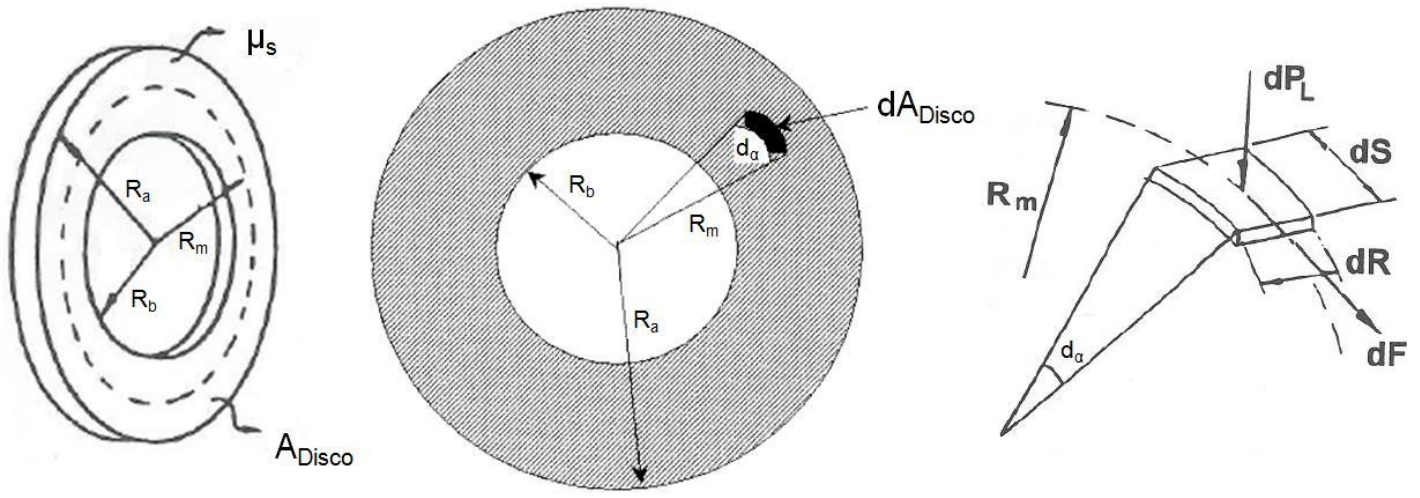

Figura 29: Dimensionamento do Disco de Embreagem (Argachoy, 2004) 
Com as suposições básicas acima, (Argachoy, 2004) define a capacidade de torque para a transmissão ( $\left.\mathrm{T}_{\text {cap }}\right)$ como sendo:

$$
T_{\text {cap }}=Z \cdot \mu_{s} \cdot P_{L} \cdot \frac{2}{3}\left(\frac{R_{a}^{3}-R_{b}^{3}}{R_{a}^{2}-R_{b}^{2}}\right)=Z \cdot \mu_{s} \cdot P_{L} \cdot R_{m}
$$

De acordo com (Argachoy, 2004), é necessário ainda introduzir um fator de segurança $(K)$, pois esta modelagem não considera as solicitações dinâmicas, como vibrações e choques. Sendo $\left(T_{\max }\right)$ o torque máximo disponível do motor ao qual a embreagem será acoplada, e (K) o fator de segurança, fica:

$$
T_{\text {cap }}=K \cdot T_{\max }=Z \cdot \mu_{s} \cdot P_{L} \cdot R_{m}
$$

Onde:

$\mathrm{K}=1,25$ a $1,50-$ Para automóveis de passeio.

Um componente importante da embreagem é a mola de absorção, ou também conhecida como mola "Cushion". De acordo com (Shaver, 1997) a mola "Cushion" é utilizada para providenciar uma suavidade / amortecimento para o material de atrito, a fim de reduzir a agressividade do engate. De acordo com (Drexl, 1998), o comportamento da mola "cushion" é dividido em três fases, como mostra a Figura 30:

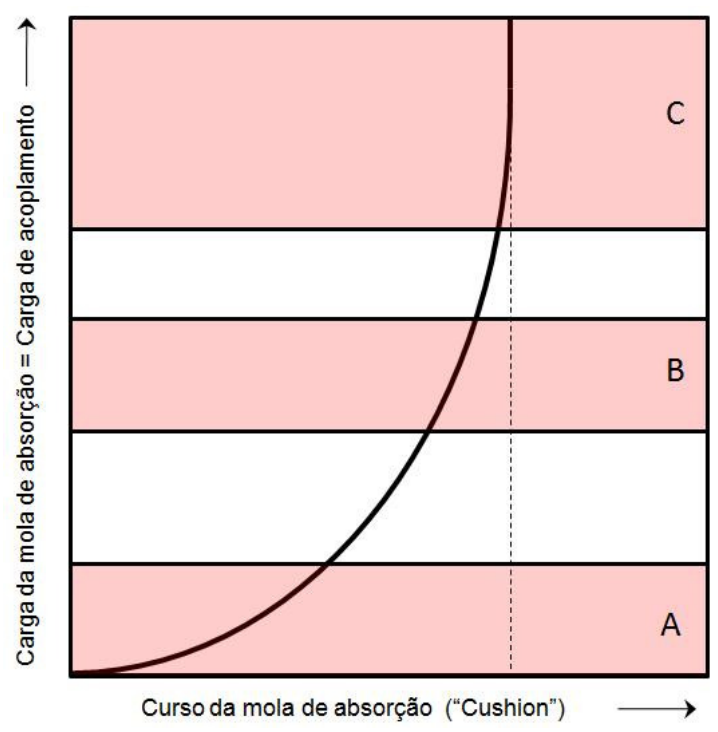

Figura 30: Representação do comportamento da mola de absorção ("Cushion")

(Drexl, 1998) 
- Fase A: determina 0 início da transmissão do torque. $O$ aumento gradual da transferência de torque permite ao condutor do veículo reduzir a velocidade do acionamento do pedal de embreagem, a fim de promover uma saída suave do veículo.

- Fase B: esta fase intermediária corresponde ao intervalo de torques para a arrancada. Cerca de um terço da carga máxima necessária para o acoplamento está nesta faixa e que permite certa flexibilidade entre as superfícies de atrito a fim de garantir um padrão de contato uniforme.

- Fase C: com 70 a $100 \%$ da carga de acoplamento, esta é a faixa de controle durante o "fading" devido ao incontrolável escorregamento. Nesta fase deve estar disponível o maior curso residual da mola, para compensar as deformações da placa de pressão e o volante do motor causado pelas severas cargas térmicas.

A Figura 31 mostra o comportamento da mola "Cushion" no acoplamento da embreagem:

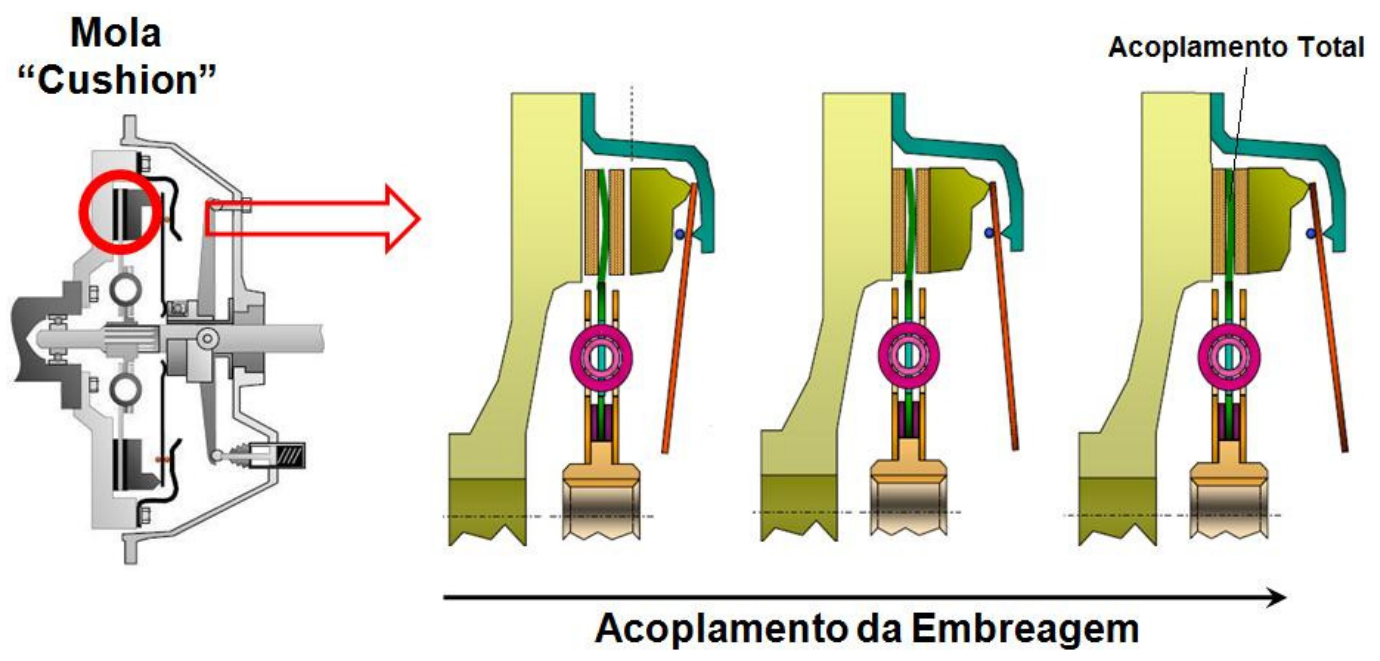

Figura 31: Comportamento da mola "Cushion" durante acoplamento da embreagem (ZF Sachs, 2010) 
A mola "Cushion" é um importante parâmetro na transferência de torque para a transmissão. É ela que determina a quantidade de torque transferido em função do curso do pedal de embreagem. Através do acoplamento da embreagem pela mola "Cushion", é transferido o torque do motor para a transmissão, conforme mostra o Gráfico 9:

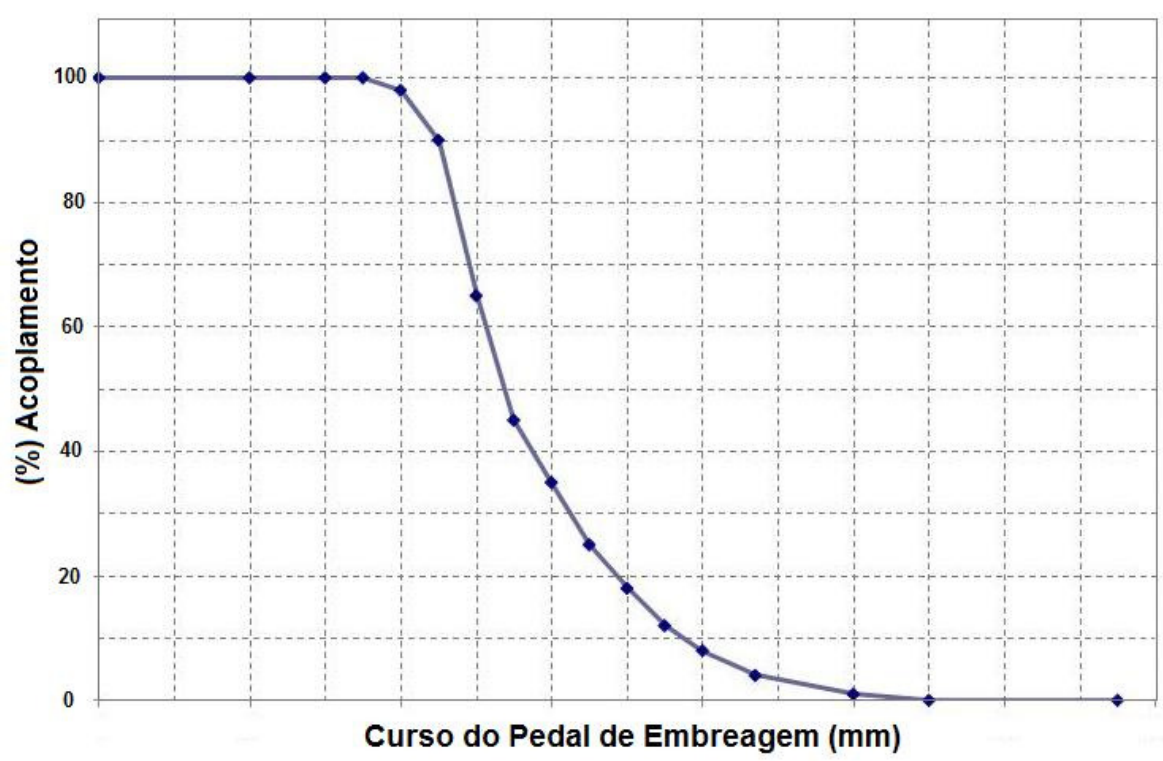

Gráfico 9: Porcentagem de acoplamento VS Curso do pedal de embreagem

De acordo com (Shaver, 1997), a principal função da embreagem automotiva é fornecer um acoplamento ininterrupto entre o motor e a transmissão sincronizada. $O$ sistema moderno de sincronização das transmissões manuais exige também uma interrupção do torque de entrada proveniente do motor para permitir a partida do motor e as trocas de marcha. A dissociação entre o torque de saída do motor e entrada na transmissão é um procedimento que pode ser executado a qualquer rotação do motor ou velocidade do veículo, onde o pressionamento do pedal da embreagem fará o papel de acoplar ou desacoplar o disco de embreagem do volante do motor. O acoplamento da embreagem, principalmente em manobras de arrancada em aclives requer uma coordenação e modulação tanto do pedal do acelerador quanto da embreagem, para permitir a transferência do torque do motor para as rodas, atingindo assim a velocidade desejada.

A especificação do pedal de embreagem é transparente para o motorista, no entanto a embreagem em si é diretamente afetada pelas características do veículo e os sistemas do trem de força, afirma (Shaver, 1997). Para ele muitas características 
do pedal de embreagem podem ser derivadas de fórmulas disponíveis, no entanto a facilidade de operação do sistema de embreagem completo por parte do motorista é muito subjetivo.

De acordo com (Shaver, 1997), a posição do pedal de embreagem baseia-se no pacote de exigências e requisitos de ergonomia. As características básicas ergonômicas do pedal da embreagem são:

- O curso do pedal para o acionamento da embreagem;

- Posição de carga ou esforço necessário para comprimir e manter o pedal em determinada posição;

- Forma e textura do pedal de embreagem no assoalho do veículo.

O posicionamento do pedal da embreagem e dos outros pedais está em uma área designada à frente do condutor do veículo e abaixo do painel de instrumentos. Tanto o pedal de embreagem quanto os outros pedais devem ter características ergonômicas e devem ser combinados de modo a otimizar a interface com 0 operador. A Figura 32 mostra a posição comum das posições dos pedais.

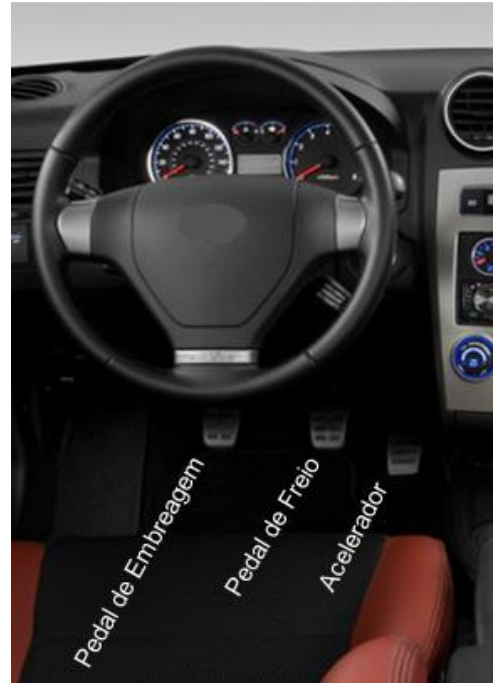

Figura 32: Posicionamento dos Pedais (Embreagem, Freios e Acelerador)

Conforme comentado acima, uma das características importantes do pedal de embreagem é o curso do pedal, o qual representa a máxima distância percorrida pelo pedal de embreagem entre o topo e o fundo. De acordo com (Shaver, 1997), analises de pesquisas independentes e governamentais de ergonomia indicam que o curso de pedal não deve ultrapassar 175mm; no entanto, fica a cargo dos fabricantes determinarem o curso ideal para a sua aplicação veicular. 
Há também uma série de fatores do curso de pedal de embreagem que afetam diretamente a percepção da qualidade de seu acionamento durante sua operação. Estes fatores são ilustrados por (Shaver, 1997), conforme mostra a Figura 33:

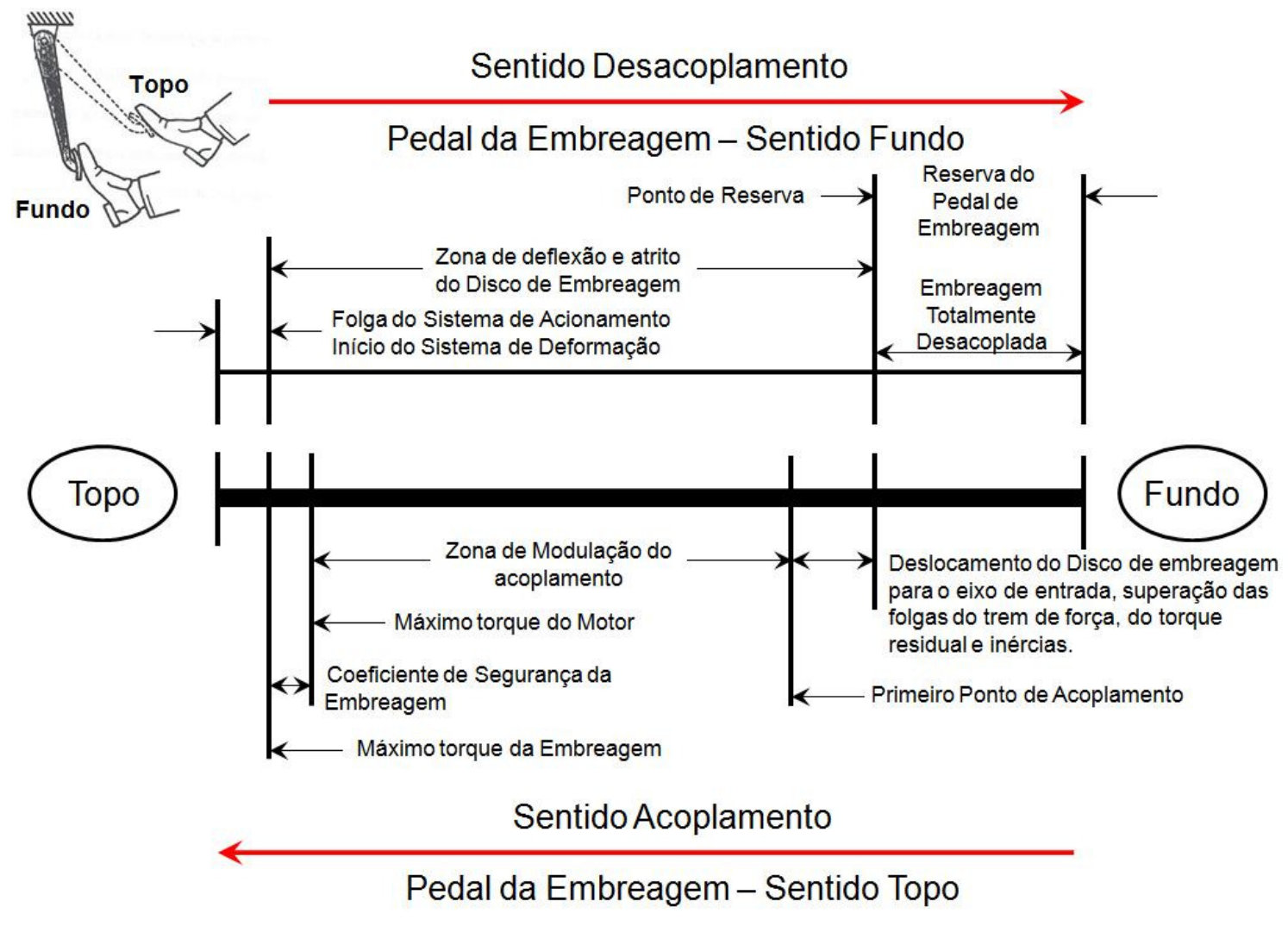

Figura 33: Descrição do curso de Pedal de Embreagem (Shaver, 1997)

Outra característica importante do pedal de embreagem é o "esforço do pedal", o que representa a máxima força necessária para pressionar o pedal. De acordo com (Shaver, 1997), o esforço do pedal é função da carga no rolamento da embreagem, a curva da mola de absorção ("cushion") e a relação sistema de acionamento da embreagem, o qual está embutida na relação de alavanca do pedal. Em geral, isso significa que para um motor com potência mais elevada e um veículo mais pesado, será necessário desenvolver uma carga maior no pedal da embreagem. Por sua vez, isso resultará em uma liberação maior de carga no rolamento e conseqüentemente um maior esforço no pedal. Aumentar a relação do sistema de acionamento da embreagem pode reduzir o esforço do pedal, no entanto, este também terá o efeito de aumentar o curso do pedal. 
A força necessária para comprimir o pedal de embreagem de mola membrana varia ao longo do curso do pedal. Uma forma de analisar a operação do pedal de embreagem é levantar o gráfico: Força do pedal de embreagem VS Curso do pedal de embreagem, o qual está representado no Gráfico 10:

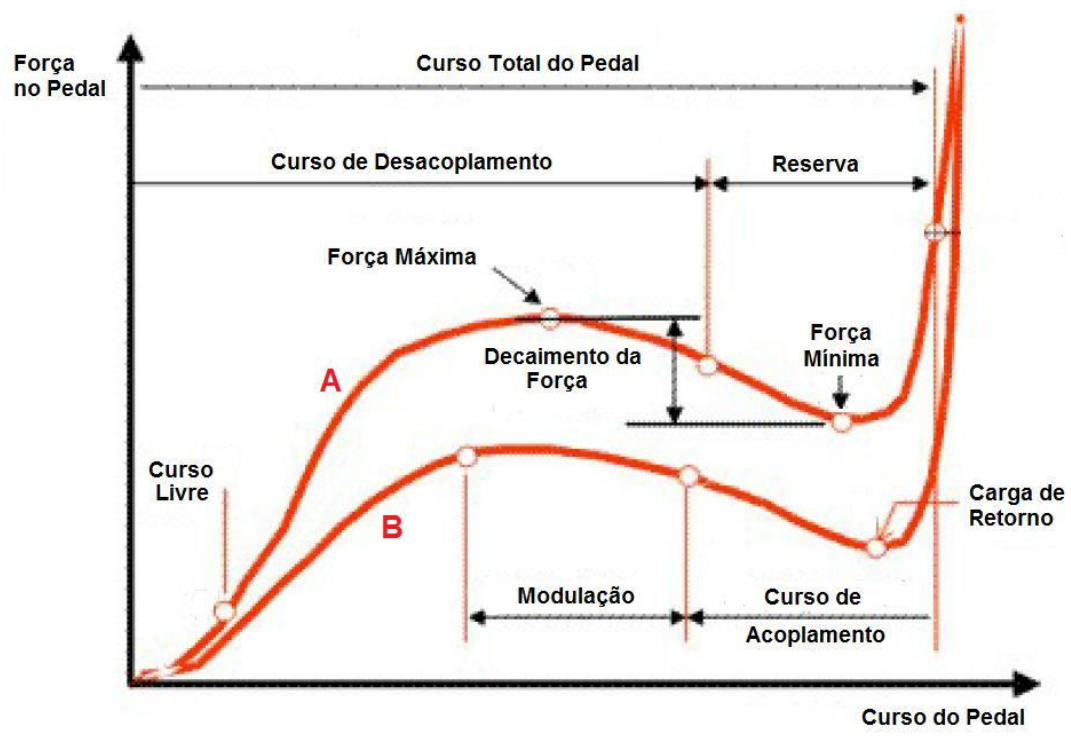

Gráfico 10: Força do pedal de embreagem VS Curso do pedal de embreagem

Onde:

A - Desacoplamento;

B - Acoplamento;

Com base nas informações provenientes do gráfico acima, é possível caracterizar e projetar os parâmetros para uma aplicação veicular, entre elas, podese destacar:

- Esforço máximo do pedal;

- Curso total;

- Curso de reserva;

- Pontos de acoplamento / desacoplamento.

Com estes dados levantados, é possível a comparação objetiva entre diversos pedais de embreagem para melhoria e ajustes de cada parâmetro para atender a critérios de aceitação de cada fabricante de veículos. 


\section{4-) Transmissão}

Antes de começar a dar uma breve explicação sobre as caixas de transmissão manual, serão apresentados rapidamente os principais conceitos fundamentados na operação de uma transmissão automotiva. De acordo com (Ball e Stone, 2004), as engrenagens da transmissão são normalmente utilizadas para transmitir potência, torque e mudar a velocidade angular, pois estas possuem dentes de engates que estão constantemente em contato garantindo rotações sem escorregamentos. Com base na literatura feita por (Ball e Stone, 2004), são apresentados abaixo alguns dos principais tipos de engrenagens na aplicação automotiva:

- Engrenagens de dentes retos: este tipo de engrenagem apresenta os dentes de engate alinhados com o eixo de rotação, é fácil de fabricar e podem transmitir torques elevados, por este motivo podem ser encontrados em transmissões automotivas em primeira marcha ou em marcha a ré. No entanto, como os dentes apresentam contatos frontais uns em relação aos outros, isso acarreta impactos repentinos provocando assim ruídos. A Figura 34 mostra este tipo de engrenagem:

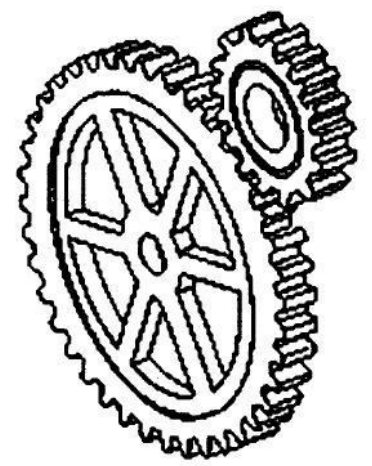

Figura 34: Engrenagens de dentes retos (Ball e Stone, 2004)

- Engrenagens helicoidais: neste tipo de engrenagem os dentes são cortados em forma de hélice em uma superfície cilíndrica. O contato dos dentes é feito através de uma malha de contato que garante instantaneamente o contato de mais de um dente, reduzindo assim a carga de impacto e ruído na operação. No entanto, este tipo de engrenagem gera uma carga de pressão axial que deve ser absorvida no final do eixo por rolamentos apropriados. A Figura 35 mostra este tipo de engrenagem: 


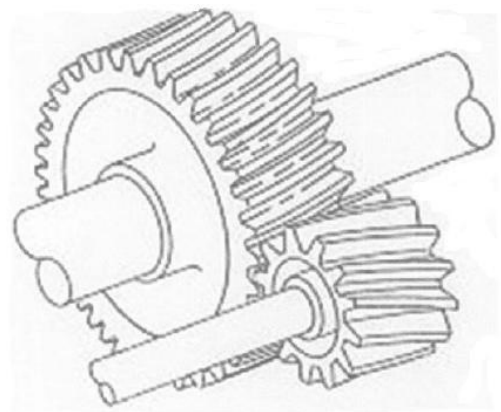

Figura 35: Engrenagem helicoidal (Ball e Stone, 2004)

- Pinhão-coroa de dentes retos: Neste tipo de engrenagem os dentes retos são cortados em superfície cônica. Eles são usados para transmitir a potência entre os eixos não paralelos e que se cruzam. Eles são utilizados em diferenciais e, semelhante às engrenagens de dentes retos, apresentam ruído elevado. No entanto, no diferencial, eles somente giram quando os eixos apresentam velocidades angulares diferentes, quando o veículo está fazendo uma curva, por exemplo. A Figura 36 mostra este tipo de engrenagem.

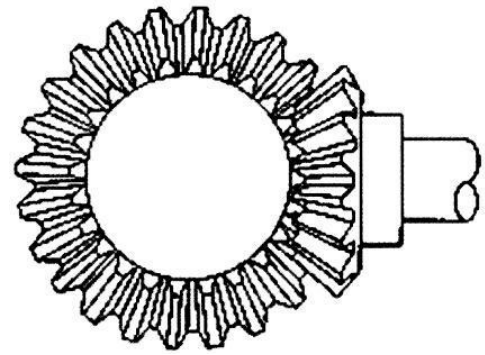

Figura 36: Engrenagem Pinhão-coroa de dentes retos (Ball e Stone, 2004)

- Pinhão-coroa espiral: Similar ao Pinhão-coroa de dentes retos, estas engrenagens têm dentes cortados em forma de hélice em uma superfície cônica. A Figura 37 mostra este tipo de engrenagem:

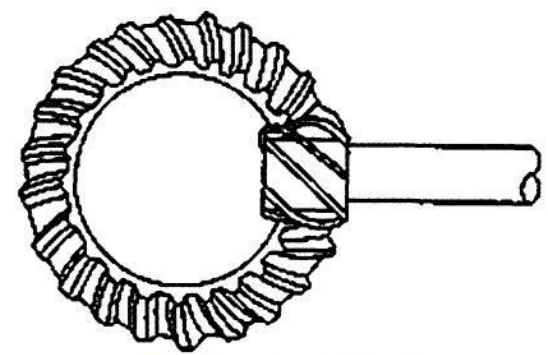

Figura 37: Engrenagem Pinhão-Coroa Espiral (Ball e Stone, 2004) 
O diagrama de forças em um par de engrenagens pode ser expresso através de um diagrama de corpo livre que atuam em ambas as engrenagens (Motora e Movida), conforme representado na Figura 38:

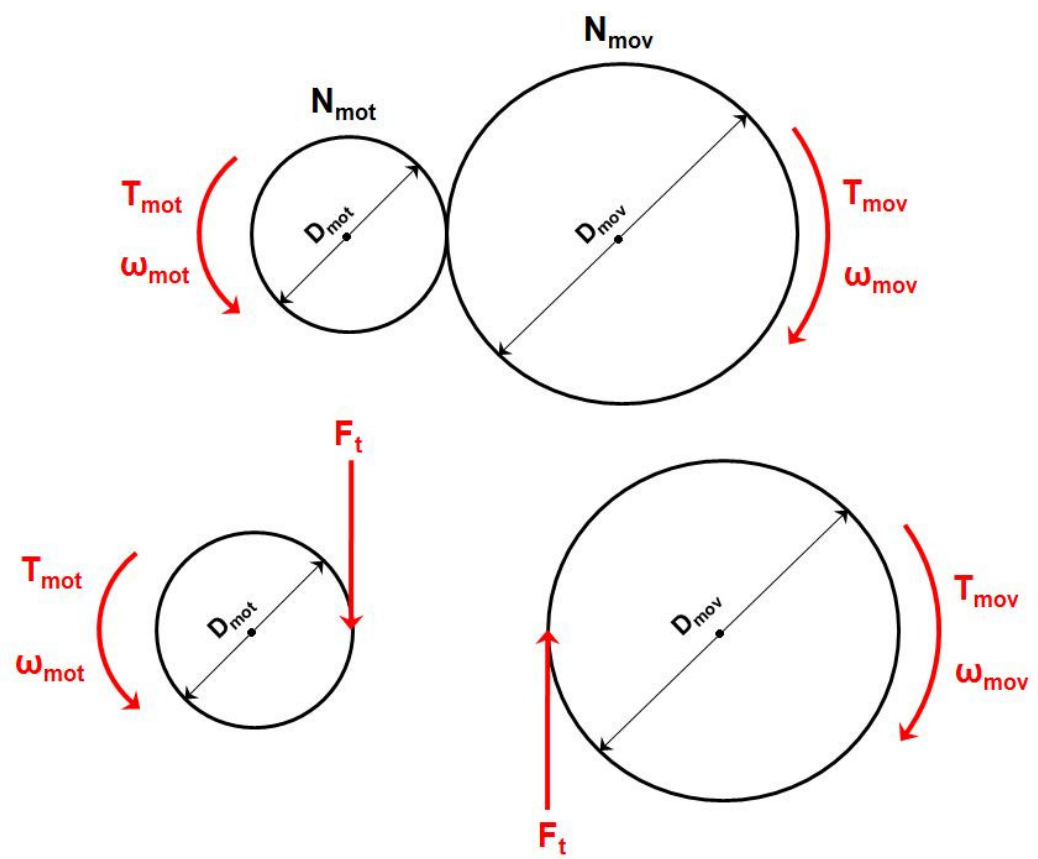

Figura 38: Esquema da transmissão de movimento e diagrama de forças na engrenagem.

(Ball e Stone, 2004)

Onde:

$\mathrm{T}_{\mathrm{mot}}=$ Torque da engrenagem motora;

$\mathrm{T}_{\text {mov }}=$ Torque da engrenagem movida;

$\omega_{\text {mot }}=$ Velocidade angular da engrenagem motora;

$\omega_{\text {mov }}=$ Velocidade angular da engrenagem movida;

$\mathrm{N}_{\text {mot }}=$ Número de dentes da engrenagem motora;

$\mathrm{N}_{\text {mov }}=$ Número de dentes da engrenagem movida;

$D_{\text {mot }}=$ Diâmetro efetivo da engrenagem motora;

$D_{\text {mov }}=$ Diâmetro efetivo da engrenagem movida;

$F_{t}=$ Força de transmissão de movimento no par de engrenagens.

De acordo com (Ball e Stone, 2004), a força de transmissão de movimento é expressa da seguinte forma:

$$
F_{t}=\frac{T_{m o t}}{\left(\frac{D_{m o t}}{2}\right)}=\frac{T_{m o v}}{\left(\frac{D_{m o v}}{2}\right)}
$$


A força tangencial no ponto de contato entre as engrenagens é igual em módulo e de sentido contrário; o diâmetro efetivo é proporcional ao número de dentes das engrenagens e estes são inversamente proporcionais às velocidades angulares de cada engrenagem. É apresentada na equação 18 (Ball e Stone, 2004) a lei das marchas:

$$
\frac{T_{m o v}}{T_{m o t}}=-\frac{D_{m o v}}{D_{m o t}}=-\frac{N_{m o v}}{N_{m o t}}=-\frac{\omega_{m o t}}{\omega_{m o v}}
$$

Com esta breve teoria das engrenagens, serão abordados a seguir, de forma superficial, os principais conceitos que estão por traz de uma transmissão manual.

Uma transmissão manual, também conhecida como caixa de velocidades, é bem utilizada em aplicações automotivas. Ela é usada em conjunto com a embreagem para a transferência do torque e um manípulo de seleção das marchas.

O objetivo da transmissão manual é transferir e multiplicar o torque proveniente do motor até o eixo das rodas, e permitir que o condutor altere o nível de torque de saída para os eixos através da seleção manual das marchas em função da velocidade escolhida. A Figura 39 mostra os principais componentes de uma transmissão manual:

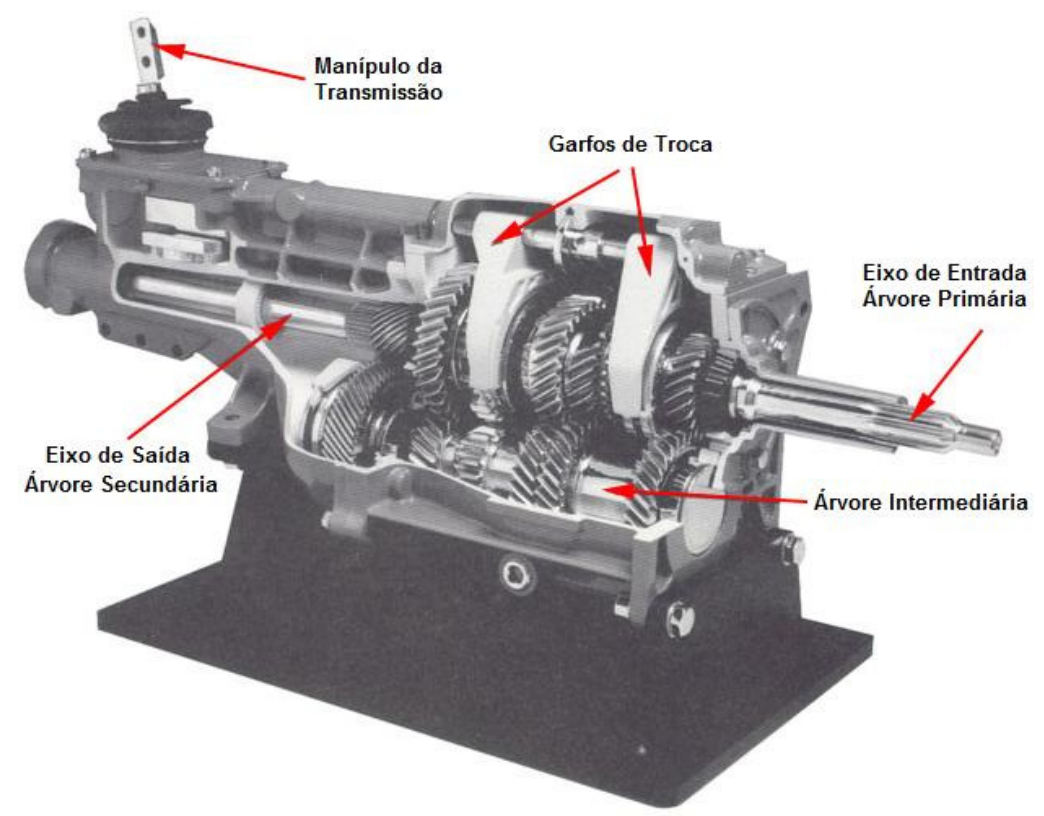

Figura 39: Principais componentes de uma caixa de transmissão manual (Clutches_N_More, 2010) 
Para exemplificar o fluxo de torque que vai do motor até as rodas, é mostrada a Figura 40 simplificada de uma transmissão manual abaixo:

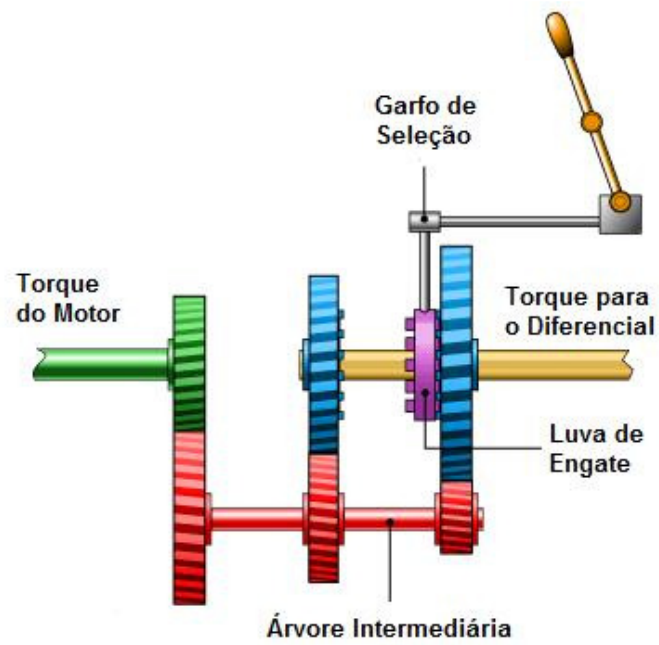

Figura 40: Caixa de transmissão simplificada (How Stuff Works, 1998-2010)

O eixo verde, denominado eixo de entrada ou árvore primária, está representando o torque principal que vem do motor através do componente embreagem. Este eixo, uma vez acoplado à embreagem, gira com a mesma rotação do motor.

O eixo e as engrenagens vermelhas compõem o denominado eixo intermediário ou árvore intermediária. Geralmente todas as engrenagens deste eixo são usinadas em uma única peça, e por esse motivo, giram com a mesma rotação. Devido à conexão direta entre o eixo verde e vermelho, há a transferência contínua de energia através do eixo verde para o vermelho, toda a vez que a embreagem estiver acoplada.

O eixo amarelo é denominado o eixo de saída ou árvore secundária e é um eixo estriado que se conecta diretamente ao eixo de acionamento através do diferencial para as rodas do carro. Se as rodas estão girando, o eixo amarelo está girando. As engrenagens azuis são montadas em rolamentos, para que elas girem no eixo de saída.

A transmissão do torque é proporcionada pelo trabalho da luva de engate, cujo seu objetivo é conectar uma das duas engrenagens azuis ao eixo estriado (eixo de saída). A luva de engate é conectada diretamente ao eixo de saída através das estrias, por este motivo, gira na mesma rotação do eixo de saída e ela pode somente 
deslizar para a esquerda ou direita ao longo do eixo de saída para conectar qualquer uma das engrenagens azuis.

De acordo com (Argachoy, 2004), os dois principais sistemas de engate de marchas nas caixas de transmissão são o sistema de garras constantes ("engate seco") e o sistema sincronizado.

O sistema de sincronização tem o objetivo de adequar a rotação do conjunto da engrenagem com o corpo de acoplamento à rotação do conjunto da luva de engate e corpo de engate, garantindo mudanças de marcha com pouco esforço e reduzido nível de ruído. De acordo com (Argachoy, 2004), o sistema mais comum é a sincronização de bloqueio, que é extremamente durável e quando bem dimensionado, confere mudanças de marcha rápidas e silenciosas. A Figura 41 mostra este tipo de sincronizador.
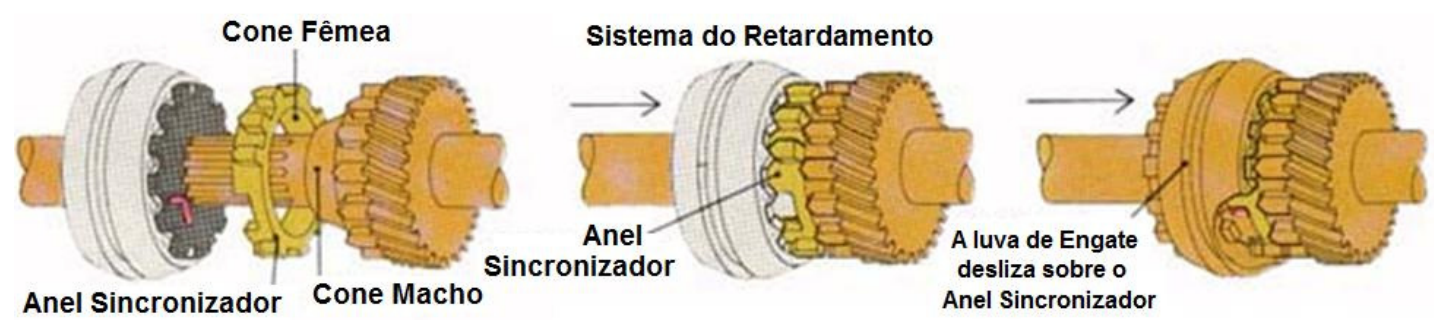

Figura 41: Sistema de engate com sincronização (Costa, 2001-2002)

Os mecanismos sincronizados atuais incluem um dispositivo que impede o movimento do sincronizador e não permite que os dentes engatem antes de se obter uma sincronização perfeita. Se as peças em rotação não girarem à mesma velocidade, por a embreagem não estar devidamente desacoplada, a alavanca de mudanças resistirá aos esforços do motorista para a mudança de posição.

Com a marcha engatada, é possível traçar o fluxo de torque na transmissão, bem como determinar as relações de transmissão de cada marcha.

Somente como exercício, (Ball e Stone, 2004) apresenta o cálculo da determinação da relação de transmissão de uma unidade veicular. O exemplo a seguir representa a determinação da relação de primeira marcha. $O$ torque proveniente do motor flui através do eixo de entrada até chegar à engrenagem de 23 dentes, entra em contato com a engrenagem de 35 dentes, onde diminui a rotação e aumenta-se o torque no eixo intermediário. Este torque prossegue na árvore intermediária e encontra a engrenagem de 18 dentes. 
Com o sincronizador acoplado na engrenagem que representa a primeira marcha no eixo de saída, ocorre mais uma diminuição na rotação e uma multiplicação do torque do motor. A Figura 42 mostra o fluxo de torque na transmissão:

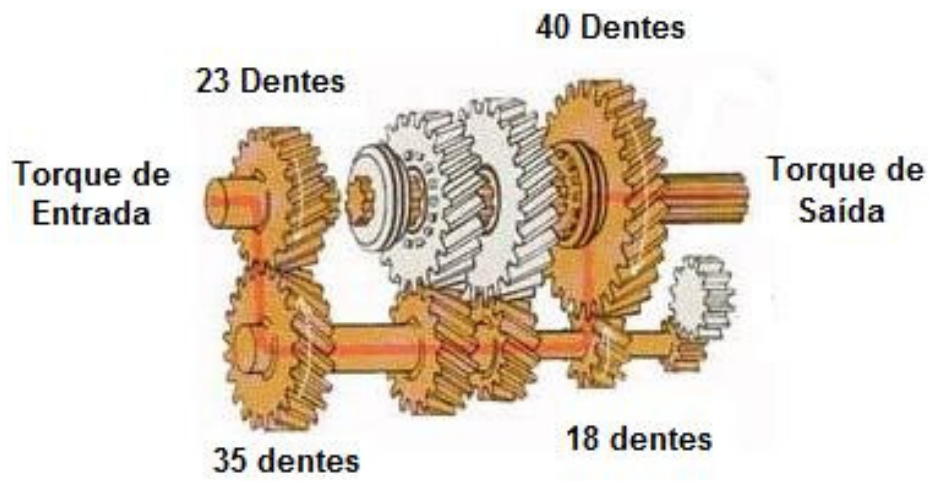

Figura 42: Fluxo de torque na transmissão (Costa, 2001-2002)

De acordo com (Ball e Stone, 2004), aplicando a lei de engrenagens, para este conjunto de engrenagens, a relação de transmissão, que é a relação de multiplicação de torque, para este exemplo fica:

$i_{1 s t}=\frac{T_{s a i}}{T_{\text {ent }}}=\frac{35}{23} \times \frac{40}{18}=3,38$

Onde:

$\mathrm{i}_{1 \text { st }}=$ Relação de transmissão de primeira marcha;

$\mathrm{T}_{\text {sai }}=$ Torque de saída da transmissão;

$\mathrm{T}_{\text {ent }}=$ Torque de entrada na transmissão;

35 = Número de dentes da engrenagem motora do eixo de entrada;

23 = Número de dentes da engrenagem movida do eixo intermediário;

18 = Número de dentes da engrenagem motora do eixo intermediário;

40 = Número de dentes da engrenagem movida do eixo de saída.

Da mesma maneira, é efetuado o mesmo cálculo para todas as outras marchas. De acordo com (Ball e Stone, 2004), se os veículos não precisassem fazer curvas, eles não necessitariam de diferenciais. Como isto não é o caso para veículos rodoviários, o torque total, até chegar às rodas, flui por este dispositivo. 
A Figura 43 mostra a necessidade do diferencial quando o veículo executa uma trajetória curvilínea de baixo raio de giro:

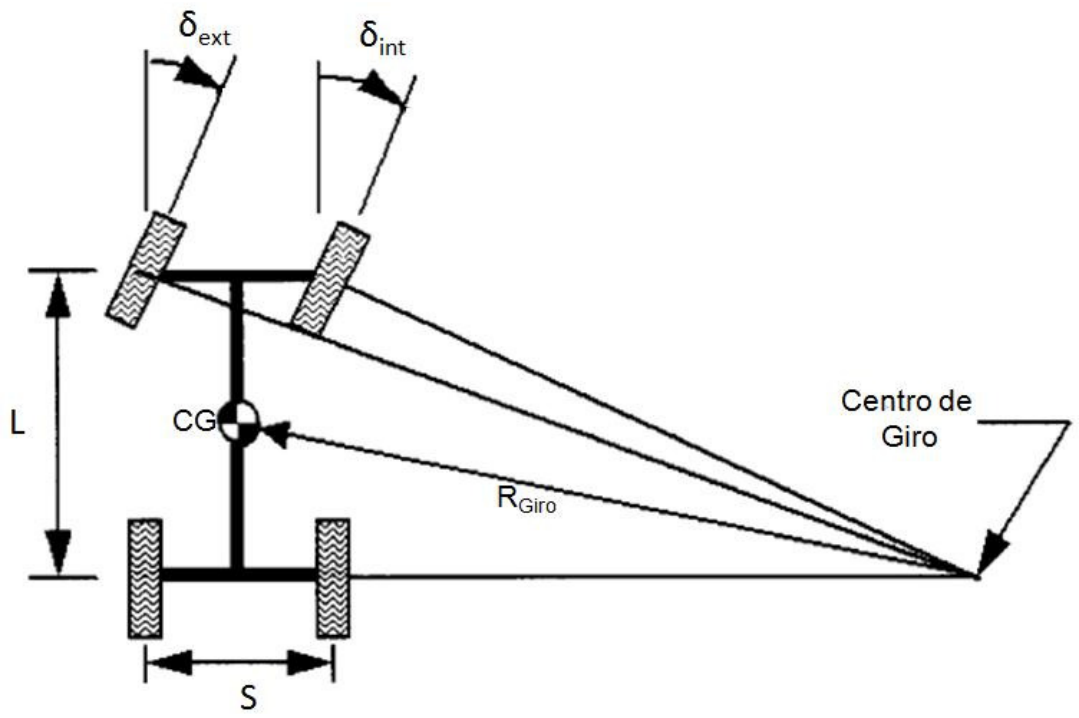

Figura 43: Veículo em Curva de Baixa Velocidade (Ball e Stone, 2004)

Onde:

$\mathrm{S}=$ Bitola do veículo;

$\mathrm{R}_{\text {Giro }}=$ Raio de giro da curva em relação ao centro de gravidade;

$\delta_{\text {ext }}=$ Ângulo de esterçamento da roda externa a curva;

$\delta_{\text {int }}=$ Ângulo de esterçamento da roda interna a curva.

Conforme mostrado na Figura 43, as rodas do veículo desenvolvem raios diferentes de giro. Neste caso a roda esquerda (externa) tende a girar mais vezes do que a roda direita (interna). Para permitir que as rodas girem de maneira independente nas curvas, se faz necessário a utilização de um diferencial.

A unidade do diferencial é projetado para dividir igualmente o torque vindo da transmissão para as rodas e permitir que elas girem com velocidades diferentes quando estiverem em curvas. Em veículos sem diferencial, por exemplo, o Kart, as rodas motrizes são forçadas a girar com a mesma velocidade, geralmente em um eixo comum, baseado em um mecanismo de acionamento simples. 
A Figura 44 mostra os principais componentes do diferencial ou "final drive":

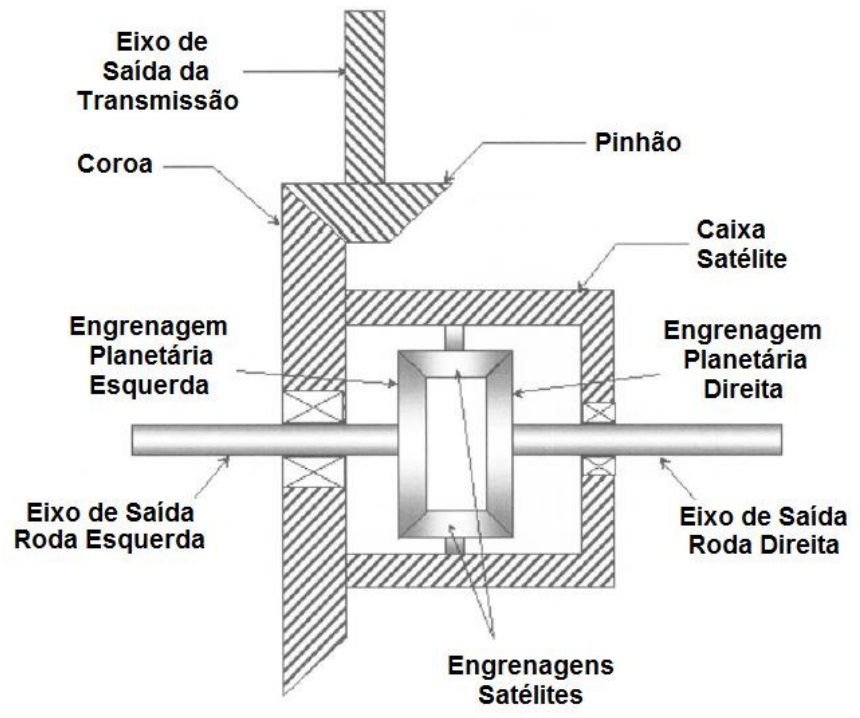

Figura 44: Componentes do diferencial (Ball e Stone, 2004)

O torque proveniente do eixo de saída da transmissão é ampliado pela relação de número de dentes entre o pinhão e a coroa, obedecendo a lei das marchas, apresentada anteriormente. Quando o veículo está se movimentando em linha reta, as engrenagens satélites não giram em torno do seu próprio eixo, apenas transladam em conjunto com a caixa satélite, fazendo com que ambos os eixos que vão para as rodas girem na mesma rotação. Quando o veículo está fazendo uma curva, a roda externa à curva gira com uma rotação maior do que a roda interna; isso é possível devido ao movimento combinado de rotação das engrenagens satélites em torno do seu próprio eixo com a translação da caixa satélite. A Figura 45 mostra estas duas situações:

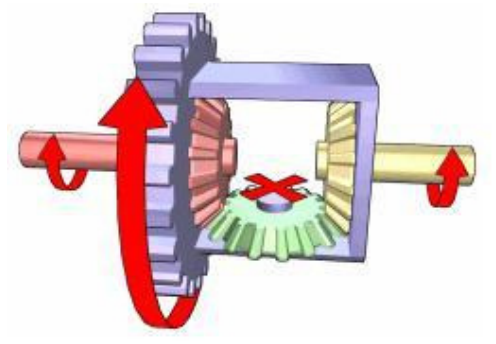

Veículo em linha reta

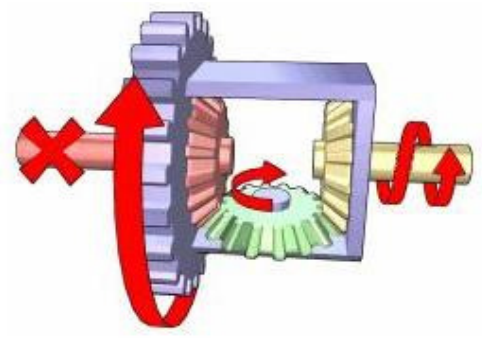

Veículo em curva

Figura 45: Dinâmica simplificada do diferencial (Wikipedia the Free Encyclopedia, 2006) 


\section{5-) Pneus}

Um componente de fundamental importância para o desempenho de um veículo é o pneu. Ele exerce várias funções importantes na dinâmica dos veículos e por esse motivo demanda um grande trabalho de engenharia especializada para atender todos os requesitos necessários.

De acordo com (Ball e Stone, 2004), o pneu representa o único ponto de contato entre o veículo e o pavimento. Assim, todas as acelerações, frenagens e as forças de tração e direção passam por essas quatro pequenas manchas (áreas) de borracha. Além disso, os pneus fazem parte do sistema de suspensão e, em si mesmo, fornecem rigidez e amortecimento influenciando diretamente as características dinâmicas dos veículos.

Para (Gillespie, 1992), as três funções básicas dos pneus são:

1. Suportar cargas verticais, enquanto amortece contra os choques do pavimento;

2. Desenvolver forças longitudinais na aceleração e frenagem;

3. Desenvolver forças laterais nas curvas.

As características de comportamento do pneu não dependem apenas das condições de funcionamento, mas de sua construção também. A estrutura do pneu é composta de uma carcaça flexível e de alta resistência a tração e compressão. A pressão de enchimento do pneu promove tensões internas na estrutura e estas se não forem bem definidas e monitoradas, podem alterar o desempenho do veículo em determinadas manobras, tais como: desempenho em curvas, frenagens, acelerações e economia de combustível.

De acordo com (Gillespie, 1992), os dois tipos básicos de construção dos pneus amplamente utilizados são - pneus diagonais e pneus radiais. Os pneus diagonais foram bastante utilizados na indústria automobilística na década de 1960, quando as vantagens dos pneus radiais, desenvolvidos na Europa, tornaram-se reconhecidas. Durante décadas os pneus radiais substituíram os pneus diagonais, tornando-se padrões nos dias de hoje. A Figura 46 mostra estes dois tipos de pneus: 


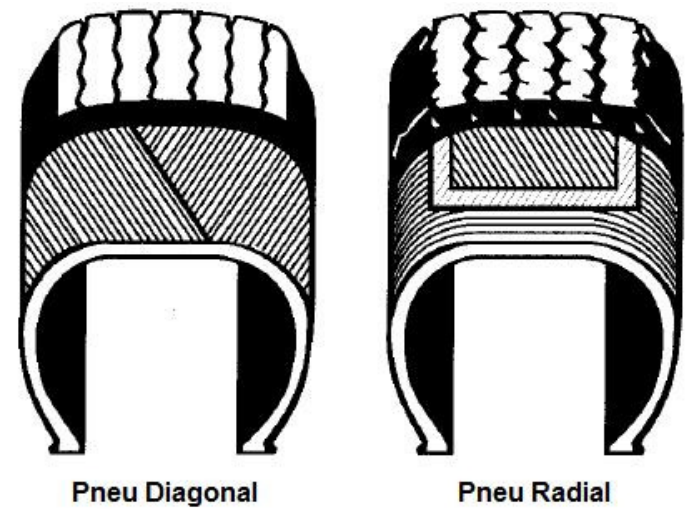

Figura 46: Tipos construtivos dos pneus: Diagonal e Radial(Gillespie, 1992)

Todo tipo de pneu apresenta uma nomenclatura própria, o que o identifica. São impressas em relevo na lateral externa do pneu uma grande quantidade de informações que ajudam o consumidor a obter o máximo desempenho do produto. De acordo com (A.L.A.P.A, 2003), mostra-se a seguir algumas das informações que são impressas no pneu:

- Nome do fabricante;

- Modelo do pneu;

- Tipos de construção;

- Carga e pressão máxima - exigência da legislação;

- Dados referentes à estrutura do pneu - exigência da legislação;

- Entre outros.

Como parâmetro crucial para a escolha de um pneu para um veículo, o conhecimento da designação do pneu faz toda a diferença para a determinação do raio dinâmico do pneu, que influencia diretamente no desempenho do veículo. A Figura 47 mostra um exemplo de uma designação de pneu:

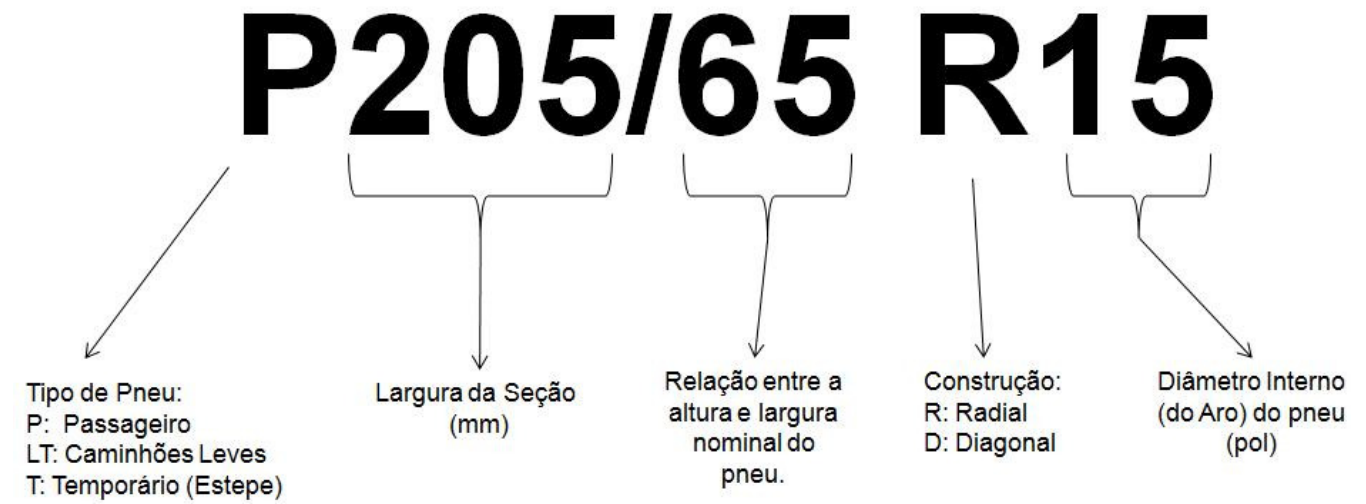

Figura 47: Designação de um pneu (Exemplo) 
Como exemplo, abaixo segue o cálculo do raio do pneu considerando a medida 205/65 R15, sem nenhuma carga aplicada:

- Diâmetro da Roda = Diâmetro interno do pneu = 15" = $381 \mathrm{~mm}$;

- Sessão Lateral do Pneu $=2^{*}\left(205^{\star} 0,65\right)=266,5 \mathrm{~mm}$;

- Diâmetro do Pneu = $381+266,5=647,5 \mathrm{~mm}$;

- Portanto o Raio do Pneu $\left(R_{\text {pneu }}\right)=647,5 / 2$ = $\underline{323,7 ~ m m}$.

O cálculo do raio do pneu efetuado acima não representa o raio dinâmico do pneu quando montado no veículo. Para o cálculo do desempenho de um veículo, utiliza-se o raio dinâmico do pneu, que é função principalmente da pressão de enchimento, carga aplicada e velocidade do veículo. A Figura 48 mostra a dimensão do raio dinâmico (r) em um veículo.
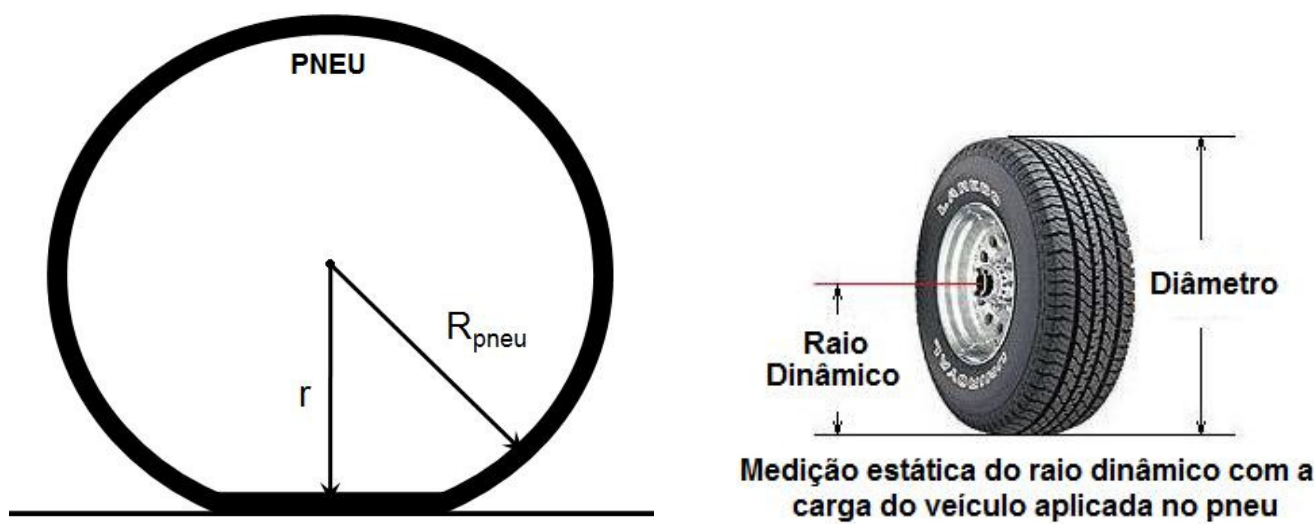

Figura 48: Representação do raio dinâmico do pneu

Uma das variáveis que pode afetar o raio dinâmico do pneu é a velocidade do veículo. De acordo com (Vibrate Software, 2009), o raio estático do pneu é 44\% do diâmetro estático. Conforme se aumenta a velocidade do veículo, aparece uma força centrífuga aplicada ao pneu, fazendo com que o mesmo se expanda, aumentandose assim o raio dinâmico do pneu.

Quando o veículo atinge $45 \mathrm{~km} / \mathrm{h}$, os pneus terão um raio dinâmico na ordem de $48 \%$ do diâmetro estático, e quando o veículo ultrapassa $110 \mathrm{~km} / \mathrm{h}$ o raio dinâmico é maior do que $50 \%$ do diâmetro estático do pneu.

O Gráfico 11 representa uma estimativa para a variação do raio dinâmico do pneu em função da velocidade do veículo: 


\section{Variação do raio dinâmico do pneu em função da velocidade}

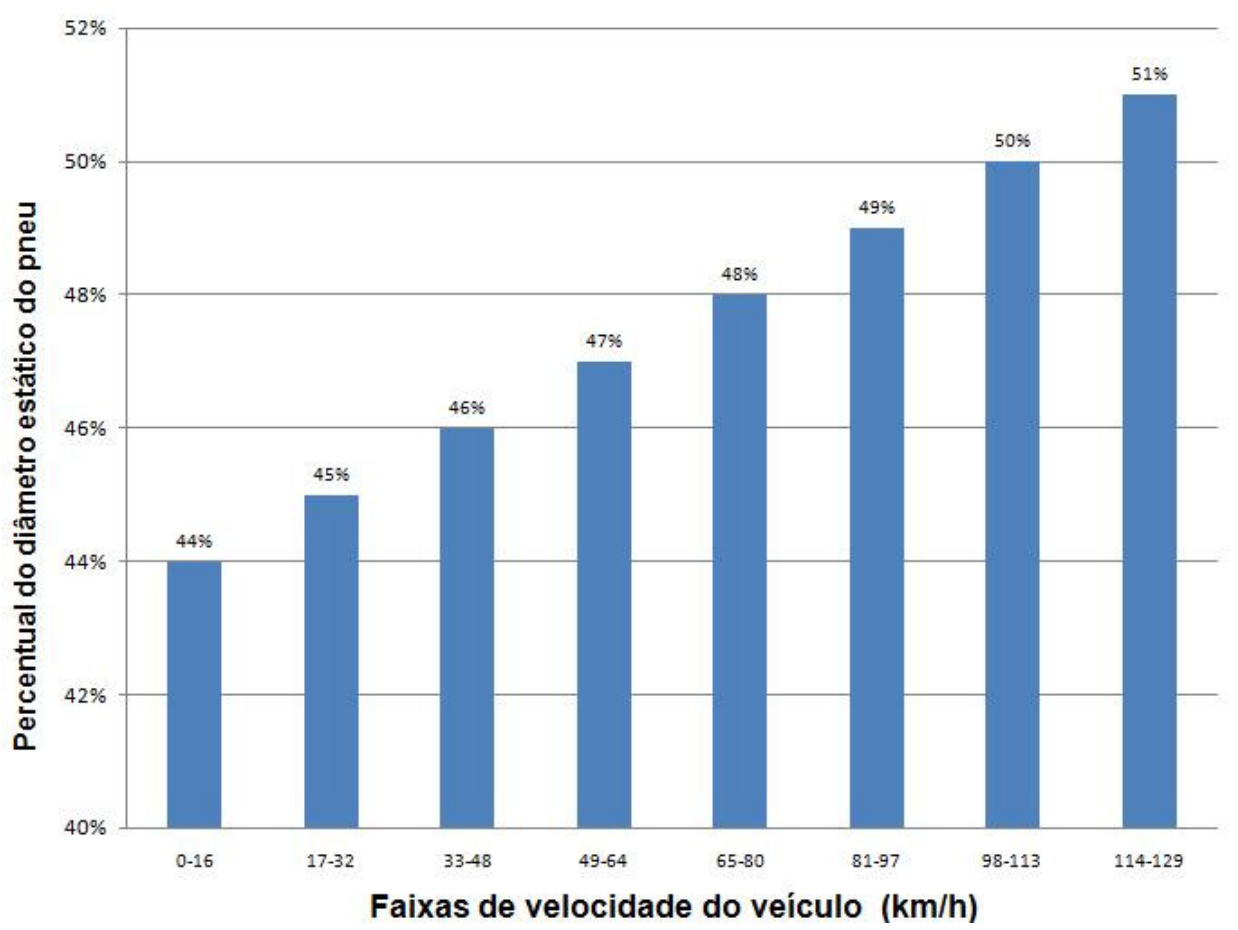

Gráfico 11: Variação do raio dinâmico do pneu em função da velocidade do veículo (Vibrate Software, 2009)

De acordo com (Gillespie, 1992), as forças em um pneu não são aplicadas em um ponto, mas sim uma área de contato. A distribuição de pressão na superfície de contato não é uniforme e pode variar nas direções X e Y. Segundo (Gillespie, 1992), quando o pneu rola, as forças não são simétricas no eixo $Y$, e tendem a ser maior na região frontal do pneu. A Figura 49 mostra a distribuição das forças no pneu:

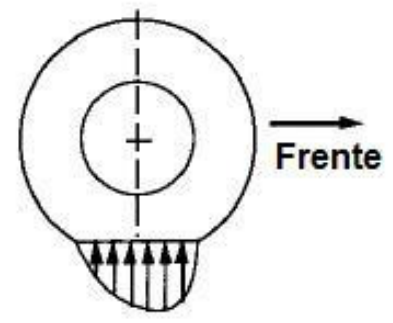

Rolagem constante

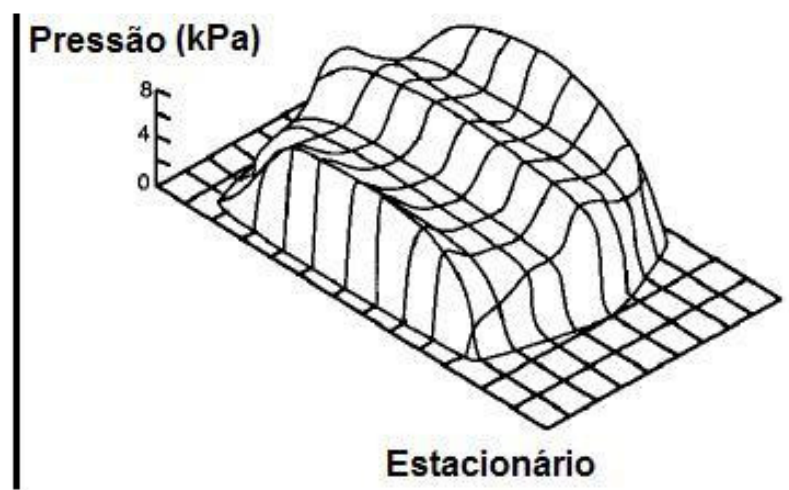

Estacionário

Figura 49: Distribuição de pressão no pneu (Gillespie, 1992)

Segundo (Gillespie, 1992) os dois mecanismos responsáveis por gerar as forças de atrito no pneu são a adesão e a histerese. A primeira está ligada com a 
interação intermolecular entre a borracha e das partículas agregadas junto ao solo, em outras palavras, a borracha da banda de rodagem flui entre os picos e vales presentes na superfície da estrada. $O$ atrito provocado pela adesão é fortemente prejudicado com a adição de água na superfície da estrada.

Já a histerese representa a perda de energia da borracha provocada pela deformação da borracha do pneu junto à superfície da estrada. Segundo (Gillespie, 1992), este mecanismo não é afetado da mesma maneira com a adição de água na superfície da estrada, no entanto, o pneu com uma borracha de alta histerese na sua banda de rodagem tende a ser melhor em pista molhada. A Figura 50 mostra estes dois mecanismos:

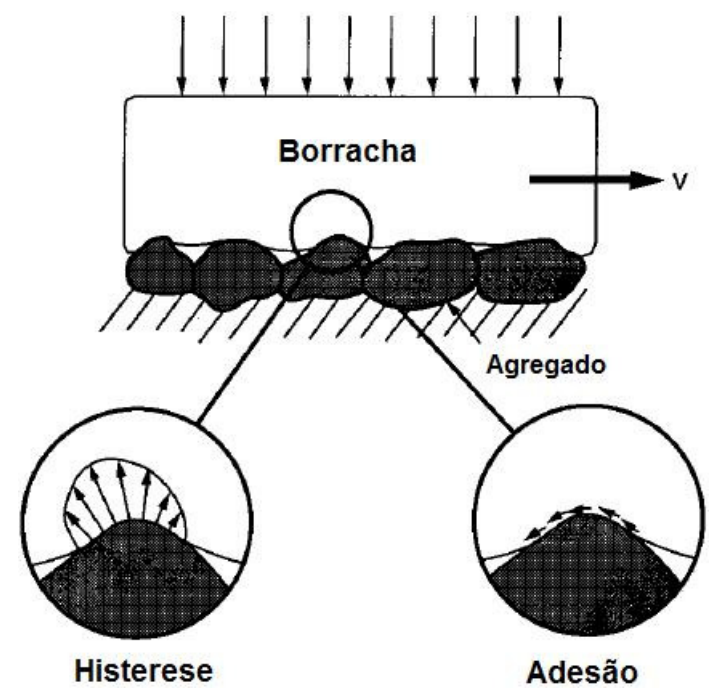

Figura 50: Mecanismos de atrito do pneu (Gillespie, 1992)

Tanto nas acelerações quanto nas frenagens, afirma (Gillespie, 1992), é observado um escorregamento adicional provocado pela deformação dos elementos da borracha da banda de rodagem do pneu para desenvolver e manter a força de atrito. Este escorregamento, ou "slip" é gerado pela diferença de rotação do pneu e a velocidade do veículo e, por definição, é um número adimensional dado pela seguinte equação:

$$
\operatorname{Slip}(\%)=\left(1-\frac{r \cdot \omega_{\text {roda }}}{v}\right)
$$


Onde:

$\omega_{\text {roda }}=$ Velocidade angular da roda;

$\mathrm{v}=$ Velocidade do veículo;

$r=$ Raio dinâmico do pneu.

De acordo com (Canale, 1989), as propriedades de um pneu não seguem exatamente as leis gerais de atrito e rolamento desenvolvidos em uma roda rígida. Quando o veículo está acelerando, a distribuição de pressão no pneu comprime e expande as fibras do pneu na área de contato e quando as fibras comprimidas se expandem, elas escorregam sobre a superfície do solo, originando um escorregamento parcial. A Figura 51 mostra a distribuição de pressão quando o veículo está em aceleração:

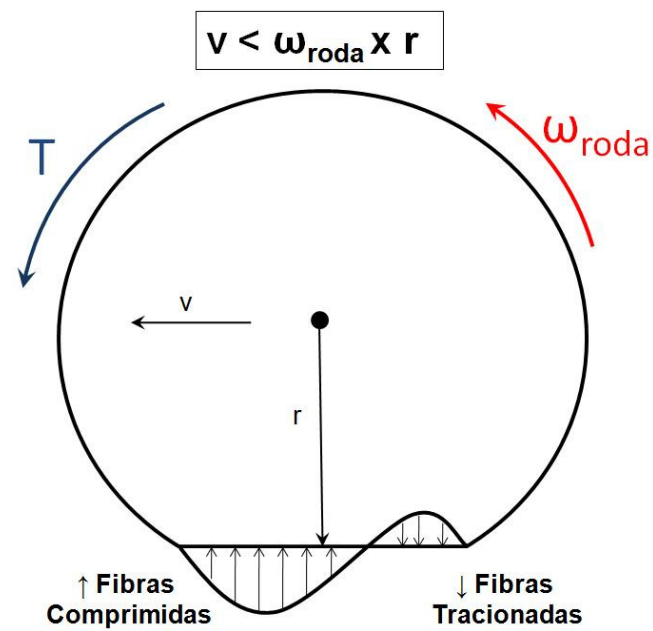

Figura 51: Distribuição de pressão na área de contato - aceleração

Todo o torque transmitido ao solo pelo pneu resulta em um escorregamento parcial do pneu e verifica-se ainda, experimentalmente, que a máxima transferência de força ao solo através do pneu, se faz quando a porcentagem de escorregamento com relação ao rolamento é da ordem de $10 \%$ a 20\%, afirma (Canale, 1989).

Para enfatizar as características particulares de um pneu, tanto na aceleração quanto na frenagem, (Ball e Stone, 2004) apresentam a variação do coeficiente de adesão $(\mu)$ em função da percentagem de escorregamento do pneu, conforme mostrado no Gráfico 12: 


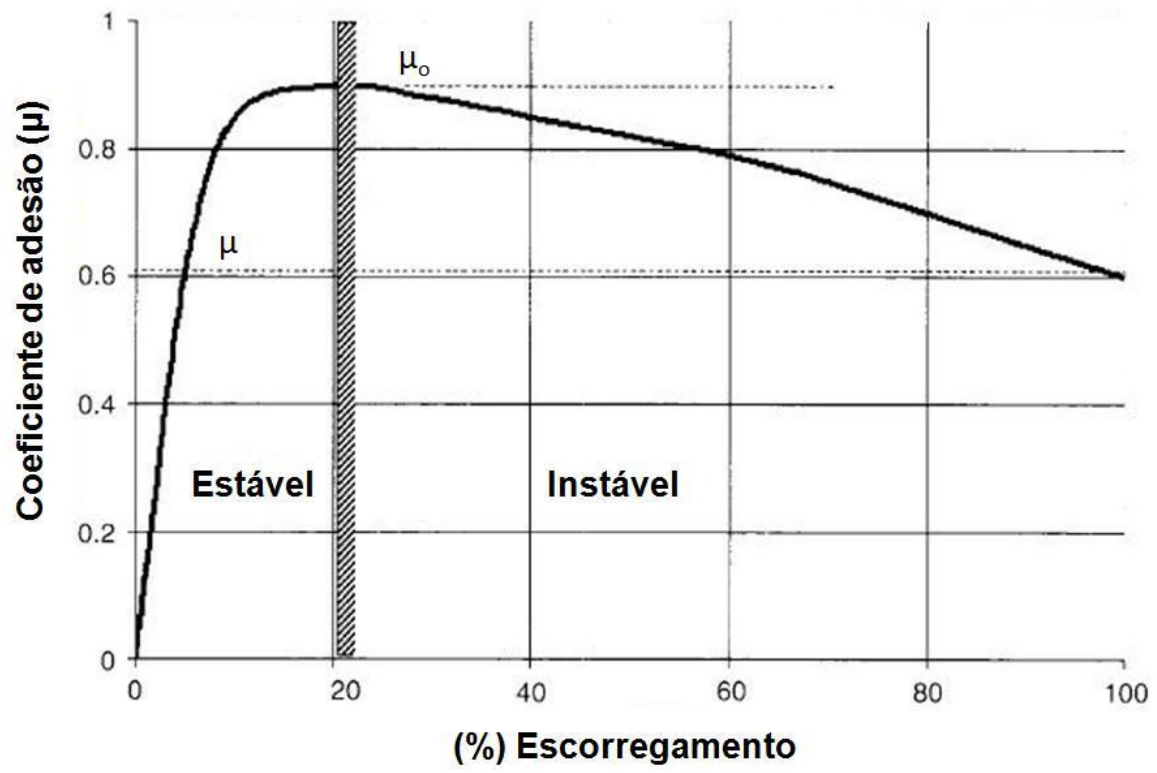

Gráfico 12: Coeficiente de adesão VS (\%) de Escorregamento (Ball e Stone, 2004)

Onde:

$\mu_{\mathrm{o}}=$ Máximo coeficiente de adesão do pneu;

$\mu=$ Coeficiente de atrito no escorregamento do pneu.

De acordo com (Canale, 1989), os coeficientes de adesão são difíceis de serem obtidos devido às muitas variáveis envolvidas no processo. Eis abaixo os principais fatores que influem no coeficiente de adesão:

- Materiais em contato: fator de grande importância e de alta variação, como mostra a Tabela 1, com alguns valores de interface:

\begin{tabular}{|l|c|c|}
\hline Faces da borracha com: & $\boldsymbol{\mu}_{\mathrm{o}}$ & $\boldsymbol{\mu}$ \\
\hline Asfalto ou concreto seco & $0,8-0,9$ & 0,75 \\
\hline Concreto molhado & 0,8 & 0,7 \\
\hline Estrada de terra seca & 0,70 & 0,65 \\
\hline Neve & 0,2 & 0,15 \\
\hline
\end{tabular}

Tabela 1: Coeficientes de adesão (Canale, 1989) 
- Condições das faces de contato;

- Características do pneu: destaca-se a elasticidade e a forma da borracha da banda de rodagem, pressão de enchimento, rigidez estrutural;

- Velocidade: um pequeno decréscimo no coeficiente de adesão é observado com o aumento da velocidade. 


\section{6-) Inércia}

O conceito de inércia vem da primeira lei de Newton que é definida como:

"Todo corpo tende a permanecer em seu estado de repouso ou de movimento retilíneo uniforme, exceto se for obrigado a mudar o seu estado inicial através da aplicação de uma força externa".

De acordo com (Newton, 1846), inércia vem da palavra latina "iners", ou seja, inato ou preguiçoso e que representa a resistência de qualquer objeto físico a uma mudança em seu estado de movimento, o qual é representado numericamente na massa de um objeto.

Nas aplicações automotivas existem várias partes girantes, o que demandam o conhecimento de momento de inércia. O conceito do momento de inércia, inércia de rotação ou a massa angular (unidade no S.I. Kg. $\mathrm{m}^{2}$ ) foram introduzidos por (Euler, 1765).

Somente como introdução ao momento de inércia é apresentada a seguir as fórmulas básicas aplicadas às massas girantes. Segundo (Euler, 1765) a definição do momento de inércia (em relação a um determinado eixo de rotação) de qualquer objeto, seja um ponto de massa ou uma estrutura 3D, é dada por:

$$
I=\int r_{o b j}^{2} \cdot d m_{o b j}
$$

Onde:

$\mathrm{m}_{\mathrm{obj}}=$ Massa do objeto;

$r_{\text {obj }}=$ é a distância perpendicular ao eixo de rotação.

O momento escalar de inércia de um ponto de massa girando sobre um eixo conhecido é dado por:

$$
I=m_{o b j} \cdot r_{o b j}^{2}
$$

$\mathrm{O}$ momento de inércia é aditivo. Assim, para um corpo rígido composto de $\mathrm{N}$

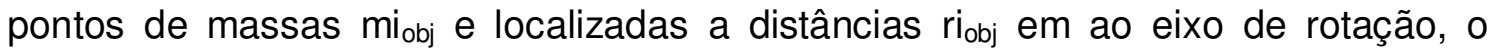
momento de inércia total é igual à soma dos momentos pontuais: 


$$
I=\sum_{i=1}^{N} m i_{o b j} \cdot r i_{o b j}^{2}
$$

Considerando o momento de inércia constante, pode se relacionar o torque em um objeto com sua respectiva aceleração angular $\left(\alpha_{o b j}\right)$, como segue:

$$
T_{o b j}=I . \alpha_{o b j}
$$

$\mathrm{Na}$ aplicação automotiva, os principais componentes cujo efeito da inércia impacta no desempenho do veículo em aceleração são:

- Inércia do volante do motor;

- Inércia do platô de embreagem;

- Inércia do disco de embreagem;

- Inércia da transmissão;

- Inércia do disco/lonas de freio;

- Inércia do conjunto pneu/roda. 


\section{7-) Rampas e Obstáculos}

Rampas e obstáculos são muito comuns nas ruas das cidades brasileiras, o que demandam veículos que cumpram com eficiência o desempenho mínimo esperado pelos seus consumidores.

Da geometria, a inclinação de um aclive ou relevo topográfico refere-se ao ângulo formado por um plano (no caso a rua), com um plano em nível (referência). A Figura 52 mostra um exemplo de inclinação presente nas vias públicas:

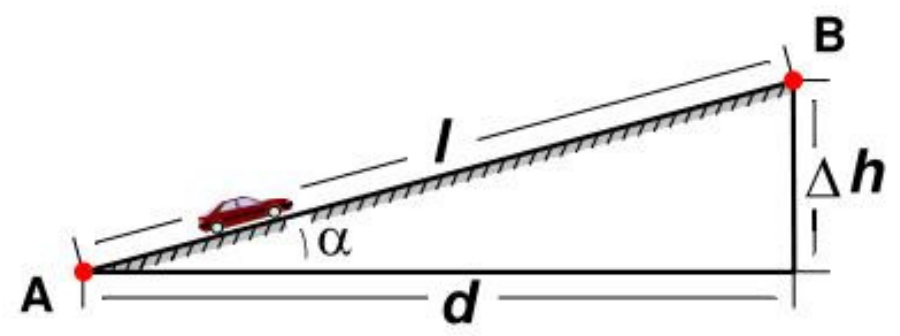

Figura 52: Representação da inclinação de rampa

Onde:

d = Distância percorrida na horizontal;

$\Delta \mathrm{h}=$ Variação de altitude em relação ao ponto inicial $(\mathrm{A})$;

I = Distância percorrida no aclive;

$\alpha=$ Ângulo de inclinação do aclive.

A inclinação de uma rampa geralmente é expressa em porcentagem, no entanto é possível converter para ângulos em graus facilmente. Segue abaixo as expressões matemáticas que descrevem a inclinação de um aclive:

- Percentual de inclinação do aclive (\% Rampa):

$$
(\%) \text { Rampa }=\tan (\alpha) .100=\frac{\Delta h}{d} .100
$$

- Ângulo da rampa (graus):

$$
\alpha=\arctan \left(\frac{\Delta h}{d}\right)=\arctan \left(\frac{(\%) R a m p a}{100}\right)
$$


A fim de facilitar a conversão entre ângulo do aclive com seu porcentual de inclinação, segue abaixo os cálculos representados no Gráfico 13:

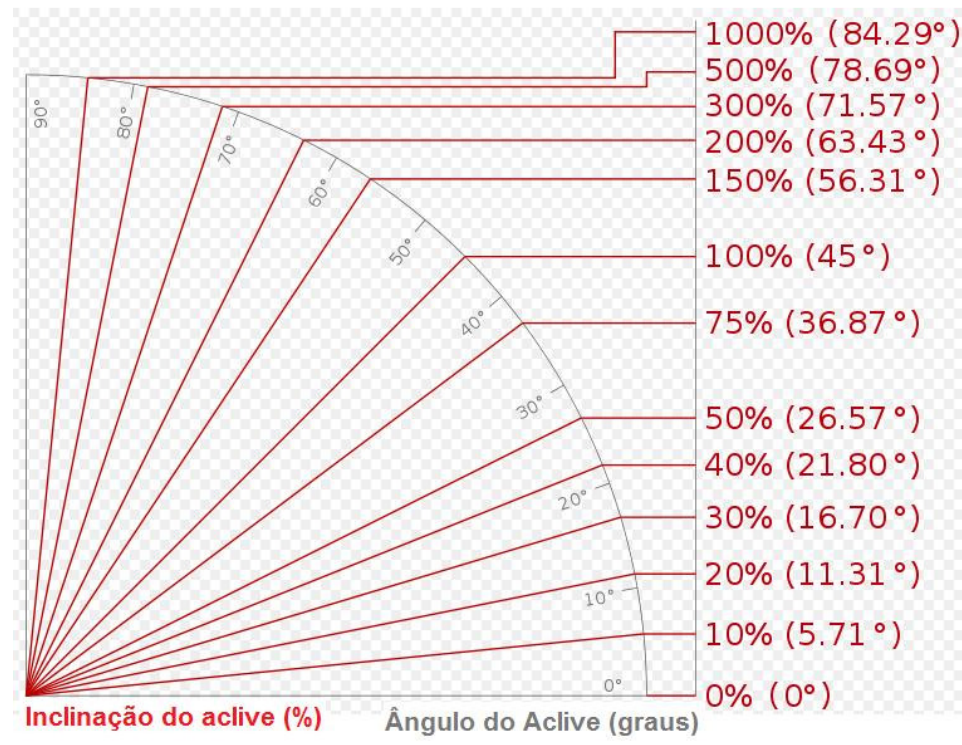

Gráfico 13: llustração do porcentual de Inclinação (\%) e ângulo de inclinação (graus) (BW95, 2010)

Ruas com aclives e declives são muito comuns nas cidades brasileiras. Um fator muito importante a ser considerado para o desenvolvimento de um novo veículo é o seu desempenho em aclives elevados, os quais são ruas que tem inclinação acima de $25 \%$.

Um trabalho feito por (Silveira, 2007) foi medir através de fotografias a inclinação de algumas ruas e estradas e comprovar que estas têm um grau de inclinação bem abaixo do que avaliado subjetivamente por seus alunos. A Figura 53 mostra esta medição na cidade de Porto Alegre:

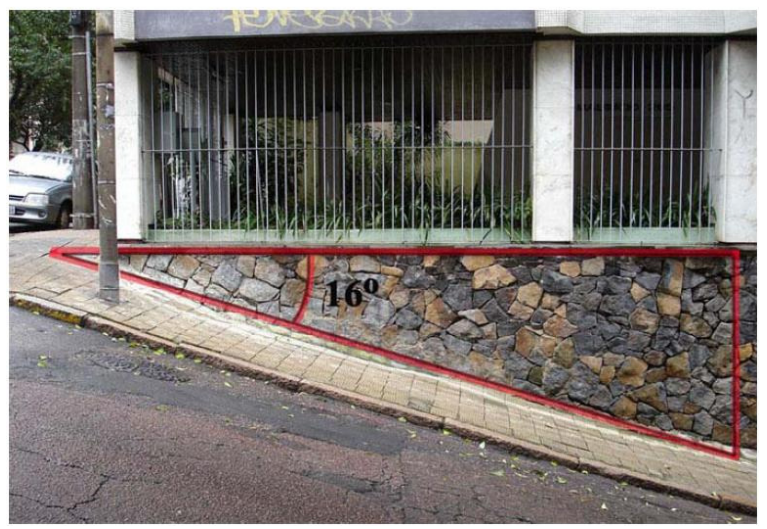

Figura 53: Rua Inclinada no centro de Porto Alegre (Silveira, 2007) 
Outro método muito simples que pode ser utilizado para a determinação da inclinação de uma rua é a utilização de um transferidor, um barbante e uma massa. Consegue-se uma boa precisão quando se mede ruas com aclives elevados. A Figura 54 mostra este método:

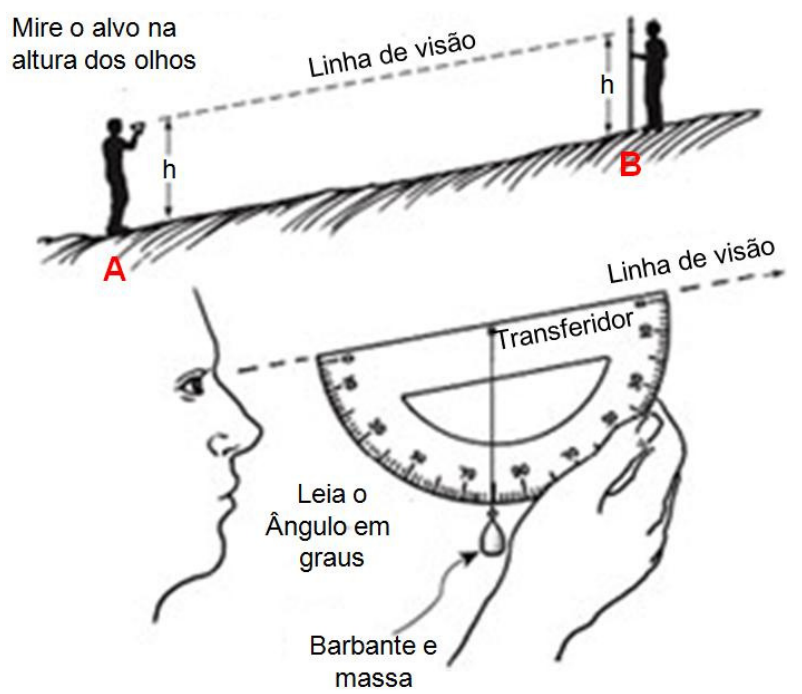

Figura 54: Medição de aclive com transferidor

Através do método acima apresentado, (Pasianot, 2006) levantou algumas das principais ruas com inclinações elevadas em São Paulo. Abaixo são apresentadas estas ruas com seus gradientes de inclinação:

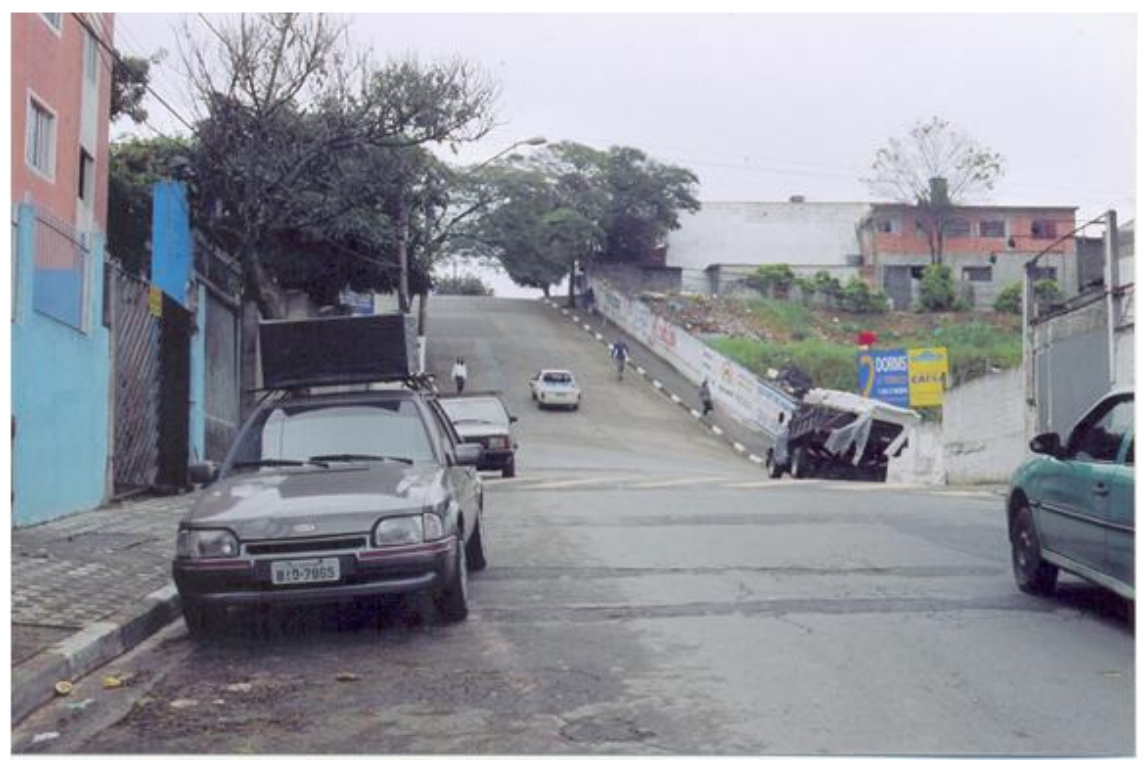

Figura 55: Rua Artur Sampaio Moreira - Diadema-SP (32\%) (Pasianot, 2006) 


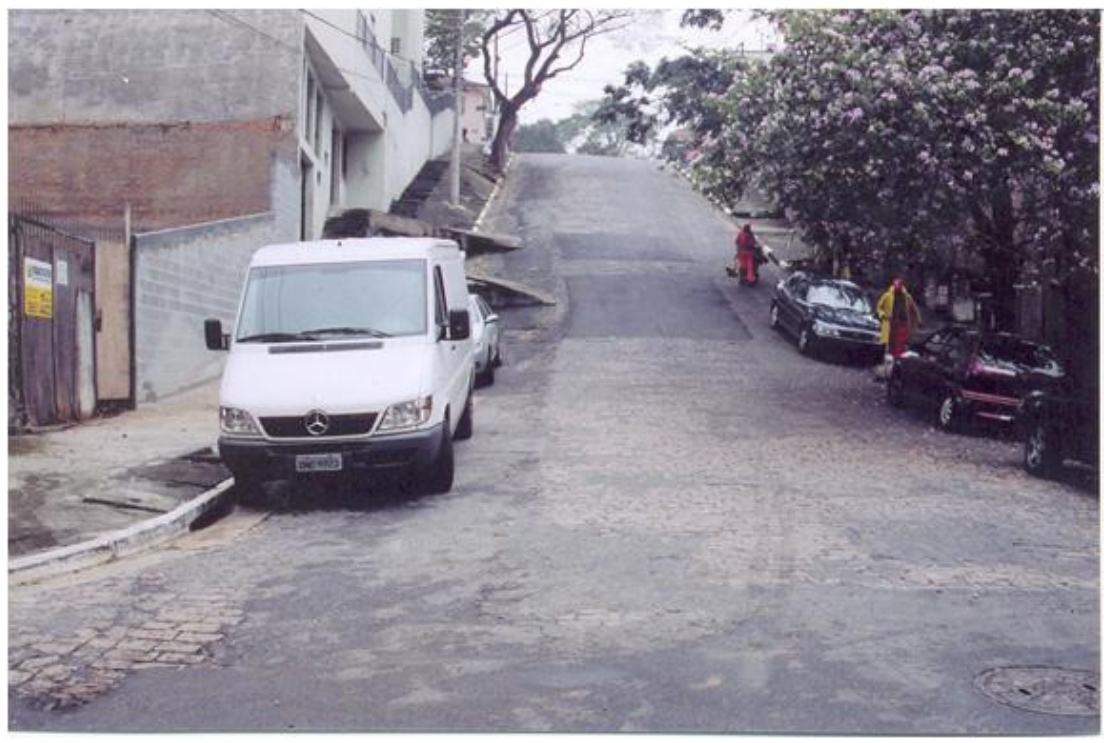

Figura 56: Rua Monte Alegre - Perdizes-SP (31\%) (Pasianot, 2006)

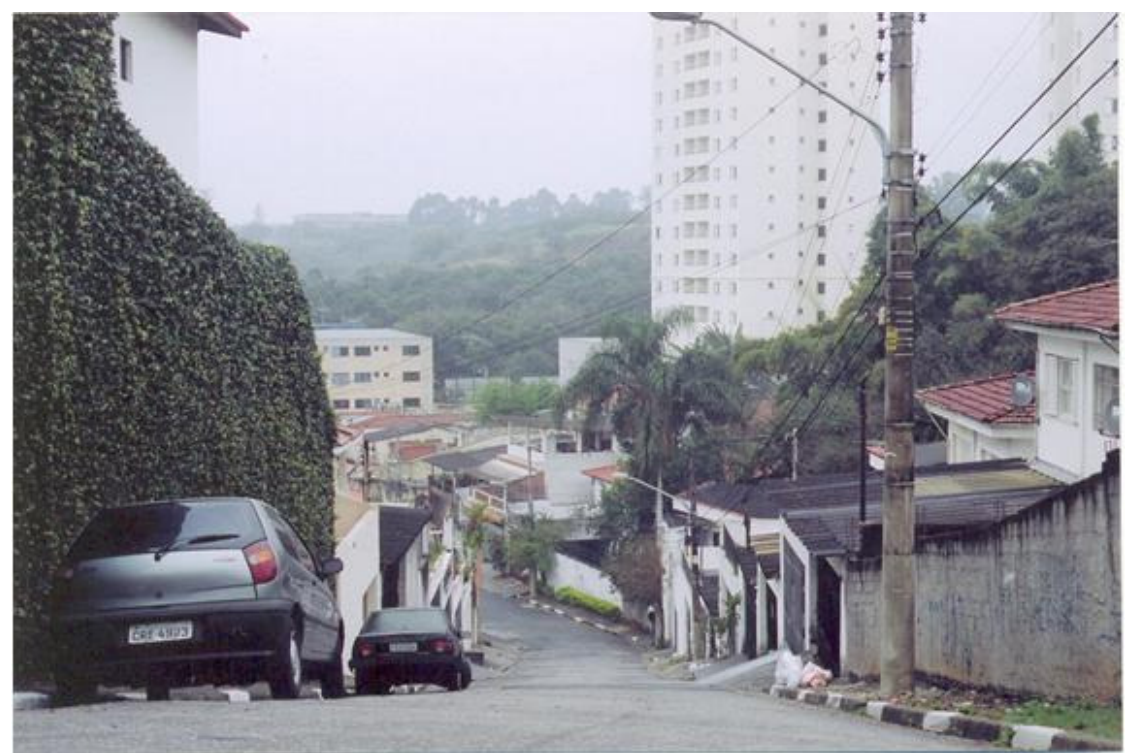

Figura 57: Rua Amorin Castro - Butantã-SP (26\%) (Pasianot, 2006)

Os exemplos reais apresentados acima demonstram as características físicas presentes nas ruas brasileiras e estas são provas reais para os veículos que nela circulam.

Na próxima sessão será apresentado o modelo matemático e de simulação computacional usado na manobra de arrancada a partir da imobilidade em aclives elevados. 


\section{4-) METODOLOGIA}

Baseado no estudo da literatura apresentada e nas referências bibliográficas de trabalhos feitos nesta área é apresentado a seguir um modelo matemático capaz de reproduzir a manobra de arrancada para aclives elevados, desenvolvido na plataforma Matlab Simulink. Os resultados obtidos deste modelo são correlacionados com medições feitas em um veículo real. O esquema da Figura 58 mostra as principais características do veículo, que estão presentes na manobra e que foram considerados no modelo:

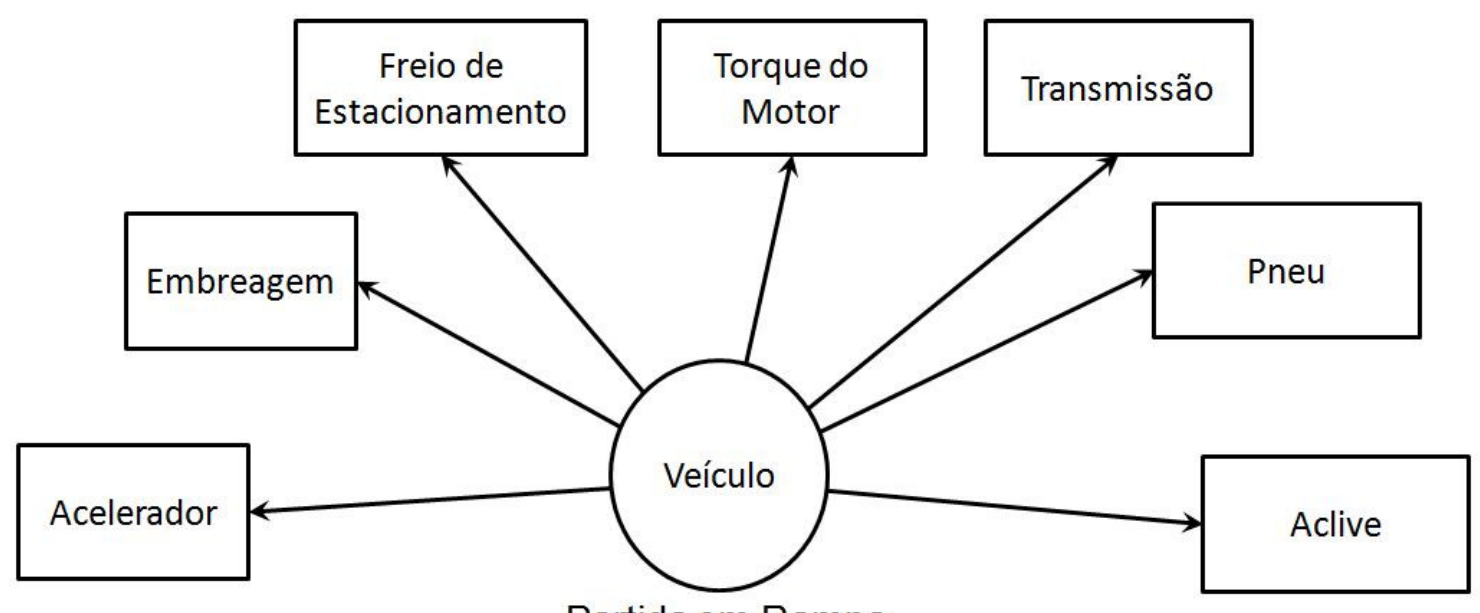

Partida em Rampa

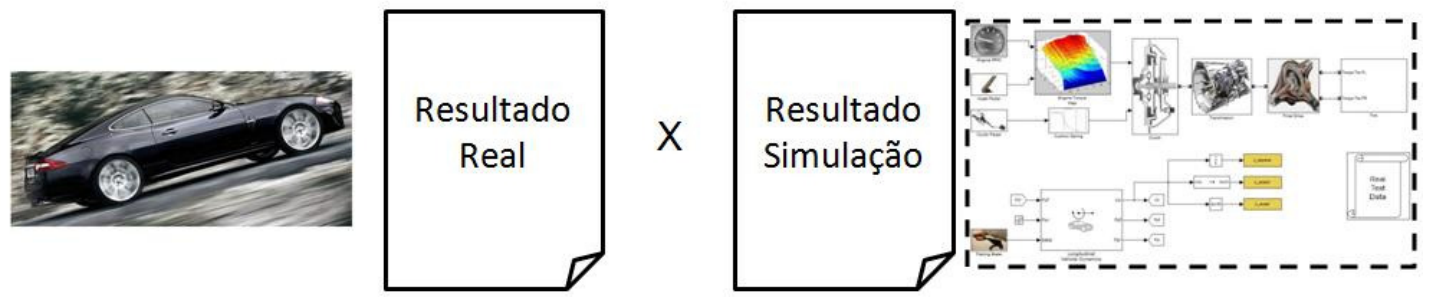

Figura 58: Ilustração da Metodologia utilizada

Para obter um resultado satisfatório de correlação foi preciso conhecer as características físicas do veículo em estudo e aplicar os conceitos de desempenho do veículo no modelo. Nas próximas sessões são descritas a metodologia de cálculo utilizada, bem como as características do veículo monitoradas em tempo e no teste real. 
A elaboração desta metodologia de análise vem de encontro à necessidade de projetar e desenvolver veículos que atendam o desempenho satisfatório nas saídas de aclives elevados.

Para a elaboração deste trabalho, foi considerado tanto para o teste físico como simulação do modelo uma rampa de $30 \%\left(17^{\circ}\right)$, pois esta inclinação representa um aclive elevado e está presente nas ruas brasileiras. O procedimento de execução desta metodologia consiste em:

1-) Executar e registrar os seguintes dados do teste veicular em uma rampa de $30 \%$ :

1.1-) Perfil da utilização do pedal de acelerador;

1.2-) Perfil da utilização do pedal de embreagem;

1.3-) Perfil de utilização do freio de estacionamento;

1.4-) Perfil de utilização da rotação do motor;

1.5-) Variação do espaço percorrido, velocidade e aceleração longitudinal.

2-) Os Parâmetros (1.1, 1.2, 1.3 e 1.4), registrados na manobra, serão as variáveis de entrada no modelo;

3-) O modelo de simulação apresenta todas as características técnicas do veículo testado, as quais se destacam:

3.1-) Mapa de torque do motor (função de: rotação do motor, posicionamento da abertura da borboleta);

3.2-) Perfil da mola "Cushion" - que determinará o gradiente de transferência de torque do motor para a transmissão;

3.3-) Relações de 1ำ marcha e diferencial;

3.4-) Dimensão do pneu utilizado;

3.5-) Inércias dos componentes do trem de força;

3.6-) Massa e características aerodinâmicas;

4-) A partir dos dados de entrada e característica do veículo simulado, o modelo terá como resposta os seguintes parâmetros (teóricos):

4.1-) Espaço percorrido;

4.2-) Velocidade longitudinal;

4.3-) Aceleração longitudinal. 


\section{1-) Modelo Físico e Matemático Proposto}

Para fazer a previsão física e matemática do desempenho do veículo em manobras de arrancada em aclives elevados, apresenta-se o modelo desenvolvido na plataforma MatLab Simulink.

O principal objetivo deste modelo é representar com certo grau de precisão o desempenho do veículo em rampa, onde as principais respostas dadas pelo modelo são:

- Espaço percorrido pelo veículo;

- Velocidade desenvolvida pelo veículo;

- Aceleração longitudinal efetuada pelo veículo.

Além das respostas acima, é possível também estudar o fluxo de torque proveniente do motor às rodas e o comportamento das reações dos eixos dianteiros e traseiros durante a manobra dinâmica de saída em rampa. A Figura 59 mostra o modelo proposto:
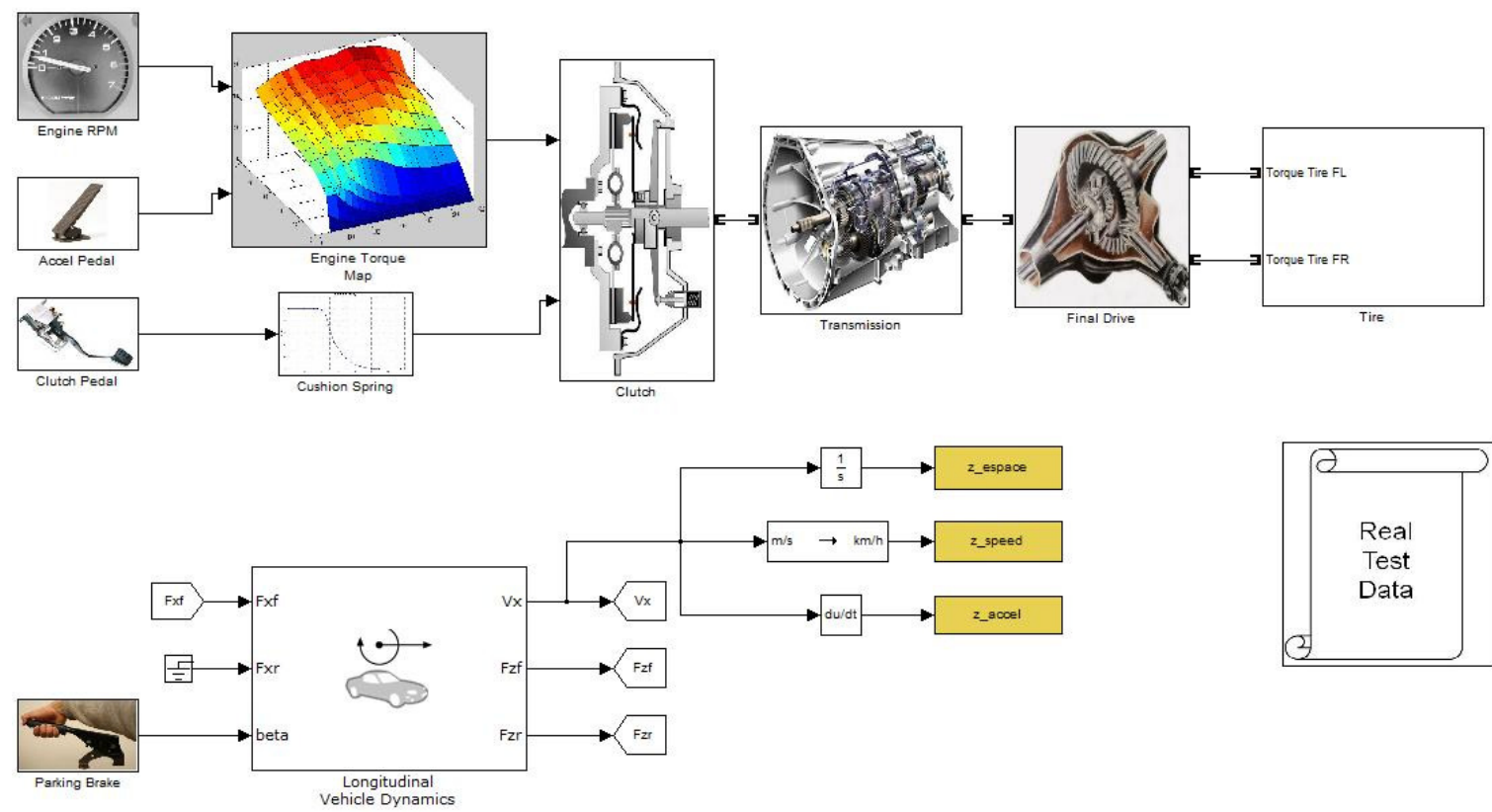

Figura 59: Modelo Matemático - Desempenho em Rampa (Programa Matlab Simulink) 
Para a elaboração deste modelo, foram utilizados blocos padrões ("tool boxes") disponíveis na biblioteca do Simulink, entre elas destacam-se Simscape / Simdriveline.

Como a proposta do modelo é validar a dinâmica da partida em rampa, os resultados da simulação são apresentados em função do tempo. Apresenta-se a seguir o descritivo de cálculo utilizado em cada parte da Figura 59.

\subsection{1-) Torque do Motor}

Em se tratando de uma manobra dinâmica, uma das entradas do modelo de simulação ocorre com os sinais de rotação do motor (em RPM) e posição do pedal do acelerador / borboleta (descrita em percentual) em função do tempo. Com estas duas informações, é possível determinar o torque instantâneo que será disponível para a embreagem.

A determinação do torque instantâneo é feita através da procura na tabela ("lookup table") do mapa de torque levantado para o motor em dinamômetro. Para vários pares (rotações do motor e posição da borboleta) determina-se o torque disponível no motor, onde os pontos do mapa do motor são medidos em condições estabilizadas. A Figura 60 mostra a determinação do torque instantâneo:
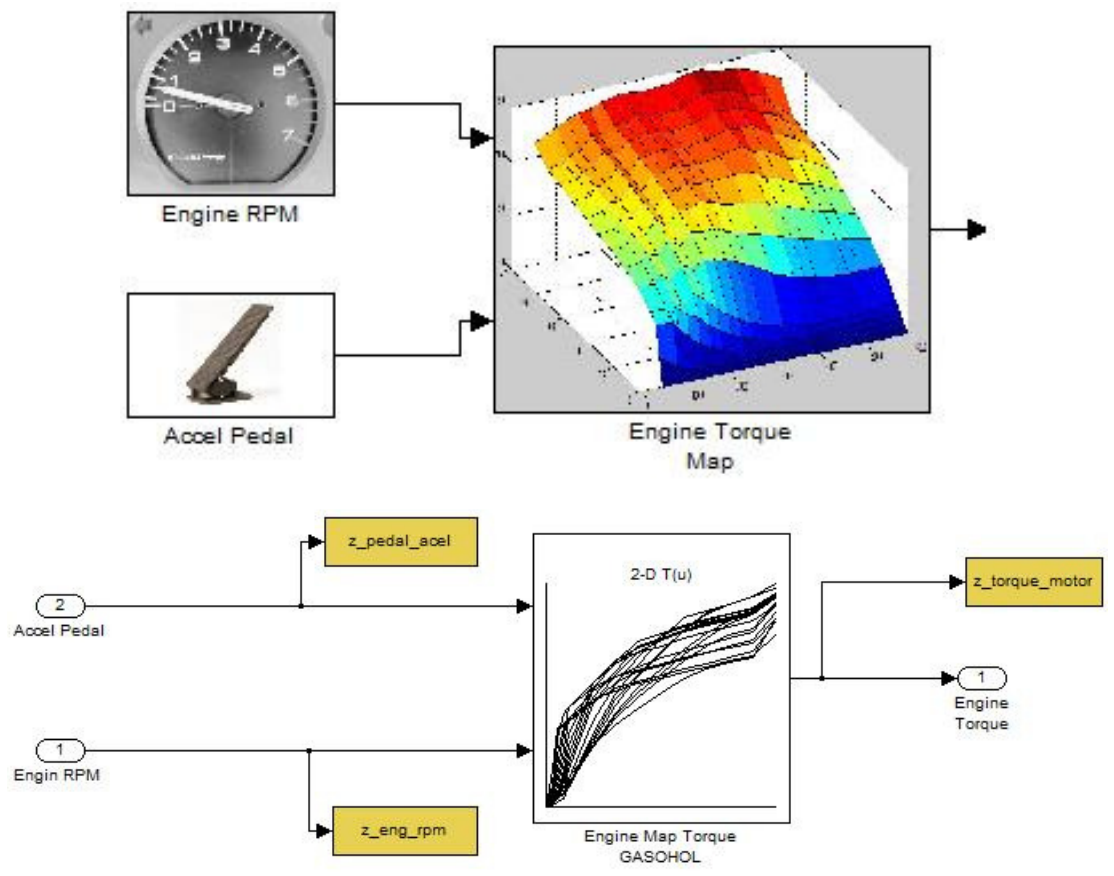

Figura 60: Determinação do torque instantâneo do motor (Programa Matlab Simulink) 


\subsection{2-) Embreagem}

Da mesma forma que a posição do pedal do acelerador, o curso do pedal de embreagem é também monitorado em função do tempo. Para a determinação do torque que entra na transmissão, o torque do motor obrigatoriamente passa pela embreagem, quando esta se encontra acoplada.

Nas manobras de saída de rampa é utilizada a modulação da embreagem e esta é representada no modelo através da mola "cushion". Esta mola é função da posição do pedal de embreagem e através de um "lookup table" determina-se a posição da mola "cushion", que por sua vez indicará quanto de torque será disponibilizado para a transmissão. A Figura 61 mostra o diagrama de bloco utilizado para representar a embreagem:
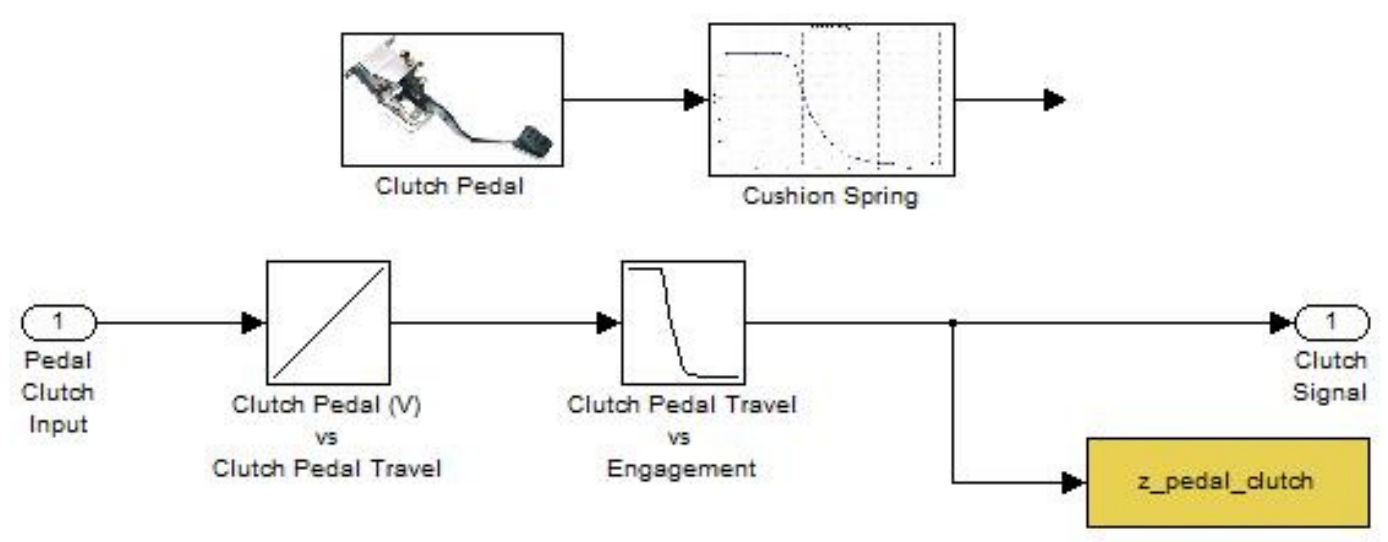

Figura 61: Representação do curso de pedal de embreagem e mola "cushion"

(Programa Matlab Simulink)

Uma vez que o par (rotação do motor e posição do acelerador / borboleta) determina um valor de torque instantâneo, o sinal deste torque se encontra com o sinal proveniente do posicionamento do pedal da embreagem, que por sua vez determina o percentual de acoplamento da embreagem (mola "cushion").

Com a combinação destes dois sinais, mais a introdução dos momentos de inércia do volante do motor e dos componentes da embreagem, determina-se o torque instantâneo que será disponibilizado para a transmissão.

A Figura 62 mostra o diagrama de blocos utilizado para a transmissão de torque da embreagem para a transmissão: 

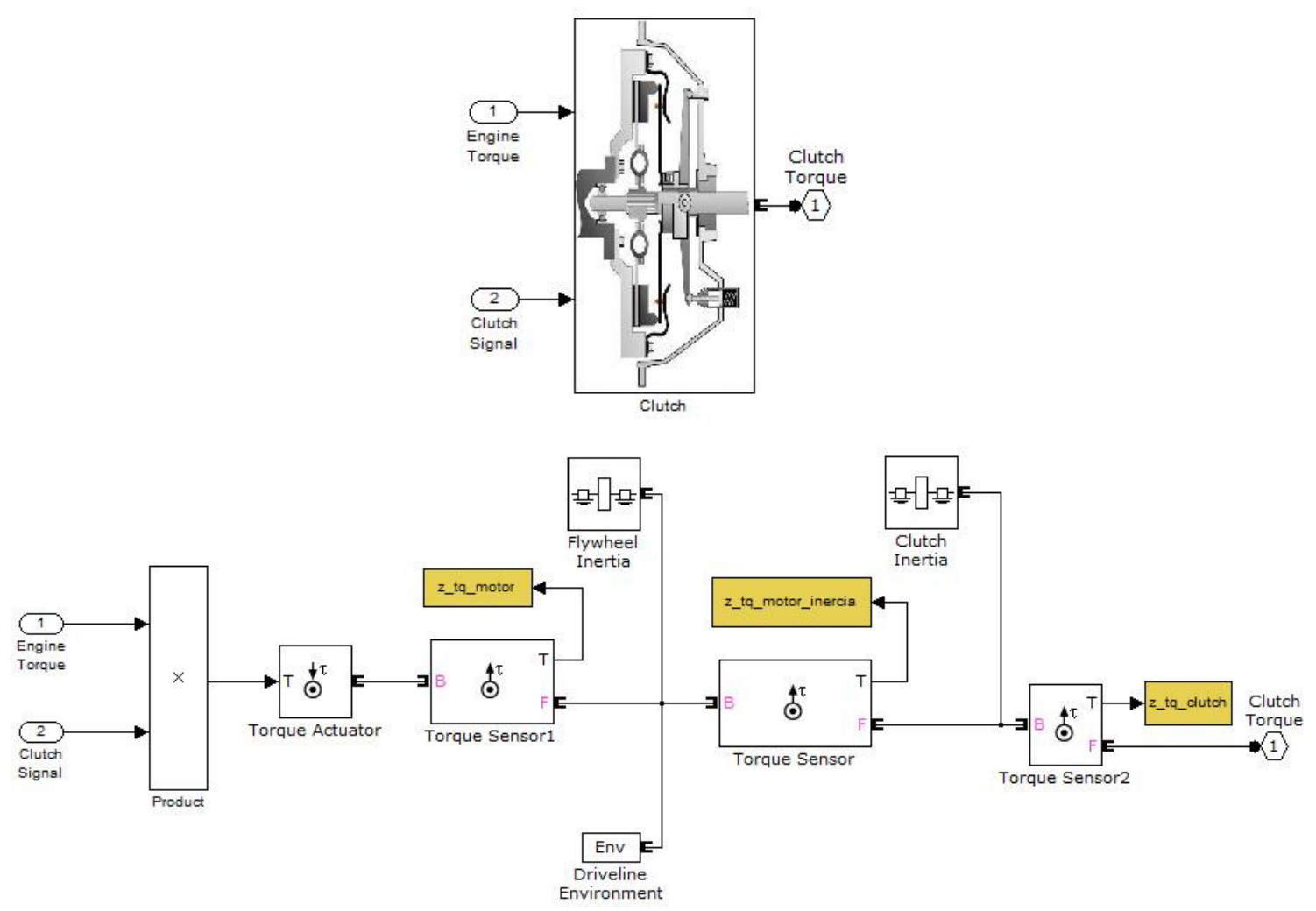

Figura 62: Representação do torque transmitido pela embreagem

(Programa Matlab Simulink)

\subsection{3-) Transmissão e Diferencial}

O torque líquido disponibilizado pela embreagem entra pelo eixo de entrada da transmissão e este torque é multiplicado pela relação de transmissão da marcha selecionada. Devido à variação da rotação angular da marcha selecionada, o momento de inércia dos componentes da marcha selecionada é também considerado no modelo.

Para manobras de arrancada em rampa, a primeira marcha é a que provêm o maior torque disponível para as rodas, que por sua vez é a que vai providenciar a maior força de tração nos pneus. Considerando-se isto, o modelo é desenvolvido para analisar o desempenho em arrancadas considerando a primeira marcha engatada.

Com a multiplicação do torque efetuado pela primeira marcha, o torque líquido da transmissão será multiplicado novamente pela relação final do diferencial. Considerando-se que o modelo foi desenvolvido para veículos de tração dianteira, o torque proveniente do diferencial será dividido de forma igualitária para os dois semi- 
eixos (lado direito e lado esquerdo), e este torque chegará até as rodas. No modelo é também considerado os momentos de inércia do conjunto de componentes das rodas e pneus.

A Figura 63 mostra o diagrama de blocos utilizado para simular o conjunto de transmissão e diferencial:
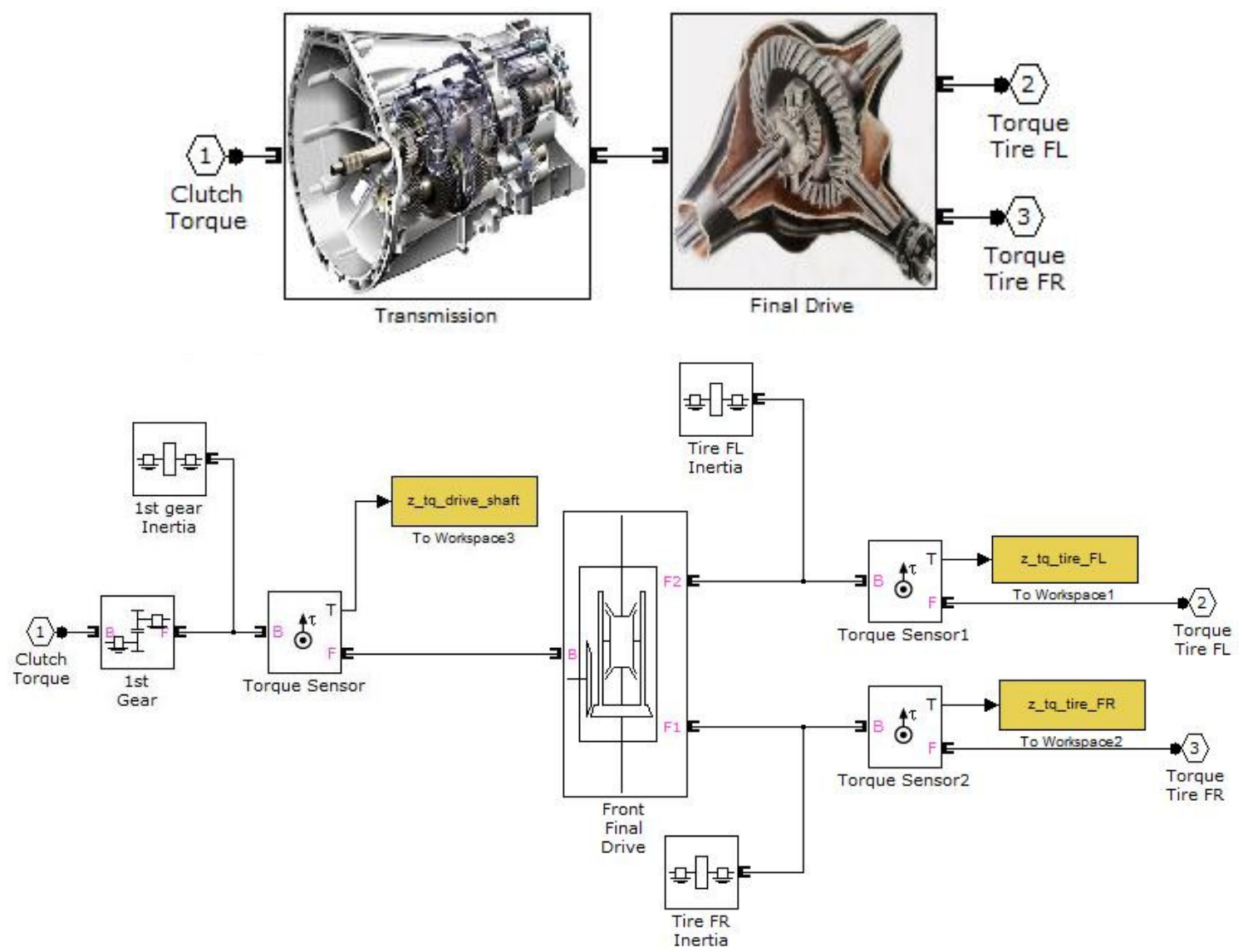

Figura 63: Representação do torque transmitido pela transmissão e diferencial para as rodas (Programa Matlab Simulink)

Desta forma, o torque líquido fornecido pelo diferencial aos semi-eixos fará o papel de fornecer a força de tração às rodas. Como o modelo de simulação é desenvolvido para veículos de tração dianteira, não há disponibilidade de torque para as rodas traseiras, sendo que estas são usadas como resistências ao movimento. 


\subsection{4-) Rodas e pneus}

Para a modelagem do comportamento da transferência de torque efetuada pelos pneus ao solo, é utilizado o bloco padrão do Simscape Tire. A partir do torque disponível pelo diferencial do veículo simulado de tração dianteira, este encontra cada uma das rodas direita e esquerda transferindo o torque instantâneo. As rodas do eixo traseiro funcionam como resistência ao rolamento e inércias rotativas e não contribuem ao movimento.

O diagrama de blocos utilizado para representar o pneu é uma combinação de um corpo flexível em contato com a estrada, onde inclui somente o movimento longitudinal. Na manobra de arrancada, onde o veículo desenvolve baixa velocidade, o pneu se comporta como uma mola deformável circular que faz parte da relação de transmissão total com o seu respectivo raio dinâmico.

A Figura 64 mostra os diagramas de blocos utilizados no modelo para representar as forças agindo no pneu:

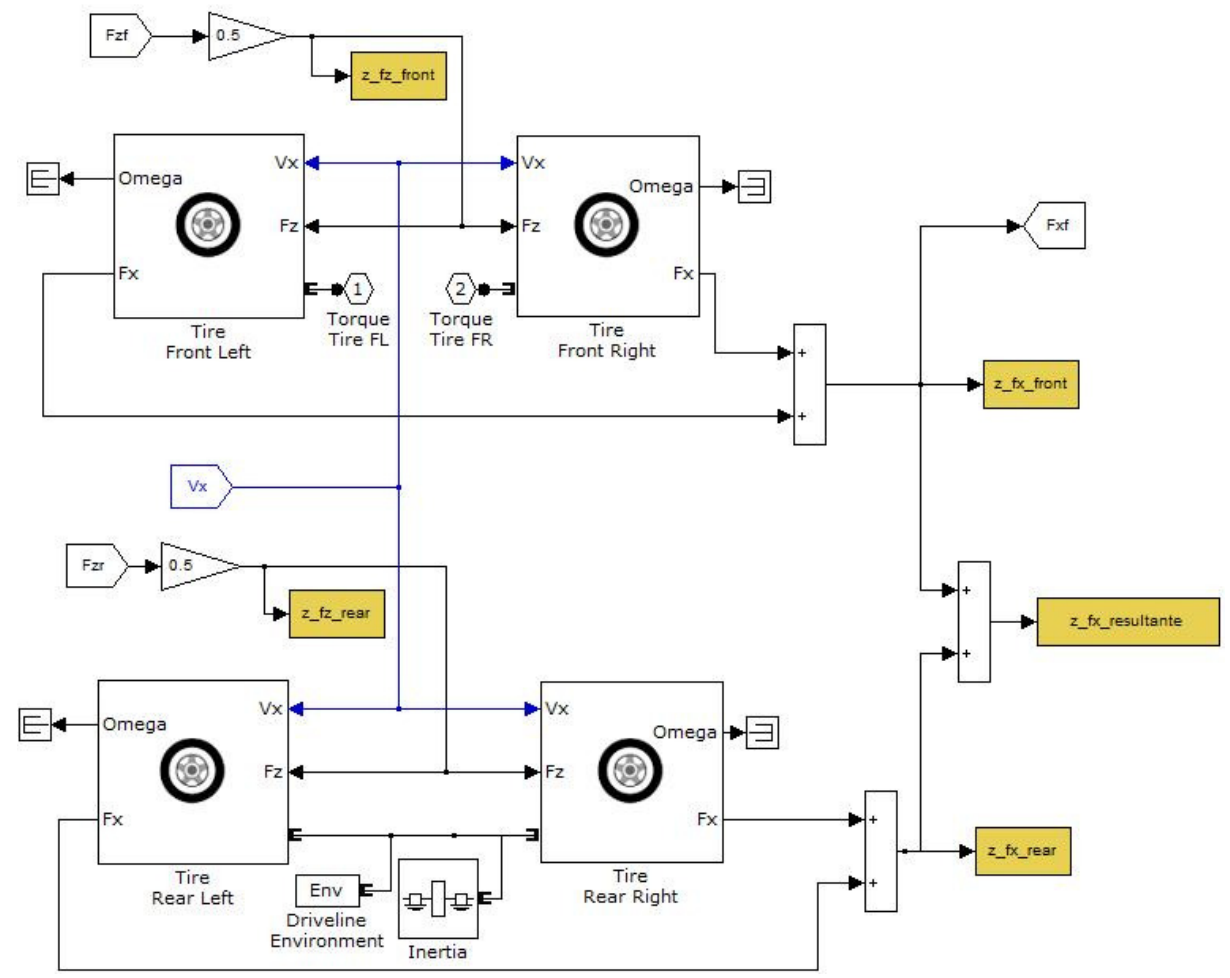

Figura 64: Representação do diagrama de blocos forças atuantes nos pneus (Programa Matlab Simulink) 


\subsection{5-) Veículo, controles e obstáculo}

Para finalizar a modelagem da partida em rampa, a força longitudinal proveniente do contato entre o pneu e o solo será responsável pelo movimento do veículo. Esta força terá que vencer todas as resistências ao movimento do veículo devido as suas características e a componente da força peso da inclinação da rampa (W.sen( $\alpha)$ ). A Figura 65 mostra as forças aplicadas ao veículo na manobra:

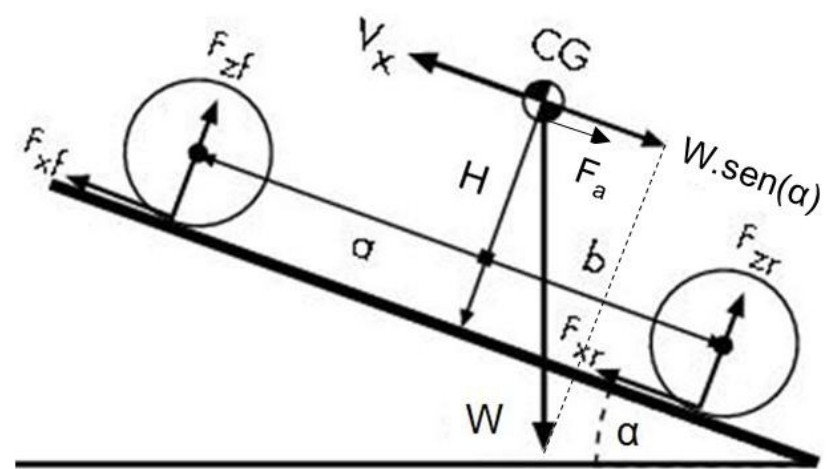

Figura 65: Forças aplicadas ao veículo na manobra de arrancada

Onde:

$\mathrm{V}_{\mathrm{x}}=$ Velocidade longitudinal do veículo;

$\mathrm{F}_{\mathrm{xf}}=$ Força de tração nas rodas dianteiras;

$F_{x r}=$ Força de tração nas rodas traseiras $\left(F_{x r}=0\right.$, veículo tração dianteira);

$\mathrm{F}_{\mathrm{zf}}=$ Reação no eixo dianteiro;

$\mathrm{F}_{\mathrm{zr}}=$ Reação no eixo traseiro;

a = distância do C.G ao eixo dianteiro;

b = distância do C.G ao eixo traseiro;

$\mathrm{H}=$ altura do centro de gravidade do veículo.

Além das informações acima, é necessário fornecer os dados de área frontal e coeficiente aerodinâmico para o cálculo da força de resistência do $\operatorname{ar}\left(F_{a}\right)$ e a massa do veículo "m" que será utilizada para a execução da manobra. As variáveis $V_{x}, F_{z f} e$ $\mathrm{F}_{\mathrm{zr}}$ são saídas do modelo de simulação. 
Com a saída da velocidade longitudinal do veículo, é possível obter o espaço percorrido e a sua aceleração longitudinal, os quais serão parâmetros para comparações com as medições em veículo real. Esta modelagem é ilustrada no diagrama de blocos da Figura 66:

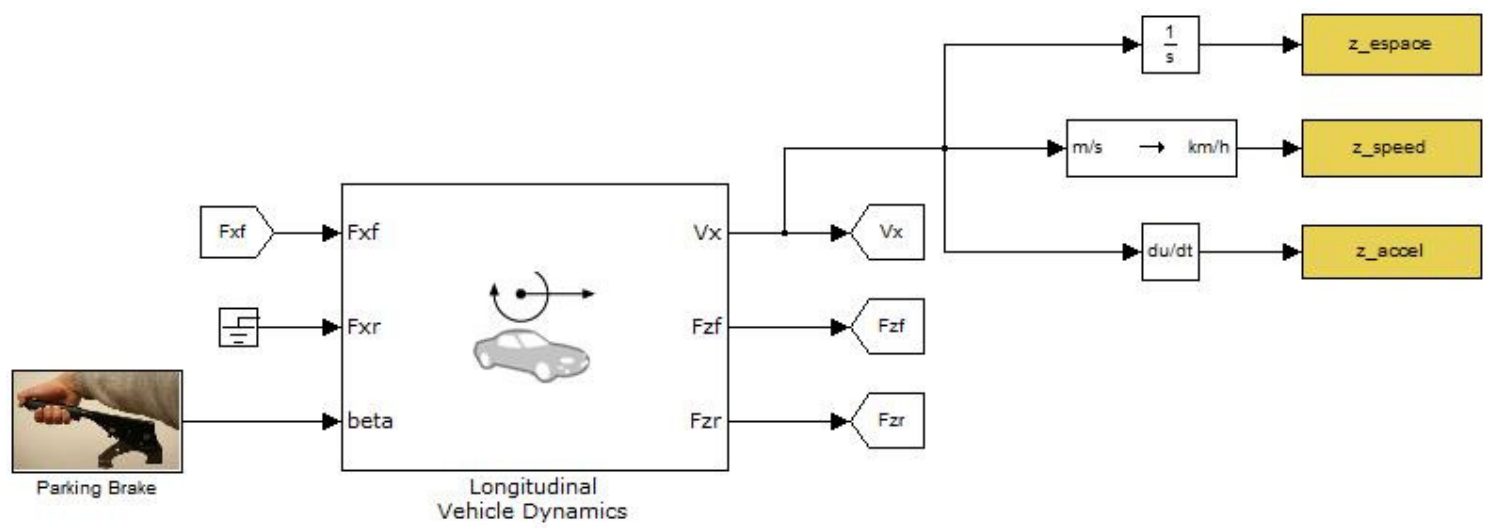

Figura 66: Diagrama de blocos representando veículo e a rampa

(Programa Matlab Simulink)

Como a proposta deste modelo é a partida em rampa a partir da imobilidade do veículo, o sinal de "Parking Brake" representado acima, indica o quanto de força longitudinal relativa à rampa é fornecido ao veículo. Isso significa que esta componente entrará em ação somente quando o freio de estacionamento estiver totalmente liberado.

Este sinal de "Parking Brake" está em função do tempo e ele varia de 0 a 1, e é responsável por fornecer o gradiente " $\alpha$ " no tempo, originando assim a resistência ao rolamento devido a rampa $(\mathrm{W} \cdot \operatorname{sen}(\alpha))$.

\section{2-) Possibilidades de aplicação}

O modelo em questão apresentado pode ser aplicado em qualquer veículo desde que seja de tração dianteira e de transmissão manual sem conversor de torque. No modelo pode-se obter o desempenho do veículo para qualquer gradiente de inclinação de rampa, onde é possível controlar de diferentes formas a maneira em que a manobra de saída em rampa é avaliada.

Esta ferramenta auxilia não somente se o veículo consegue cumprir a manobra de arrancada, muitas vezes avaliada subjetivamente, mas também no nível de aceleração que o veículo desenvolve em determinada condição de rampa. 


\section{3-) Veículo exemplo estudado}

O veículo estudado tem um motor 1.6L volume deslocado com tração dianteira e transmissão manual de cinco velocidades. A Tabela 2 mostra os dados técnicos do veículo exemplo estudado:

\begin{tabular}{|c|c|c|c|}
\hline Abreviatura & Descrição & Valor & Unidade \\
\hline$A_{f}$ & Área frontal do veículo & 2,38 & $\mathrm{~m}^{2}$ \\
\hline $\mathrm{cd}$ & Coeficiente de arrasto aerodinâmico & 0,415 & - \\
\hline $\mathrm{m}$ & Massa do veículo em ordem de marcha & 1208 & $\mathrm{~kg}$ \\
\hline m_teste & Massa de teste do veículo & 1344 & $\mathrm{~kg}$ \\
\hline pct_diant & Percentagem do peso no eixo dianteiro & 57,3 & $\%$ \\
\hline pct_tras & Percentagem do peso no eixo traseiro & 42,7 & $\%$ \\
\hline $\mathrm{C}$ & Comprimento máximo do veículo & 4228 & $\mathrm{~mm}$ \\
\hline I & Largura do veículo & 1980 & $\mathrm{~mm}$ \\
\hline L & Distância entre eixos & 2150 & $\mathrm{~mm}$ \\
\hline S & Bitola do veículo & 1734 & $\mathrm{~mm}$ \\
\hline Cx & Centro de Gravidade em relação ao eixo dianteiro & 918 & $\mathrm{~mm}$ \\
\hline $\mathrm{Cz}$ & Centro de Gravidade em relação ao solo & 640 & $\mathrm{~mm}$ \\
\hline i_1st & Relação de transmissão de primeira marcha & 3,846 & - \\
\hline i_fdr & Relação de transmissão do diferencial & 4,56 & - \\
\hline r_din & Raio dinâmico do pneu & 0,313 & $\mathrm{~m}$ \\
\hline rend_trans & Rendimento da transmissão & 87 & $\%$ \\
\hline I_engine & Inércia do Volante do Motor & 0,217 & $\mathrm{~kg} \cdot \mathrm{m}^{2}$ \\
\hline I_clutch & Inércia dos componentes da embreagem & 0,033 & $\mathrm{~kg} \cdot \mathrm{m}^{2}$ \\
\hline I_transm & Inércia dos componentes da transmissão & 0,043 & $\mathrm{~kg} \cdot \mathrm{m}^{2}$ \\
\hline I_driveline & Inércia dos semi-eixos, rodas e pneus dianteiros & 0,724 & $\mathrm{~kg} \cdot \mathrm{m}^{2}$ \\
\hline I_rodas_tra & Inércia dos pneus e rodas traseiras & 0,10 & $\mathrm{~kg} \cdot \mathrm{m}^{2}$ \\
\hline Motor & 1.6L Rocam Flex com gasolina & & \\
\hline Embreagem & Sachs - 200mm de diâmetro externo & & \\
\hline Pneu & Pirelli P4 - 205/65 R15 - 30 psi & & \\
\hline
\end{tabular}

Tabela 2: Dados técnicos do veículo exemplo estudado

Com a utilização dos dados técnicos do veículo no modelo de simulação, é analisado o desempenho do veículo na manobra de arrancada para se obter a 
correlação do modelo com o teste real em pista. São mostrados a seguir a descrição do teste real.

\section{4-) Descrição do experimento em campo}

\subsection{1-) Introdução}

O teste escolhido para fazer a correlação com o modelo de simulação é a arrancada em uma rampa com gradiente de $30 \%$ de inclinação ou $17^{\circ}$. A manobra de arrancada do veículo parte da imobilidade (velocidade inicial igual a $0 \mathrm{~km} / \mathrm{h}$ ).

\subsection{2-) Instrumentação usada no veículo real}

Para a execução dos testes físicos foram monitorados os seguintes componentes / características do veículo:

- Massa de teste: O teste foi feito com uma massa de $1344 \mathrm{~kg}$, o que equivale à massa do veículo em ordem de marcha com acréscimo de duas pessoas e as massas dos equipamentos;

- Velocidade do veículo: Com a instalação de um sensor ótico, foi medida a velocidade instantânea do veículo em uma taxa de aquisição de $125 \mathrm{~Hz}$. A Figura 67 mostra o sensor ótico utilizado Correvit DATRON modelo DC-UVT0534-195:

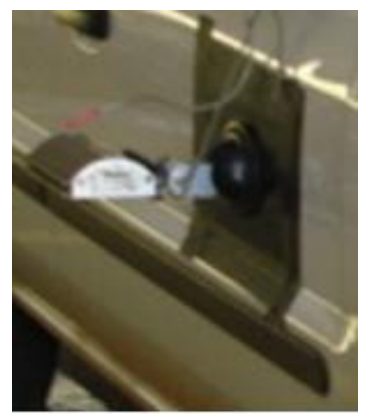

Figura 67: Sensor ótico de velocidade (Correvit DATRON) 
- Tacômetro: Foi monitorada a rotação instantânea do motor com uma taxa de aquisição de $125 \mathrm{~Hz}$. O equipamento utilizado foi Calibration Tool - Helios V10.

- Curso do pedal do acelerador: Foi monitorada a posição instantânea do curso do pedal do acelerador através da utilização de um transdutor de curso da marca Space Age modelo PN-160-1505-C6SS. A resposta do curso do pedal do acelerador, dada em $\mathrm{mm}$, é correlacionada com a abertura da válvula de admissão de ar do motor ("Borboleta"). Com o sensor registra-se a posição instantânea da "borboleta", também a uma taxa de $125 \mathrm{~Hz}$. A Figura 68 mostra a instrumentação do pedal do acelerador.
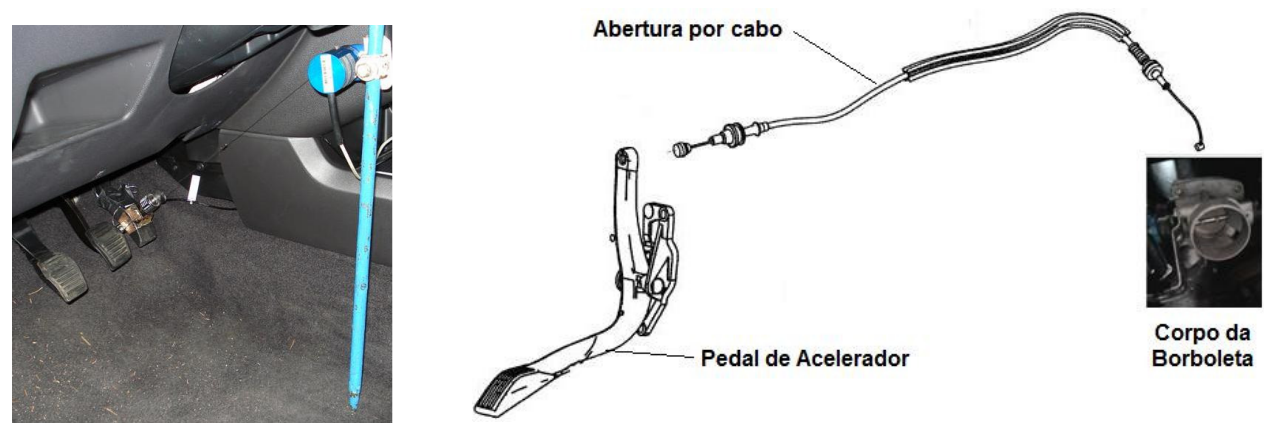

Figura 68: Monitoramento do curso de pedal de acelerador

- Curso do pedal de embreagem: Foi monitorada e obtida a posição instantânea do pedal de embreagem através da utilização do transdutor de curso Space Age modelo PN-160-1505-C6SS. O transdutor de curso foi utilizado para a determinação exata do pedal de embreagem, que por sua vez indicou o posicionamento da mola "cushion". A Figura 69 mostra a instrumentação do pedal de embreagem: 


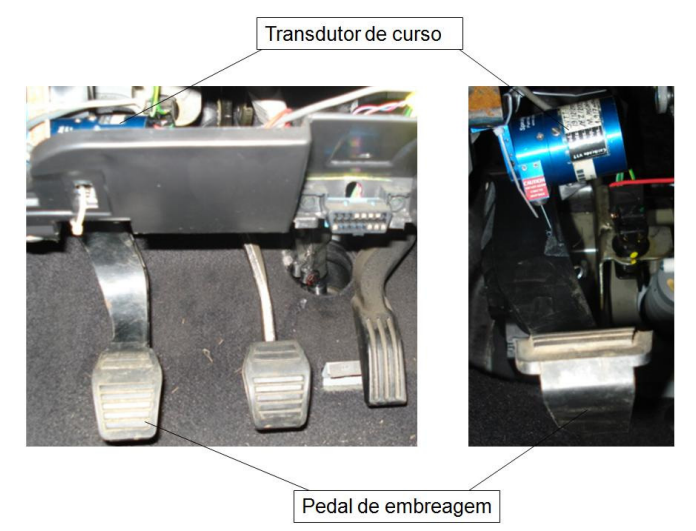

Figura 69: Monitoramento do curso do pedal de embreagem

- Curso da alavanca do freio do estacionamento: Para a execução da manobra de arrancada foi necessário fazer o uso da alavanca do freio de estacionamento. A alavanca do freio de estacionamento foi liberada gradativamente e de forma manual a partir do momento em que a embreagem começou a acoplar e o veículo dá início à transferência de torque para as rodas.

- Calibracão dos pneus: Os pneus foram calibrados de acordo com a recomendação do fabricante do veículo - 30 psi nos quatro pneus.

\subsection{3-) Operação do veículo}

Antes de começar o teste propriamente dito, foi necessário fazer um aquecimento do veículo de 10 minutos, com o veículo rodando em $4^{\circ} \mathrm{e} 5^{\circ}$ marchas a uma velocidade variável entre 80 e $100 \mathrm{~km} / \mathrm{h}$. Com o aquecimento do motor, aqueceram-se também os componentes do trem de força, pneus e rolamentos.

Feito o aquecimento do veículo e o ajuste de sua massa de teste, levou-se o mesmo para a rampa de $30 \%$ de inclinação. O veículo foi parado na região central da rampa, com o auxílio do freio de estacionamento. Neste momento, o veículo permaneceu parado na região central da rampa em rotação de marcha lenta, com a primeira marcha desengatada e o freio de estacionamento acionado.

Antes de dar início à manobra de arrancada, todos os sistemas de aquisições de dados foram ligados para registrar os dados provenientes do teste.

Feito isto, na eminência de começar a movimentar o veículo para frente, aplicou-se um conjunto de comandos necessários para esta manobra: 
1) Acionamento do pedal da embreagem (desacoplamento da embreagem do volante do motor);

2) Engate da primeira marcha;

3) Ainda com o pedal da embreagem acionado, buscou-se a rotação de saída do veículo com o pedal do acelerador, o qual se deu em torno de 3000 rpm;

4) Com a rotação relativamente estabilizada, começou-se o processo de acoplamento da embreagem, através da modulação gradativa do pedal da embreagem.

5) Com a modulação do pedal da embreagem, a rotação do motor cai até chegar à rotação de acoplamento total;

6) Neste ponto iniciou-se o processo conjunto de três ações realizadas ao mesmo tempo e de forma gradativa: liberação do freio de estacionamento; acoplamento total do pedal da embreagem (liberação total do pedal) e acionamento do pedal do acelerador para manter a velocidade do veículo contra a componente da força de resistência (rampa), que resiste ao seu movimento.

7) Conclui-se a manobra a partir do momento em que o veículo consegue atingir uma aceleração positiva e é capaz de manter uma velocidade no aclive, tornando assim uma evidência a capacidade do veículo cumprir a manobra de arrancada.

Foram feitos três repetições de saída na rampa de $30 \%$ e os dados registrados nos testes foram aplicados como parâmetros de entrada no modelo. A seguir são apresentados os resultados de um dos testes. 


\section{5-) RESULTADOS OBTIDOS}

Com a medição objetiva da manobra de arrancada na rampa, foram coletados todos os dados e estes analisados e tratados em planilha Excel e no MatLab.

A seguir, apresentam-se os dados levantados na manobra. As medições do comportamento do pedal do acelerador, do pedal da embreagem, do freio de estacionamento e da rotação do motor. Estes serão utilizados como fatores de entrada do modelo de simulação. As medições do espaço percorrido, velocidade e aceleração longitudinal do veículo serão utilizadas para a correlação do modelo.

\section{1-) Do Ensaio em Campo}

Os gráficos a seguir $(13,14$ e 15) mostram os dados levantados na medição real do veículo. O Gráfico 14 mostra o comportamento e progressão da abertura da borboleta no decorrer da manobra de arrancada na rampa de 30\% de inclinação:

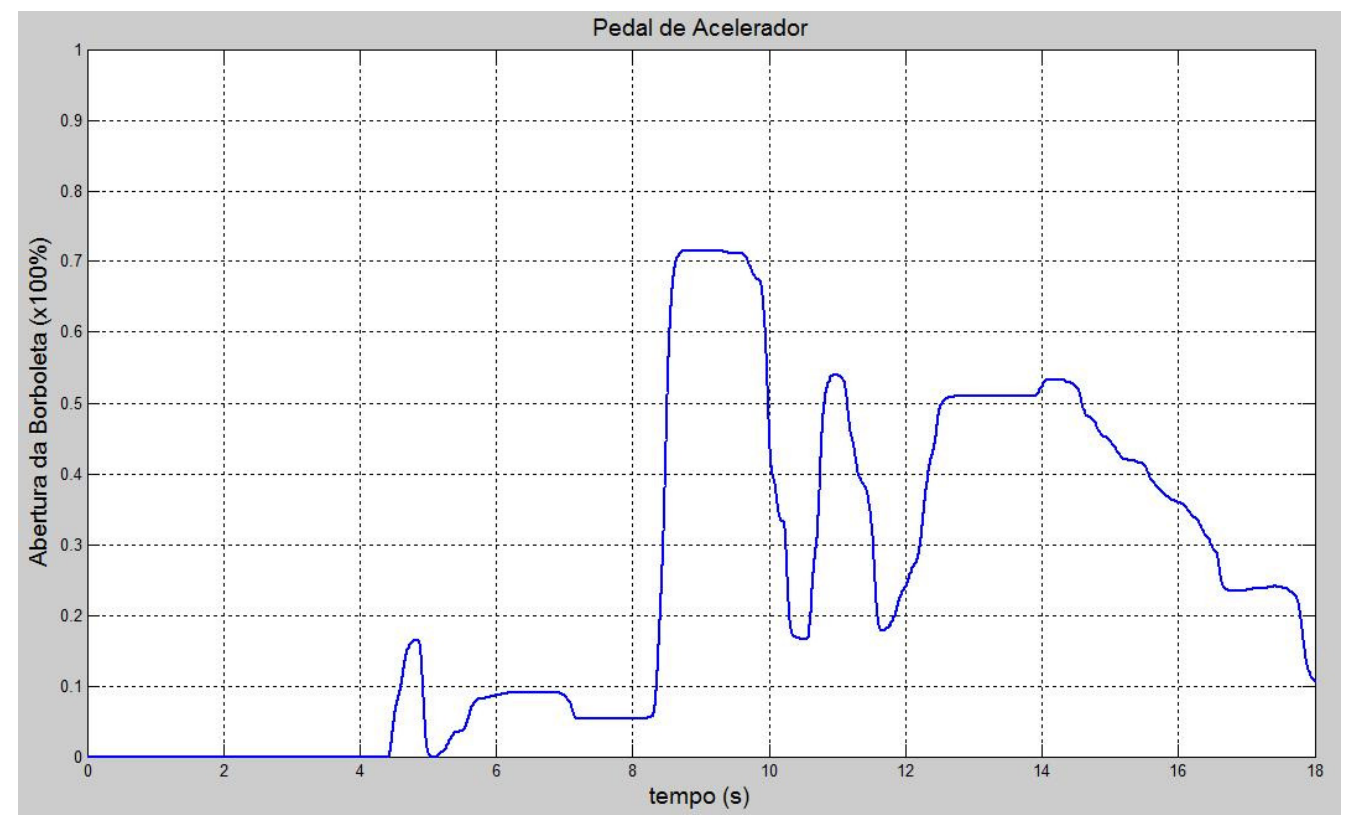

Gráfico 14: Progressão da abertura da borboleta

O Gráfico 15 mostra a variação da rotação do motor no decorrer da manobra de arrancada. Esta rotação é função do posicionamento da abertura da borboleta e do acoplamento de embreagem: 


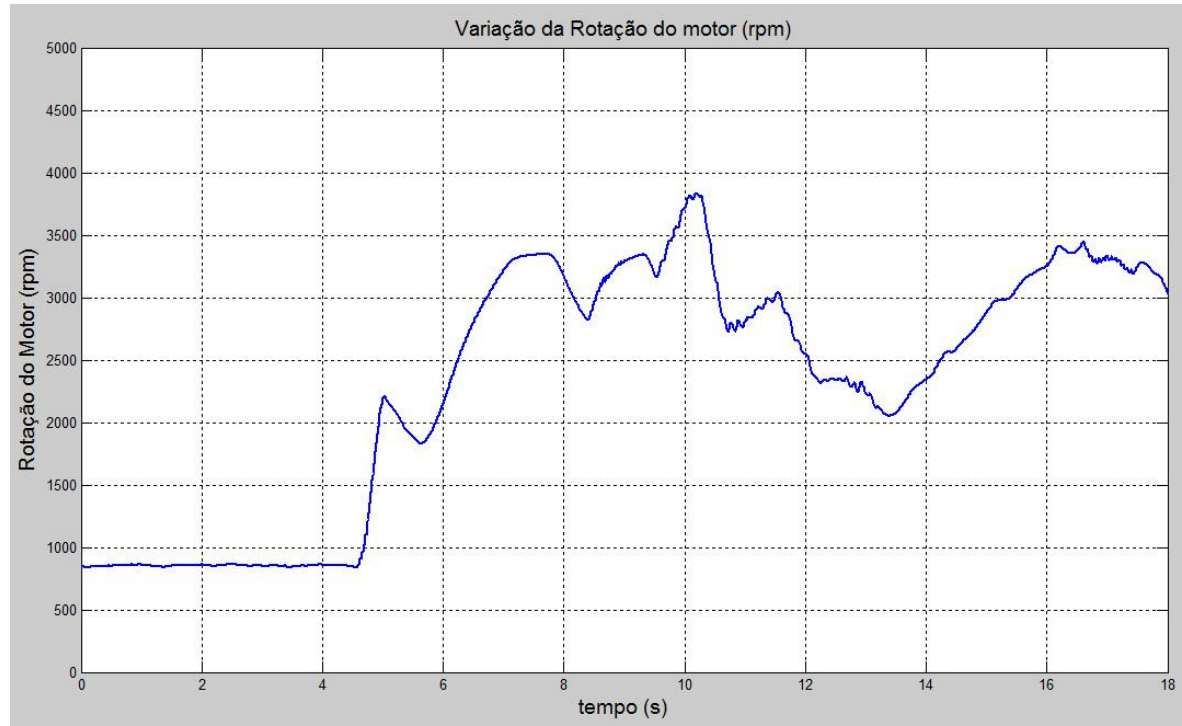

Gráfico 15: Variação da Rotação do motor

O Gráfico 16 mostra a progressão do acoplamento da embreagem no decorrer da manobra de arrancada:

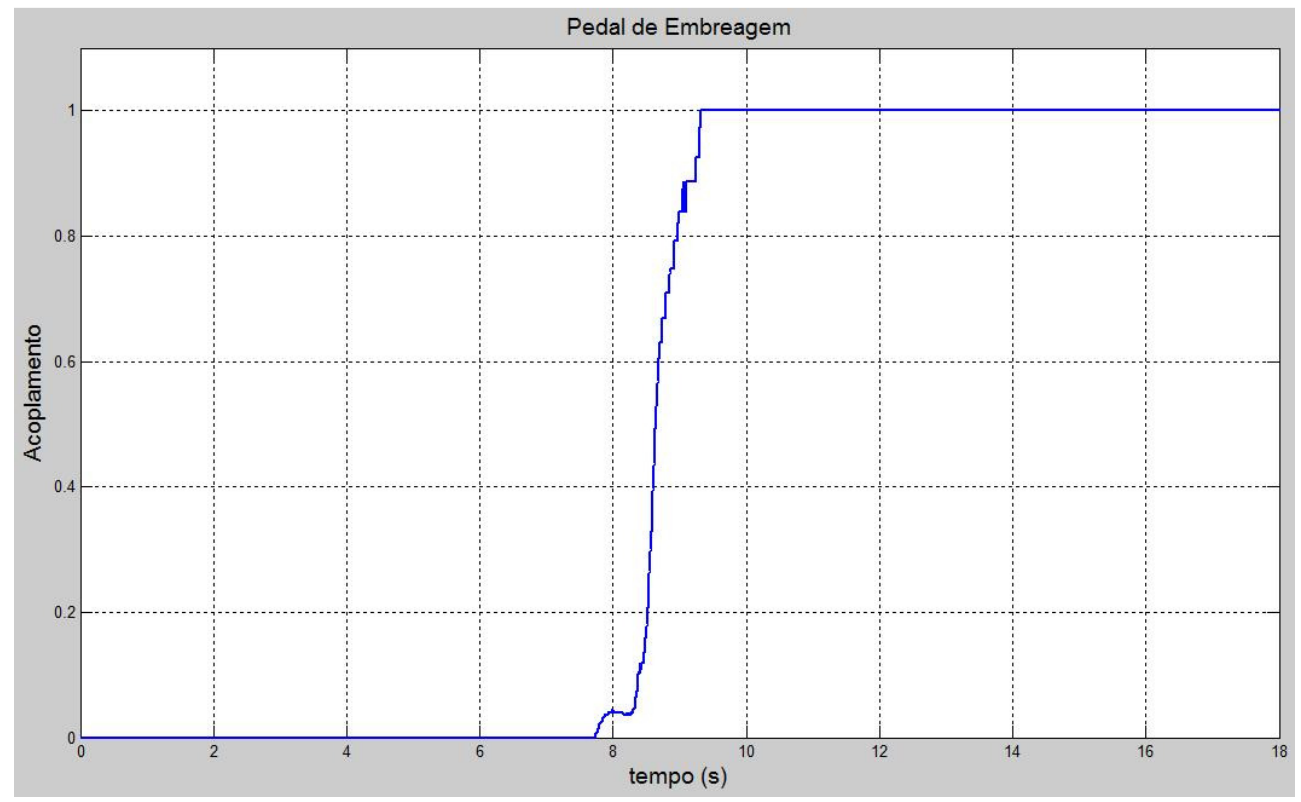

Gráfico 16: Progressão do acoplamento da embreagem

No Gráfico 16, o eixo Y representa a progressão do pedal de embreagem, onde: 0 = pedal da embreagem totalmente pressionado (embreagem desacoplada) e 1 = pedal da embreagem totalmente liberado (embreagem acoplada). 
O Gráfico 17 mostra a progressão da liberação do freio de estacionamento no decorrer da manobra:

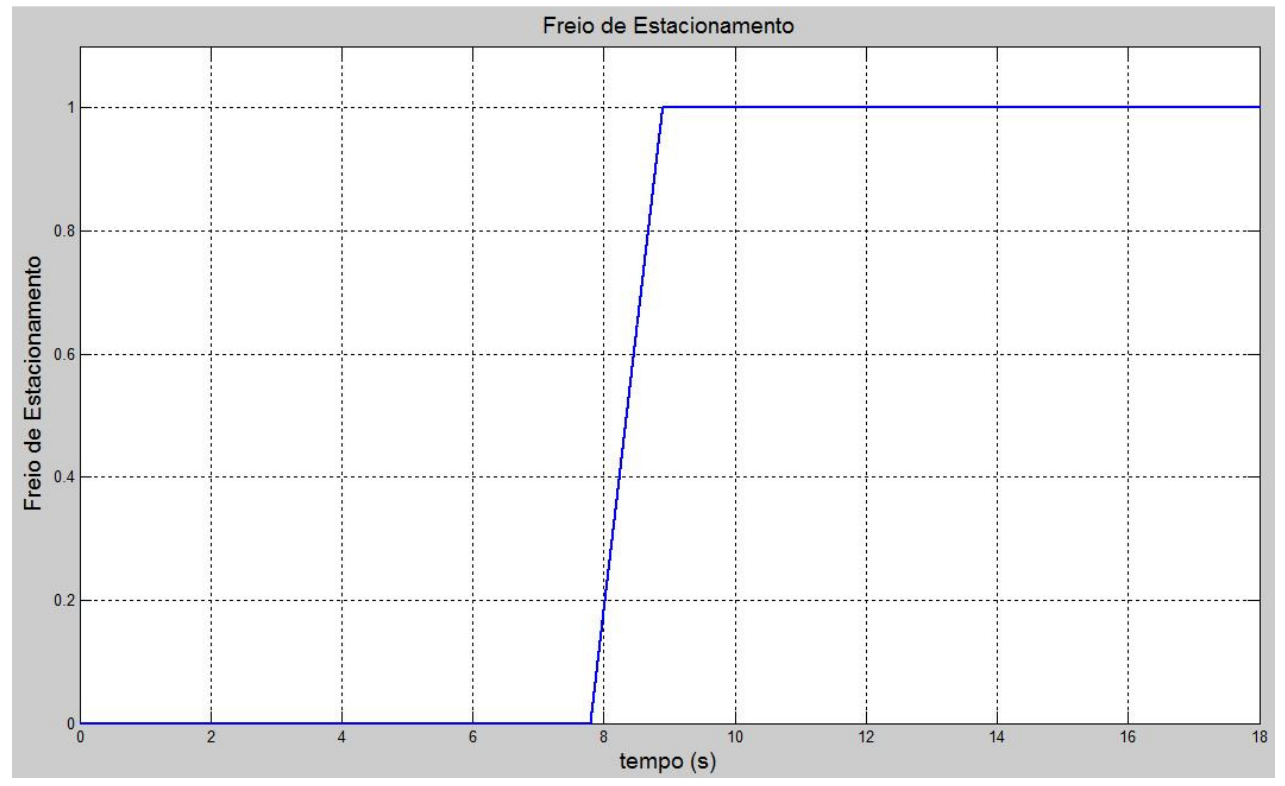

Gráfico 17: Liberação do freio de estacionamento

No Gráfico 17, o eixo Y representando a progressão da liberação do freio de estacionamento, onde: 0 = posição da alavanca de freio totalmente acionada (freio travado) e 1 = posição da alavanca de freio totalmente liberada (força devido ao gradiente de rampa, atuando no veículo).

O Gráfico 18 mostra a velocidade longitudinal desenvolvida pelo veículo e a velocidade tangencial da roda:

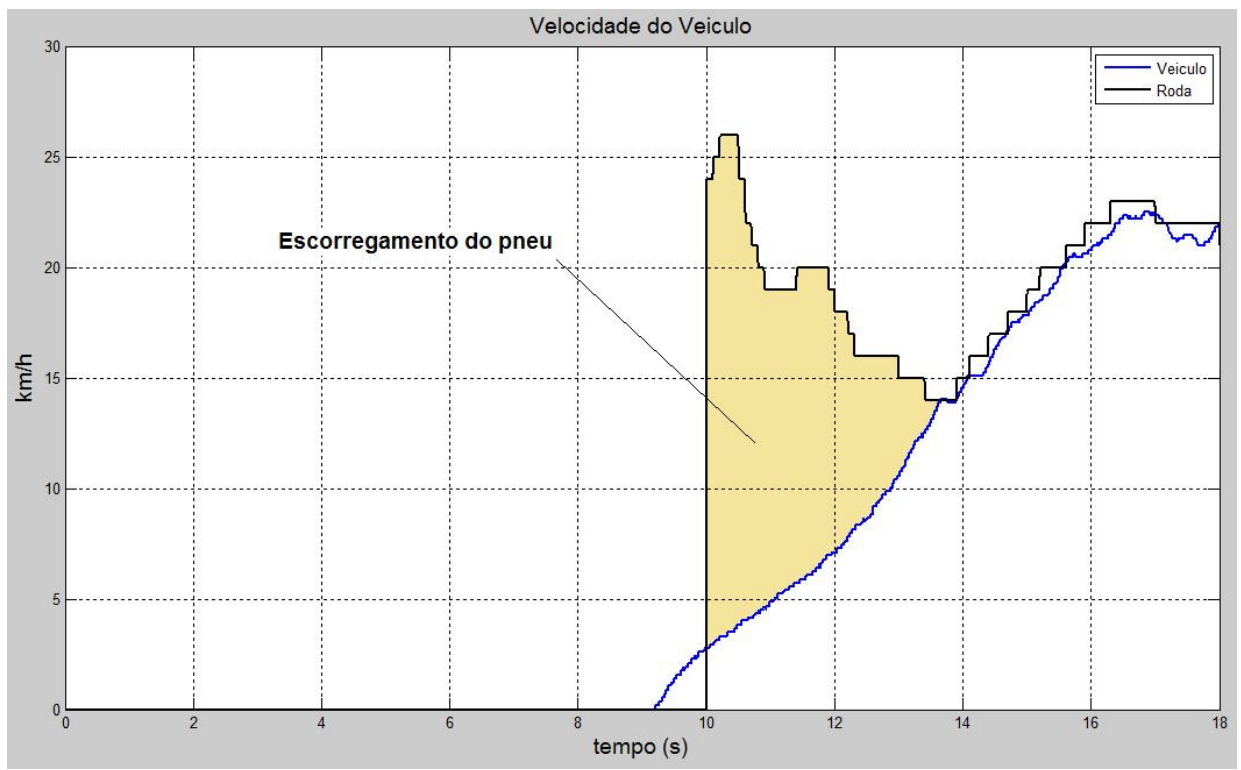

Gráfico 18: Velocidade longitudinal desenvolvida pelo veículo 
No Gráfico 18, a linha azul representa os dados extraídos da medição do correvit, onde foi captada a movimentação do veículo pelo sensor ótico. Já a linha preta, representa os dados provenientes do módulo de controle do veículo, captada pelos sensores de velocidade. Este último registrou o sinal que alimenta 0 velocímetro do painel do veículo, podendo assim verificar a velocidade tangencial da roda no instante inicial do movimento de arrancada.

A partir do sinal da velocidade instantânea do veículo, foi possível registrar o espaço percorrido e a variação da aceleração longitudinal do veículo, como mostra o Gráfico 19:
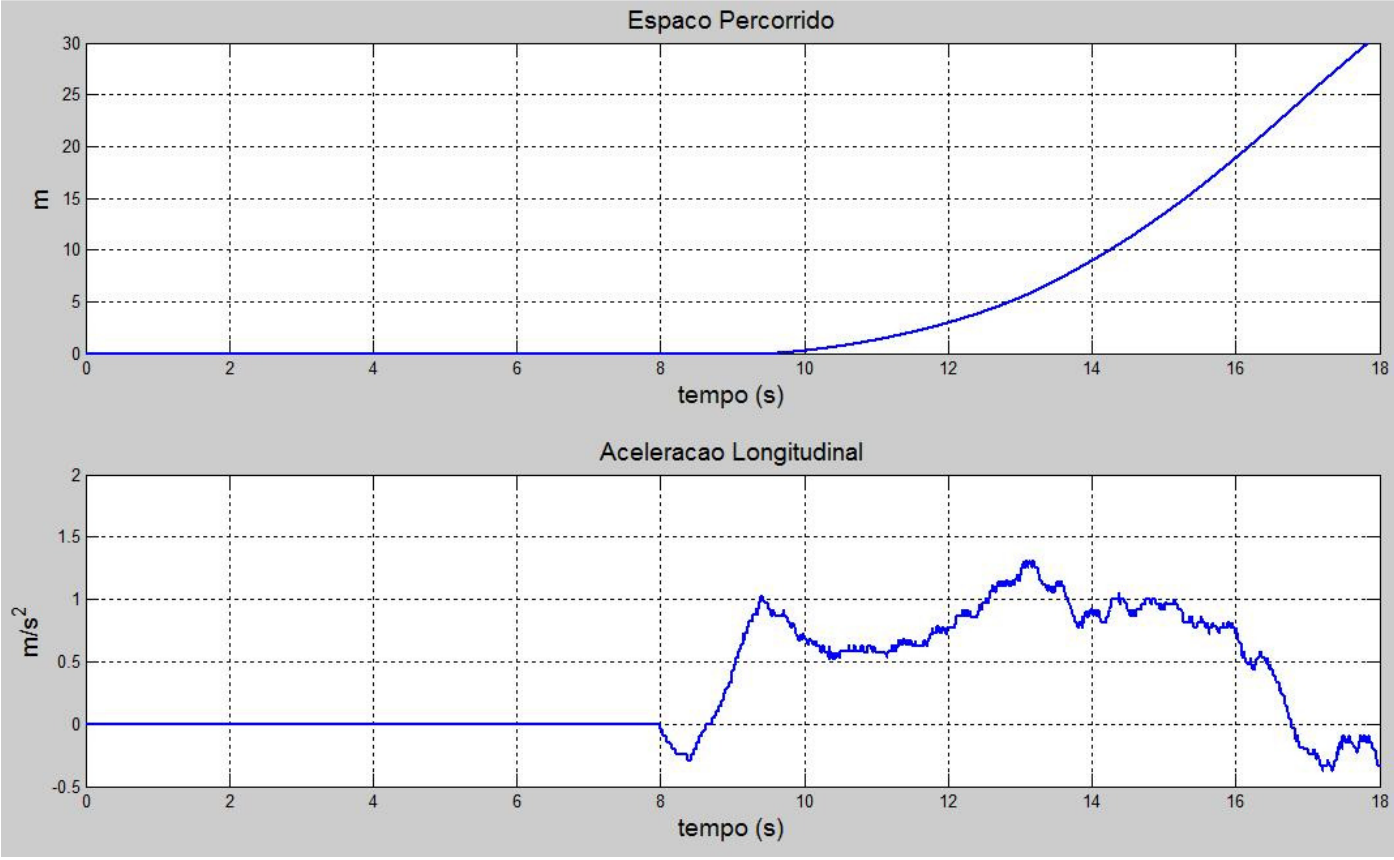

Gráfico 19: Espaço percorrido e aceleração longitudinal desenvolvida pelo veículo

Para melhor representar o gráfico da aceleração longitudinal do veículo foi aplicado um filtro passa baixa em seu sinal, proveniente da derivada da velocidade.

Conforme mencionado anteriormente, foram feitos 3 repetições de saída de aclive onde estas apresentaram características distintas. Para mostrar a correlação do modelo, foram escolhidos os dados de entrada acima para efetuar a correlação. 


\section{2-) Resultados do Modelo Teórico e programa de simulação}

Com a intenção de reproduzir os mesmos resultados de saída do veículo (espaço percorrido, velocidade e aceleração) para o teste em questão, foram utilizados os dados registrados na manobra e estes foram introduzidos como parâmetros de entrada no modelo de simulação. Mostra-se a seguir estes dados:

- A variação da rotação do motor;

- A variação do pedal do acelerador;

- A progressão do pedal de embreagem;

- A liberação do freio de estacionamento.

Colocando-se os parâmetros de entrada no modelo, foi possível gerar os gráficos para estudar a precisão dele. Apresenta-se a seguir os gráficos que foram obtidos com as aquisições levantadas na manobra.

O Gráfico 20 mostra os resultados obtidos a partir do modelo de simulação elaborado neste estudo. Sendo eles: variação da velocidade longitudinal do veículo e da velocidade tangencial da roda:

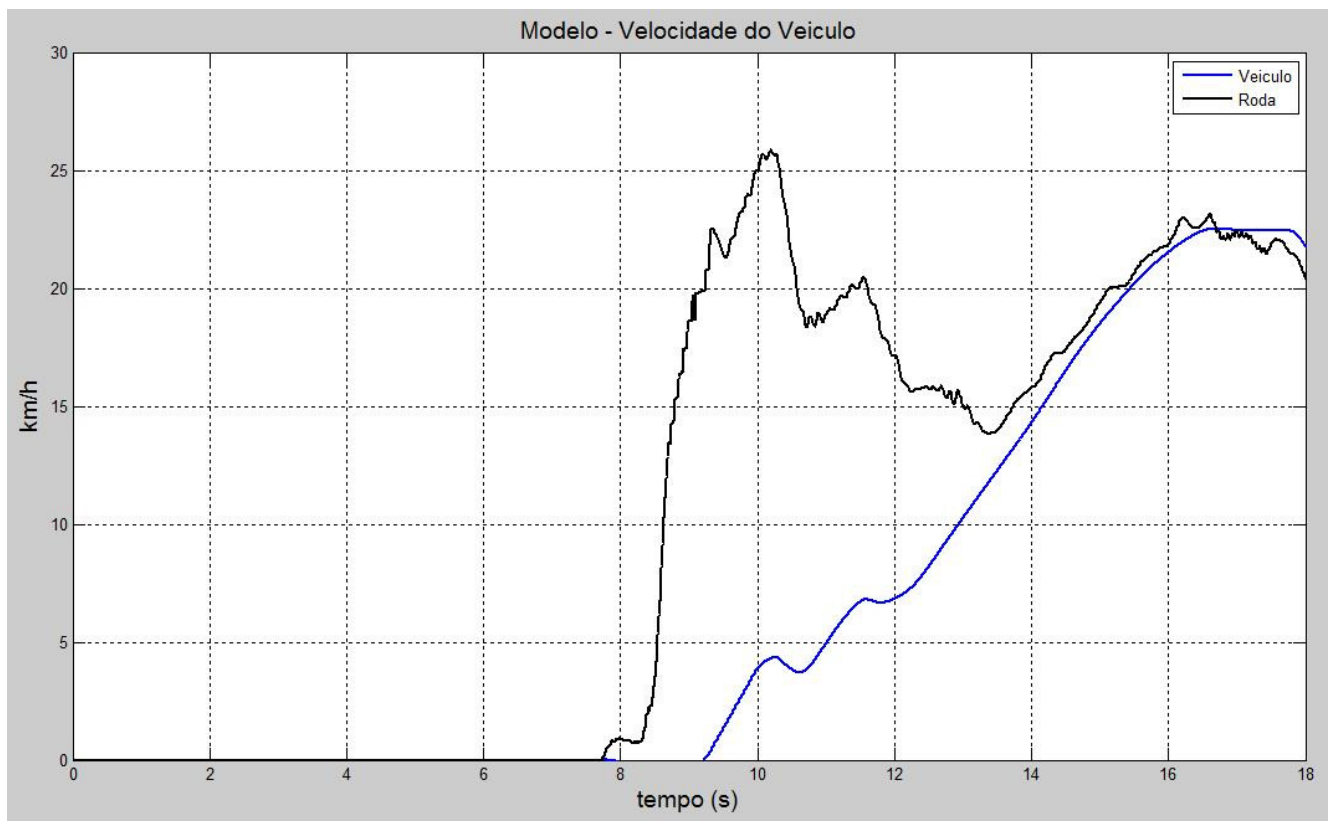

Gráfico 20: Resultado do Modelo - velocidade do veículo e tangencial da roda

O Gráfico 21 mostra o espaço percorrido e a aceleração longitudinal obtida pelo modelo de simulação: 

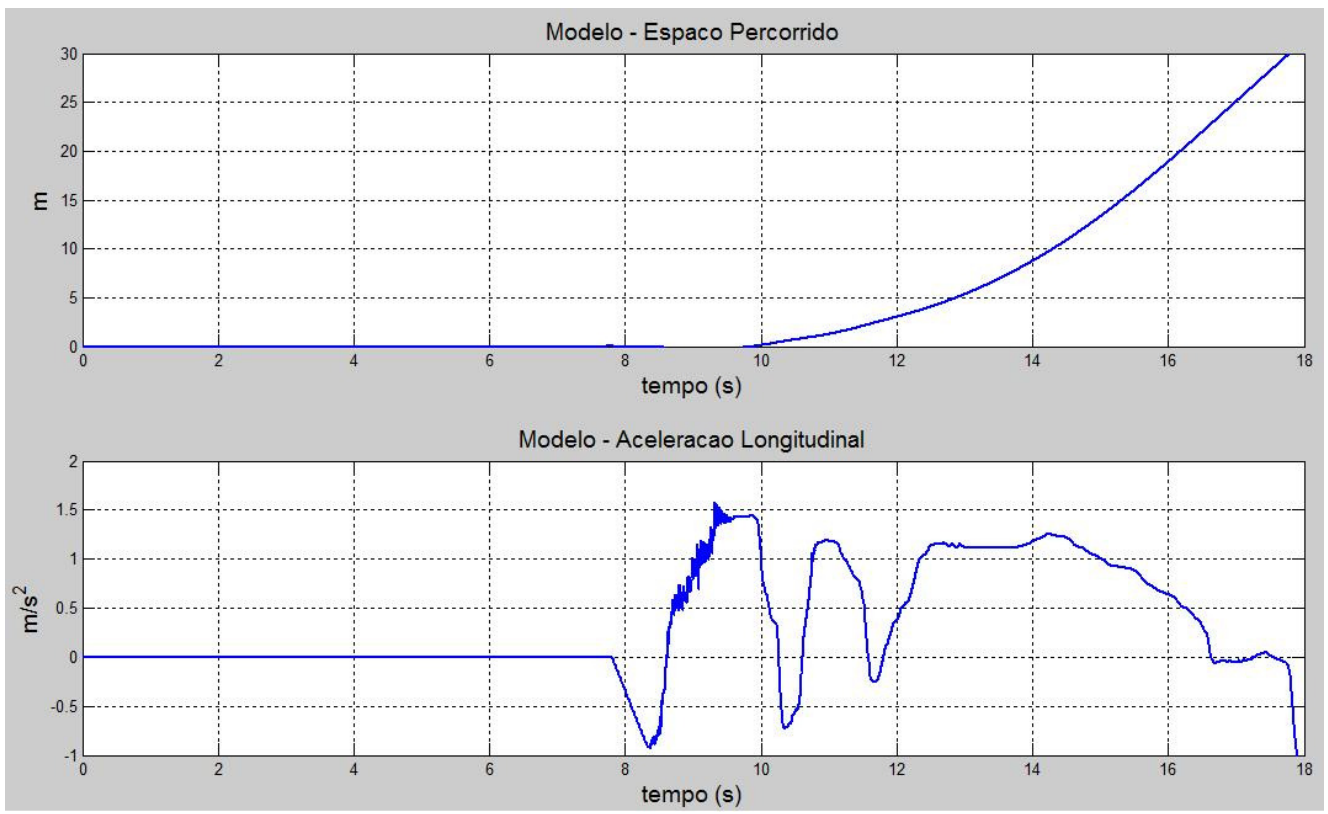

Gráfico 21: Resultado do modelo: Espaço percorrido e Aceleração longitudinal

O modelo de simulação em estudo permite elaborar outros gráficos importantes para a análise do desempenho do veículo em manobras de arrancada em aclives elevados. Apresentam-se a seguir alguns deles adicionais aos que foram extraídos do modelo de simulação:

O Gráfico 22 mostra como o torque disponível varia com a inércia do volante do motor e dos componentes da embreagem:

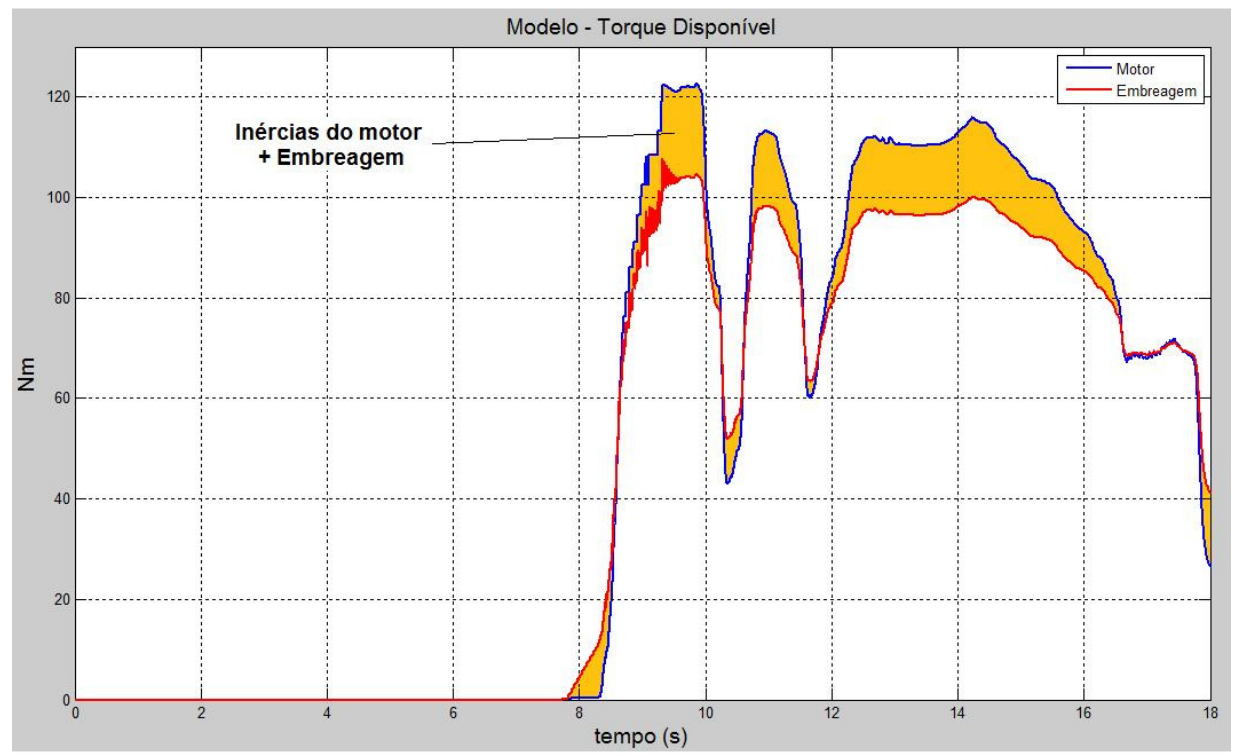

Gráfico 22: Efeito das inércias no torque disponível pela embreagem 
O Gráfico 23 representa a força de tração nas rodas do eixo dianteiro no decorrer da manobra:

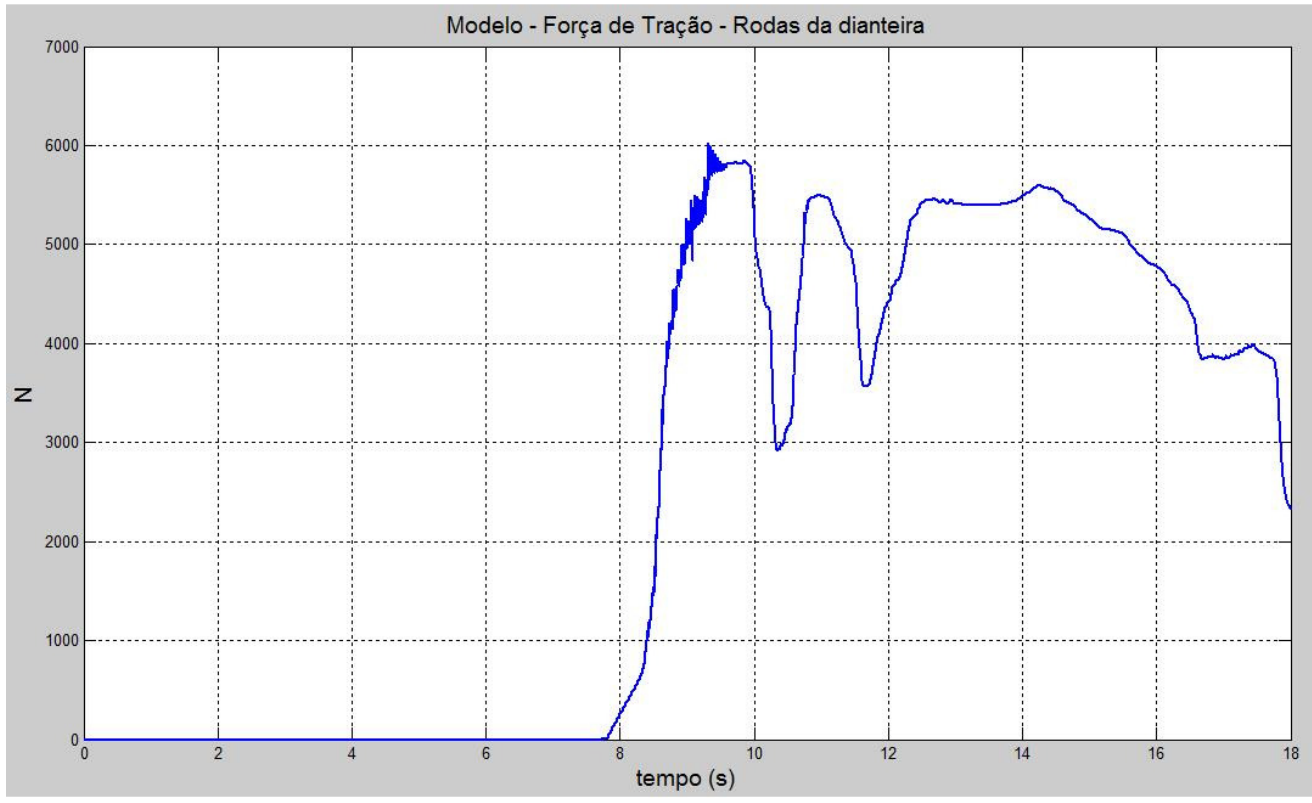

Gráfico 23: Força de tração das rodas dianteiras na manobra de arrancada

A partir do aplicativo do Simulink®, onde registra-se a força normal de cada eixo (dianteiro e traseiro), é possível levantar também o comportamento dessas forças normais no decorrer da manobra, conforme mostra o Gráfico 24:

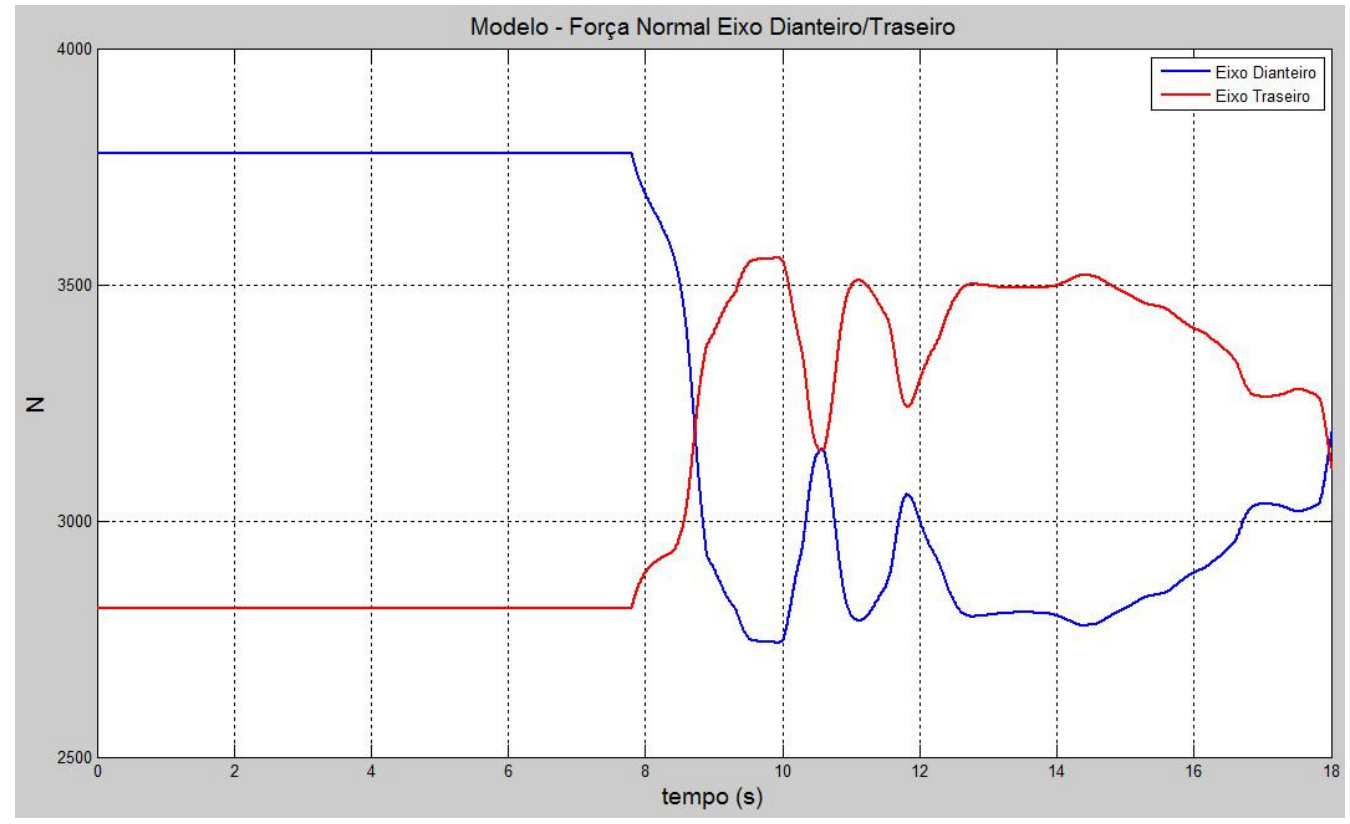

Gráfico 24: Forças Normais nos eixos dianteiro e traseiro 


\section{3-) Validação do Modelo}

O Gráfico 25 faz um comparativo das medições feitas no teste experimental e os resultados teóricos obtidos no modelo de simulação:

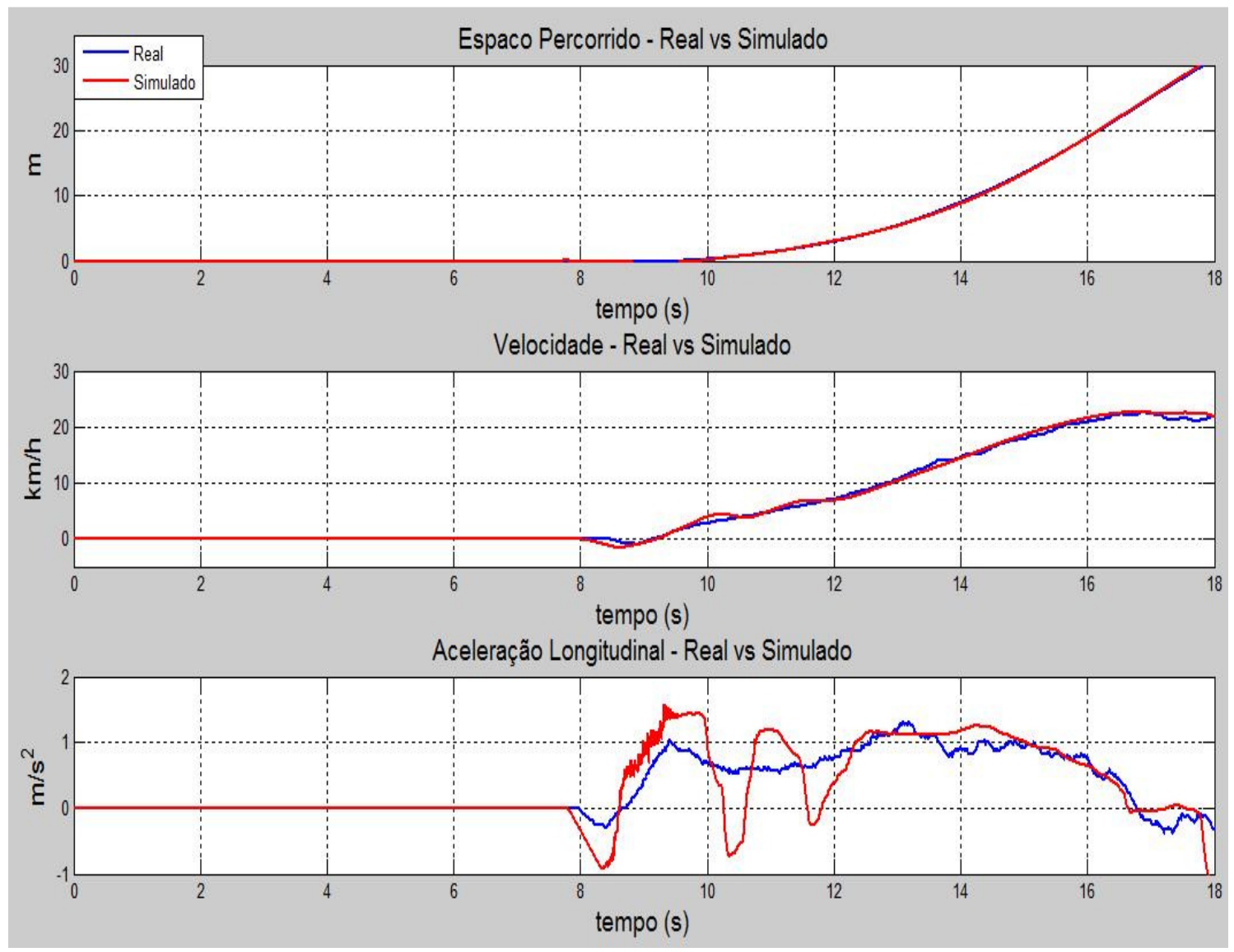

Gráfico 25: Comparativo entre os resultados reais e resultados do modelo

Analisando-se os resultados da comparação acima, pode-se comentar:

1. Espaço Percorrido: os resultados mostraram uma excelente correlação entre o modelo e a medição em veículo real.

2. Velocidade Longitudinal: A análise do gráfico permite afirmar que os dados provenientes do modelo representam com considerável precisão a dinâmica do movimento do veículo, obedecendo ao formato e a tendência da variação da velocidade longitudinal.

3. Aceleração Longitudinal: Esta foi obtida no modelo de simulação através da derivada da velocidade longitudinal. Ao derivar o sinal de velocidade, pequenas variações nesse sinal, são suficientes para causar grandes 
variações no sinal de aceleração. Apesar de aceleração apresentar alguns pontos fora da curva em relação à medição real, ela expressou com razoável precisão a intensidade da aceleração máxima desenvolvida pelo veículo.

Os gráficos de correlação apresentados foram suficientes para revelar que os dados provenientes do modelo de simulação estão bem próximos e coerentes aos de medição em pista, o que indica que esta metodologia e o modelo têm um bom potencial para serem utilizados na indústria automobilística. 


\section{6-) CONCLUSÃO}

O modelo matemático e o programa computacional desenvolvido apresentaram resultados próximos ao teste feito em veículo.

O programa é de fácil utilização e isto futuramente pode ser de grande valia para análises de o desempenho veicular em manobras de aclives elevados.

É extremamente interessante para o fabricante veículo possuir um estudo computacional para avaliar o desempenho do veículo e seus respectivos componentes em manobras severas em aclives elevados. Desta maneira, a utilização deste modelo pode contribuir tanto nas fases iniciais dos projetos, ajudando na melhor definição de seus componentes, bem como na melhoria de um projeto corrente.

Vale salientar também que além do modelo matemático proposto, este trabalho vem a contribuir para com uma metodologia de avaliação do veículo em aclives elevados. Para uma determinada condição de inclinação de aclive, é possível verificar qual é a máxima aceleração que o veículo pode desenvolver. Isso pode ser útil para o desenvolvimento de componentes, tais como: motor, embreagem, transmissão e pneus, que auxiliam na obtenção de um possível objetivo de aceleração para uma determinada condição de aclive.

Diversos gráficos são obtidos através do modelo de simulação, o que permite 0 estudo em diversas condições, o que auxilia o engenheiro automotivo e o projetista a definir os melhores componentes para atender os requerimentos necessários. Assim, o projeto veicular reduz o tempo necessário para a definição de seus sistemas e subsistemas, diminuindo os testes em pista e obviamente os custos envolvidos no desenvolvimento do projeto.

Portanto, através da utilização deste modelo matemático e da metodologia, é possível acessar em segundos o desempenho veicular para um determinado aclive e isso tem um potencial de tornar-se uma ferramenta muito importante para a avaliação deste atributo, bem como prover resultados analíticos capazes de servir como evidência para a tomada de decisão para um determinado projeto. 


\section{REFERÊNCIAS BIBILOGRÁFICAS}

A.L.A.P.A. Manual de Normas Tecnicas. In: A.L.A.P.A Manual de Normas

Tecnicas. São Paulo: [s.n.], 2003. Cap. 1, p. 22-23.

ANDREW, D. et al. A Co-Simulation Environment for Virtual Prototyping of Ground Vehicles. SAE TECHNICAL PAPER SERIES, n. SAE 2007-01-4250, 2007.

ANFAVEA. Anuário da Industria Automobilística. [S.I.]. 2008.

ARGACHOY, C. Transmissão I: Sistema de Embreagem Caixa de Transmissão. In: ARGACHOY, C. Transmissão I: Sistema de Embreagem Caixa de Transmissão. [S.I.]: [s.n.], 2004. p. 1-25; 91-93.

AUTOMOTIVE Design. Automotive Design, 2010. Disponivel em: <http://en.wikipedia.org/wiki/Vehicle_design>. Acesso em: 25 Abril 2010.

BALL, J. K.; STONE, R. Automotive Engineering Fundamentals. In: BALL, J. K.; STONE, R. Automotive Engineering Fundamentals. [S.I.]: SAE International, 2004. Cap. 1, p. 16 ; 238-240; 243-253; 290-292; 426-433; 436-437.

BW95. Wikipedia - The Free Encyclopedia, 2010. Disponivel em: <http://en.wikipedia.org/wiki/Grade_(slope)>. Acesso em: 20 Junho 2010.

CANALE, A. C. Automobilística Dinâmica e Desempenho. In: CANALE, A. C. Automobilística Dinâmica e Desempenho. São Paulo: Livros Érica Editora LTDA, 1989. Cap. 1; 2, p. 17-20; 31-35.

CLUTCHES_N_MORE. Clutches N More web Site, 2010. Disponivel em: $<$ http://www.clutchesnmore.com/howitallworks/>. Acesso em: 14 Junho 2010.

COSTA, P. G., 2001-2002. Disponivel em: $<$ http://www.oficinaecia.com.br/bibliadocarro/biblia.asp?status=visualizar\&cod=91>. Acesso em: 16 Junho 2010.

DATTA, G.; SINAN, K. Automotive Powertrain Modeling, Simulation and Control Using Integrated System's CASE Tools. SAE TECHNICAL PAPER SERIES, 1994. ISSN SAE 940180.

DREXL, H. J. Motor Vehicle Clutches - Function and Design. In: DREXL, H. J. Motor Vehicle Clutches - Function and Design. Segunda Edição. ed. [S.I.]: Landsberg/Lech: Verl. Moderne Industrie, 1998. p. 4-8; 22-24.

ECKERMANN, E. Wikipedia - The Free Encyclopedia. Disponivel em: <http://en.wikipedia.org/wiki/History_of_the_automobile>. Acesso em: 25 Abril 2010.

EULER, L. Wikipedia The free Encyclopedia, 1765. ISSN ISBN 978-1429742818.. Disponivel em: <http://en.wikipedia.org/wiki/Moment_of_inertia>. Acesso em: 5 Junho 2010. 
GAO, Y. et al. Investigation of Proper Motor Drive Characteristics for Military Vehicle Propulsion. SAE TECHNICAL PAPER SERIES, n. SAE 2003-01-2296, 2003.

GARCIA, O.; BRUNETTI, F. Motores de Combustão Interna. In: GARCIA, O.;

BRUNETTI, F. Motores de Combustão Interna. 2nd Edition. ed. São Paulo: [s.n.], 1992. Cap. 1; 3, p. 1-7; 32-38;82-91;106-111.

GILLESPIE, T. D. Fundamentals of Vehicle Dynamics. In: GILLESPIE, T. D.

Fundamentals of Vehicle Dynamics. 1st Edition. ed. [S.I.]: SAE International, 1992. p. 335-374.

HEYWOOD, J. B. Internal Combustion Engine Fundamentals. In: HEYWOOD, J. B. Internal Combustion Engine Fundamentals. [S.I.]: [s.n.], 1988. p. XVII; 9-11; 4251.

HOW Stuff Works, 1998-2010. Disponivel em:

<http://auto.howstuffworks.com/engine1.htm>. Acesso em: 4 Março 2010.

HOW Stuff Works, 1998-2010. Disponivel em:

<http://auto.howstuffworks.com/transmission3.htm>. Acesso em: 18 Junho 2010.

HWANG, D. N. Fundamental Parameters of Vehicle Fuel Economy and Acceleration. SAE TECHNICAL PAPER SERIES, n. SAE 690541.

MANOZ, K. et al. Optimization of a Manual Transmission Gear Ratio for a Small Cargo Carrier using Statistic Based Simulation Techniques. Society of Automotive Engineers of Japan, n. SAE 20056520/2005-32001, 2005.

MASATOSHI, A. et al. Development of a New Hybrid Transmission for RWD Car. SAE TECHNICAL PAPER SERIES, n. SAE 2006-01-1339, Abril 2006.

MENCIK, Z.; TOBLER, W. E.; BLUMBERG, P. N. Simulation of Wide-Open Throttle Vehicle Performance. SAE TECHNICAL PAPER SERIES, 1978. ISSN SAE 780289.

MICHAEL, B. Uncommon knowledge Automotive Plataform Sharing's Potential Impacts on Advanced Technologies. SAMPE -. Detroit, Michigan: Hypercar, Inc. 1999.

MICHAEL, P.; JOHN, S. Nonlinear Vehicle Performance Simulation with Test Correlation and Sensitivity Analysis. SAE TECHNICAL PAPER SERIES, n. SAE 960521, 1996.

MOHAMED, E.-S.; DONG, S. Automotive Performance Optimization. SAE TECHNICAL PAPER SERIES, 1998. ISSN SAE 980825.

MUFFATTO, M. Introducing a platform strategy in product development. International Journal of Production Economics, p. 145-153, Abril 1999. 
NEWTON, I. Mathematical Principles of Natural Philosophy. In: NEWTON, I.

Mathematical Principles of Natural Philosophy. 1st American Edition. ed. Nova York: [s.n.], 1846. p. 72.

PASIANOT, E. São Paulo Grades. São Paulo. 2006.

QUAN, Z.; KRISHNASWAMY, S. Transmission Clutch Pressure Control System: Modeling, Controller Development and Implementation. SAE TECHNICAL PAPER SERIES, n. SAE 2000-01-1149, 2000.

RAFAEL, L. et al. Software for Vehicles Propulsion Systems Calculation. SAE TECHNICAL PAPER SERIES, n. SAE 2007-01-2618, 2007.

REMPEI, M. et al. Development of a Front-Wheel-Drive Car. SAE TECHNICAL PAPER SERIES, n. SAE 770803, 1977.

SCHLIE, E.; YIP, G. Regional follows global strategy mixes in the world automotive industry. European Management Journal , p. 343-354, Agosto 2000.

SETZ, H. L. Computer Predicts Car Acceleration. SAE Transactions, v. 69, p. 351359, 1961.

SHAVER, R. Manual Transmission Clutch Systems. In: SHAVER, R. Manual

Transmission Clutch Systems. [S.I.]: Society of Automotive Engineers, 1997. p. 123;42;71-76;133.

SHIH, S. Simulation Modeling Guided Transmission Design- A Case Study. SAE TECHNICAL PAPER SERIES, n. SAE 2000-01-2641, 2000.

SILVEIRA, F. L. D. Inclinações das ruas e das estradas. Física na Escola, São Paulo, 16-18 Agosto 2007.

STARKEY, J. M.; GRAY, S.; WATTS, D. Vehicle Performance Simulation and Optimization Including Tire Slip. SAE TECHNICAL PAPER SERIES, n. SAE 881733, 1988.

SWEBER.DE. Wikipedia - The Free Encyclopedia, 2008. Disponivel em: <http://en.wikipedia.org/wiki/Cone_clutch>. Acesso em: 14 Abril 2010.

VIBRATE SOFTWARE. Vibrate Software, 2009. Disponivel em: $<$ http://www.vibratesoftware.com/html_help/html/Diagnosis/Tire/Static_Loaded_Radiu s.htm>. Acesso em: 15 Junho 2010.

WATERS, W. C. General Purpose Automotive Vehicle Performance and Economy Simulator. SAE TECHICAL PAPER SERIES, n. SAE 720043, 1972.

WIKIPEDIA - The Free Encyclopedia, 2010. Disponivel em: <http://en.wikipedia.org/wiki/Wheelbase>. Acesso em: 15 Fevereiro 2010. 
WIKIPEDIA the Free Encyclopedia, 2006. Disponivel em:

<http://en.wikipedia.org/wiki/Differential_(mechanical_device)>. Acesso em: 14 Junho 2010.

WIKIPEDIA The Free Encyclopedia. Wikipedia The Free Encyclopedia Web Site, 2010. Disponivel em: <http://en.wikipedia.org/wiki/Automobile_layout>. Acesso em: 15 Abril 2010.

WILLIAM, M. Merits of Front-, Rear-, and Four-Wheel Drive. In: WILLIAM, M. Race Car Vehicle Dynamics. [S.I.]: SAE International, 1995. p. 730.

XI, W.; GIORGIO, R. Objective Metrics of Fuel Economy, Performance and Driveability - A Review. SAE TECHNICAL PAPER SERIES, n. SAE 2004-01-1338, 2004.

ZF SACHS. Fundamentos da Embreagem Automotiva. [S.I.]: [s.n.]. 2010. p. 4. 